\title{
Gold Nanozymes: From Concept to Biomedical Applications
}

Cite as

Nano-Micro Lett.

(2021) 13:10

\author{
Javier Lou-Franco $^{1}$, Bhaskar Das ${ }^{1,2}$, Christopher Elliott $^{1}$, Cuong Cao $^{1}{ }^{凶}$
}

Received: 11 June 2020

Accepted: 2 September 2020

Published online: 27 October 2020

(C) The Author(s) 2020

\section{HIGHLIGHTS}

- The capability of gold nanomaterials to mimic enzyme activities offers new approaches for diagnosis and treatment in the field of biomedicine, which are discussed in this review.

- Controlling the physicochemical properties of the nanomaterials (size, morphology and surface chemistry) remains the first obstacle for endeavouring real-life applications.

- Numerous examples of ex vivo applications in the field of diagnosis are a reality today, whereas further controlling side effects is required for in vivo applications like tumour treatment or intracellular ROS level control.

ABSTRACT In recent years, gold nanoparticles have demonstrated excellent enzyme-mimicking activities which resemble those of peroxidase, oxidase, catalase, superoxide dismutase or reductase. This, merged with their ease of synthesis, tunability, biocompatibility and low cost, makes them excellent candidates when compared with biological enzymes for applications in biomedicine or biochemical analyses. Herein, over 200 research papers have been systematically reviewed to present the recent progress on the fundamentals of gold nanozymes and their potential applications. The review reveals that the morphology and surface chemistry of the nanoparticles play an important role in their catalytic properties, as well as external parameters such as $\mathrm{pH}$ or temperature. Yet, real applications often require

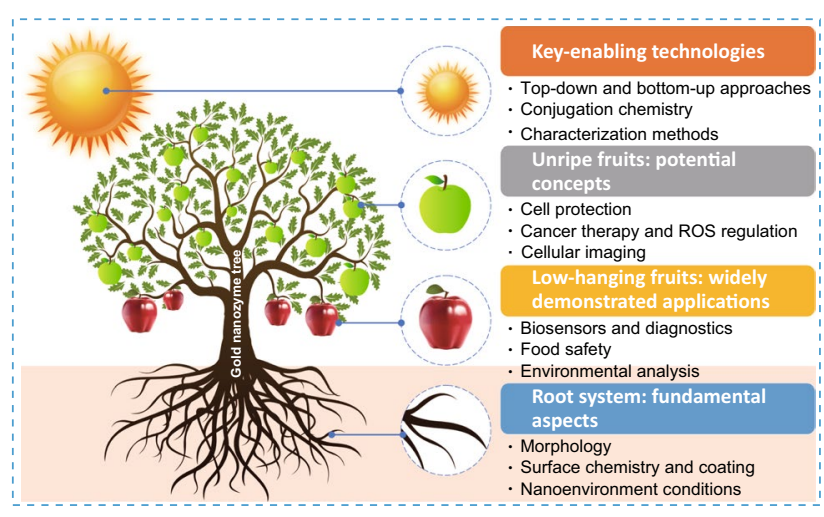
specific biorecognition elements to be immobilized onto the nanozymes, leading to unexpected positive or negative effects on their activity. Thus, rational design of efficient nanozymes remains a challenge of paramount importance. Different implementation paths have already been explored, including the application of peroxidase-like nanozymes for the development of clinical diagnostics or the regulation of oxidative stress within cells via their catalase and superoxide dismutase activities. The review also indicates that it is essential to understand how external parameters may boost or inhibit each of these activities, as more than one of them could coexist. Likewise, further toxicity studies are required to ensure the applicability of gold nanozymes in vivo. Current challenges and future prospects of gold nanozymes are discussed in this review, whose significance can be anticipated in a diverse range of fields beyond biomedicine, such as food safety, environmental analyses or the chemical industry.

KEYWORDS Gold nanoparticles; Catalysis; Nanozymes; Diagnosis; Nanomedicine

Cuong Cao, c.cao@qub.ac.uk

1 Institute for Global Food Security, School of Biological Sciences, Queen's University of Belfast, 19 Chlorine Gardens, Belfast BT9 5DL, UK

2 Present Address: Department of Biotechnology and Medical Engineering, National Institute of Technology Rourkela, Rourkela, India 


\section{Introduction}

Colloidal gold nanoparticles (AuNPs) have been widely used for centuries owing to their unique properties not found in their bulk form. Dating back to ancient times (Fig. 1), Persians already knew in the ninth century that metallic nanomaterials could be used to produce special shinning effects on the surface of ceramic materials [1]. Older examples are the Lycurgus cup produced during the Roman time in the fourth century, which contains silver-gold alloy nanoparticles that result in a green-red dichroic effect [2]. Nevertheless, the first information on colloidal gold was reported by Chinese, Arabic and Indian sources from as early as the fifth and fourth centuries B.C. [3]. Since that time, little interest was shown for medical applications until the thirteenth century, when European alchemists started to advocate potable gold (i.e., a preparation containing gold particles) for medicinal use [4]. Not many advances were observed for the next 400 years, with some alchemists supporting the medicinal use of gold [5] and some others referring to gold just as "an antidote to poverty" [6]. This impasse started to change in the nineteenth century, when Chrestien [7] published his work that describes the cases of seven syphilis patients treated with gold. In parallel, Michael Faraday produced the first examples of metallic gold colloids, while he was mounting thin sheets of gold leaf onto microscope slides. In 1890, Robert Koch discovered the in vitro bacteriostatic properties of gold, which led to gold-based therapies for tuberculosis and rheumatoid arthritis (thought to be caused by the tubercle bacillus at that time) [8]. All this development culminated with detailed studies of the process of nucleation and growth of colloidal gold carried out by Turkevich et al. [9], which established the basis for the recent boost of gold nanomaterials applied in different fields, including biomedicine.

Despite a wide use of gold colloids throughout history, it was not until 1959 that all the potential implementations of nanomaterials started to be considered, especially after Richard Feynman gave his famous lecture "There's Plenty of Room at the Bottom: An Invitation to Enter a New Field of Physics" [10]. This has led to seminal developments in the field of nanotechnology in the last century, elucidating that properties of materials in the nanoscale differ enormously from the ones found in the bulk material as a result of quantum-sized effects. A large number of excellent studies have reviewed all these specific properties, either physical (optical, electronic, magnetic), chemical (catalytic, supramolecular) or biological (biotoxicity, bioconjugation) [11-14]. These include localized surface plasmon resonance (LSPR), a phenomenon based on the interaction of gold colloids with visible light in which the conduction electrons on the surface of the nanomaterial oscillate in resonance with the frequency of the incident light. Surface plasmons can be used to enhance the sensitivity of several spectroscopic techniques, such as those based on fluorescence and Raman scattering $[15,16]$. In addition, novel surface reactivity has been observed in gold nanomaterials, which is at the basis of the catalytic behaviour characteristic of these nanomaterials.

These properties of AuNPs are dependent on their size, shape and surface chemistry. Therefore, controlling these parameters is of paramount importance for the development of AuNP-based chemical and biological sensors. Two approaches are widely used for the synthesis and fabrication of gold nanostructures: bottom-up and top-down. The former relates to techniques such as chemical synthesis, self-assembly or molecular fabrication which involve the nucleation of gold atoms and their growth into colloidal AuNPs from a molecular precursor. The latter refers to methods such as photolithographic micropatternings, pyrolysis and attrition [17]. Micropatterning techniques employ a light, electron or ion beam to selectively pattern nanostructures from precursor resist materials, i.e., photolithography [18], electron beam lithography [19], soft lithography [20], nanocontact printing [21], nanoimprint lithography [22], nanosphere lithography [23], colloidal lithography [24] or scanning probe lithography [25]. Pyrolysis consists in bringing under high pressure and burning a vaporous precursor to generate ashes that are further processed to produce nanoparticles [26-28]. Attrition (or milling) consists in grinding macroand microscale materials to generate particles of nanosized range [29]. These methods have shown limitations in terms of physical conditions and required equipment, as they are most commonly based on lithography which is neither cost nor time-effective [30, 31]. The high amount of energy required for pyrolysis and the inherent imperfection of attrition methods do not solve the limitations of top-down approaches. Thus, bottom-up approaches have been widely explored to produce AuNPs with a diverse range of sizes and shapes, such as spheres [9, 32], rods [33, 34], cubes [35], prisms [36, 37], stars [38], cages [39], polygons [40] and many others [41, 42] (Fig. 2). This list can be expanded to hybrid gold-related materials [43], self-assembled gold 


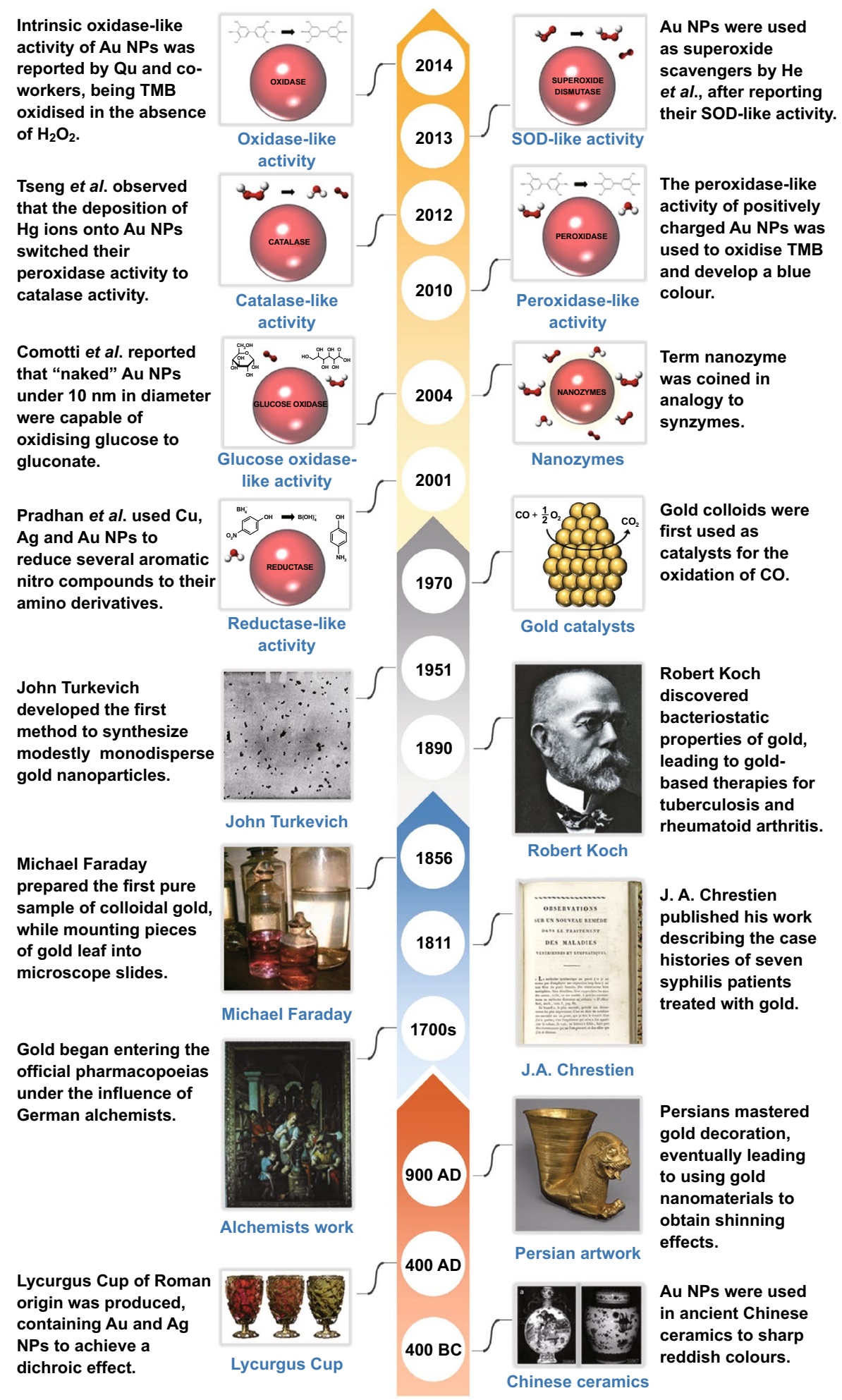

Fig. 1 Timeline highlighting relevant historical events that contributed to the development and implementation of gold nanoparticles. Ancient examples are shown before the arrow break, mostly related to the use of AuNPs as an ornament material, whereas biomedical implications are described after the break point. These include John Turkevich's experiments [9], the first report on the use of gold colloids as catalysts [65] or the first time the term "nanozyme" was used [76]. The yellow arrow shows the years when each nanozyme activity was first reported for gold nanoparticles (reductase [74]-, glucose oxidase [69]-, peroxidase [71]-, catalase [73]-, SOD [72]- and oxidase [68]-like activities) 
superlattices [44] and many other complexes that have been extensively reviewed $[45,46]$. The main advantage of these approaches is that they can produce homogeneous nanostructures with well-defined crystallographic and surface structures. They include chemical reduction, microemulsion, laser ablation, microwave irradiation and green or biological methods [29]. These methods, however, often require reactants that are toxic and can potentially have negative effects in real applications that use gold nanomaterials. In any case, bottom-up approaches have become the preferred method of synthesis in most nanozyme studies. Moreover, unlike other metallic nanoparticles that can also be tuned in different shapes and sizes, AuNPs have shown great stability and rich surface chemistry which allows easy conjugation approaches for biomolecules [47-51]. This versatility together with their attractive optical and electronic properties mentioned above has enabled gold nanozymes to experience a great popularity over other types of nanozymes.

As mentioned, care must be taken when using gold nanomaterials for biomedical applications, as their toxic effects
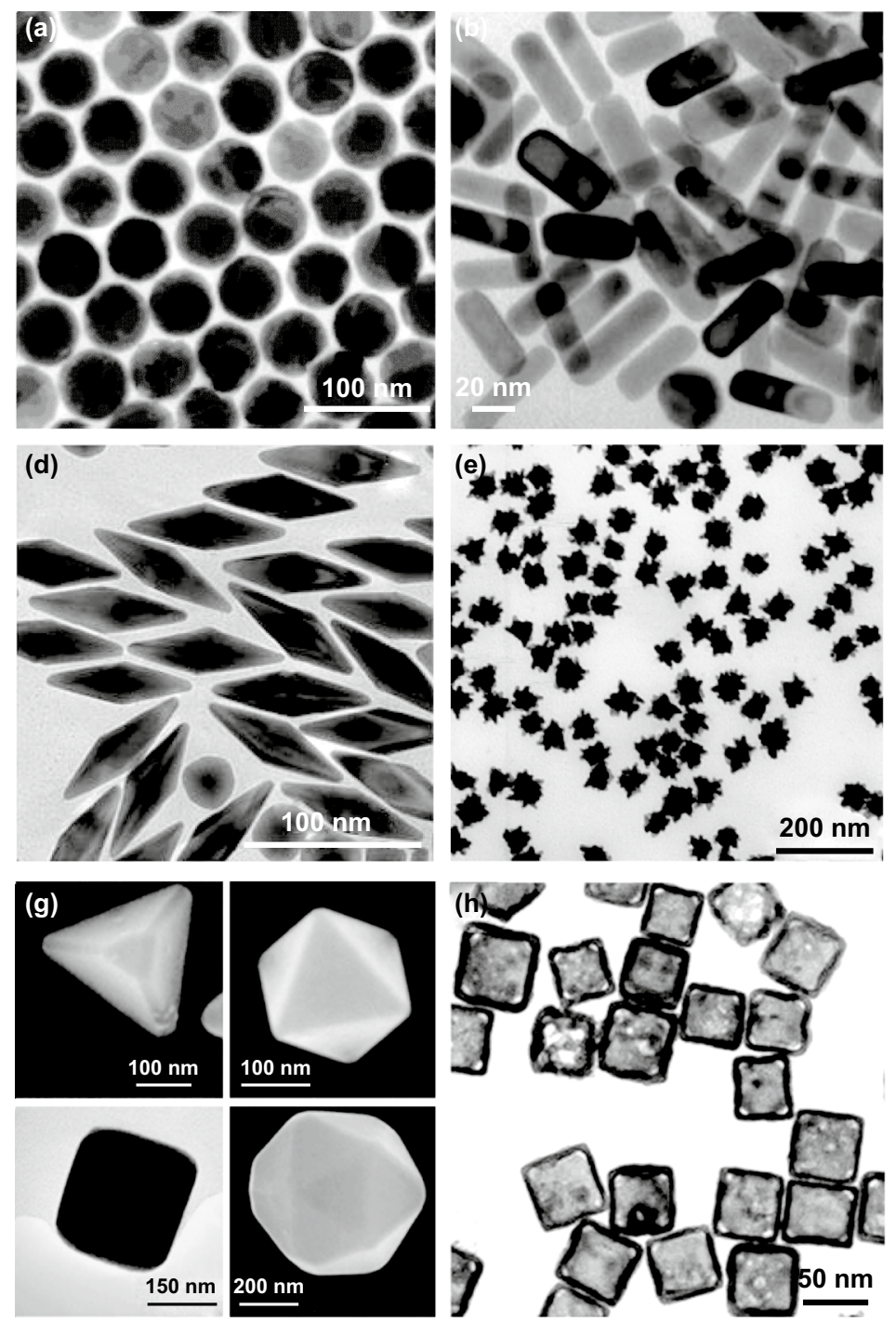
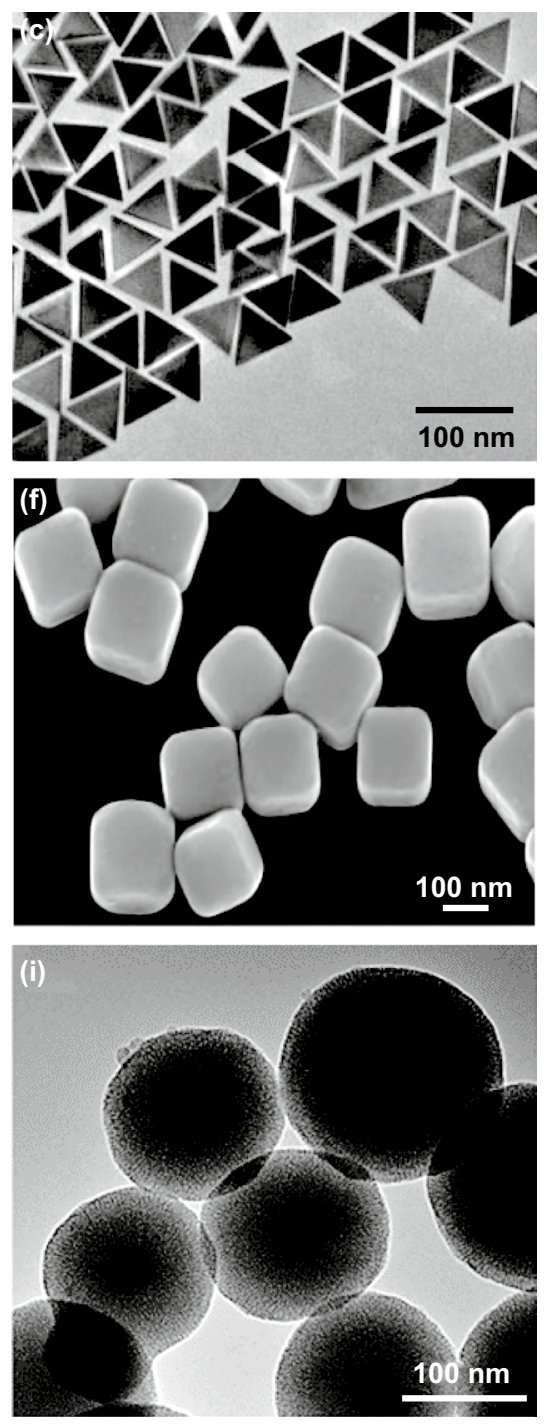

Fig. 2 AuNPs synthesized with different shapes following bottom-up approaches: a spheres [32]. Copyright 2013 Wiley-VCH Verlag GmbH \& Co. KGaA; b rods [34]. Copyright 2011 The Royal Society of Chemistry; c prisms [37]. Copyright 2015 The Royal Society of Chemistry; d bipyramids [42]. Copyright 2016 Fang et al.; e stars [38]. Copyright 2008 IOP Publishing Ltd.; f cubes [35]. Copyright 2002 Sun et al.; g polygonshaped nanocrystals [40]. Copyright 2004 Wiley-VCH Verlag GmbH \& Co. KgaA; h cages [39]. Copyright 2010 Wiley-VCH Verlag GmbH \& Co. KgaA; i gold@ silica hybrid nanoparticles [43]. Copyright 2019 Vega et al. 
for in vitro and in vivo applications must not be disregarded. Although the bulk gold material is benign and biologically inert, AuNPs in solutions or in aerosols that exhibit mobility (a property that forms toxicity of free nanoparticles) can induce toxicity [52]. This might be caused by small-sized AuNPs which have shown unusual chemical reactivity, especially under $2 \mathrm{~nm}$ in diameter, leading to oxidative stress and mitochondrial damage that trigger necrosis [53]. This toxicity, however, very often derives from surfactant or capping agents used during the nanoparticles synthesis, such as cetyl trimethyl ammonium bromide (CTAB) [54-56]. This problem can be addressed by replacing CTAB by biofriendly polymers, such as PEG which has shown little cytotoxicity in vitro and enables a long-lasting circulation in blood due to a stealth character [56]. Larger AuNPs or gold nanostructures being an integral feature of a larger object (the glass or polymer substrate), however, do not show the same problem. Lai et al. [57] prepared microcapsules containing thioridazine, a common antipsychotic, adsorbed on AuNPs to enhance the encapsulation efficiency and obtain a sustained and controlled release of the drug in blood. These oral formulations were administrated to rats with a $\mathrm{LD}_{50}$ of nanogold suspension greater than $5000 \mathrm{mg} \mathrm{kg}^{-1}$ of body weight, leading to no signs of gross toxicity, adverse pharmacological effects or abnormal behaviour. These results have also been confirmed in vitro by Connor et al. [58], who exposed human K562 leukaemia cells to AuNPs for 3 days and studied the cell viability by MTT assay to determine the survival rate. This study showed that 18-nm AuNPs with various coatings were not toxic in the micromolar range, as opposed to the gold-salt $\left(\mathrm{AuCl}_{4}\right)$ precursor or unwashed CTAB-AuNPs. In vivo studies, on the other hand, require more extensive biodistribution assays to determine where the potential harmful effects may lie. The observed differences are size-dependent in this case, being the smaller ones (15-50 nm in size) accumulated in different tissues like blood, liver, lung, spleen, kidney and stomach, also being able to pass the blood-brain barrier, whereas larger AuNPs were only detected in blood, liver and spleen [59]. Several reviews have tried to shed some light on this matter $[60,61]$. It was also suggested that there is no reason to suppose that the immobile nanostructures pose a greater risk for health or environment than larger-scale material, which is gold - a non-toxic material [62]. Nonetheless, any applications of these materials in the biomedical field need to undergo comprehensive safety assessments to determine the physicochemical forms and the concentration at which they would trigger toxicity effects. Safety and toxicity of gold nanomaterials have been substantially reviewed elsewhere [63, 64].

\section{Catalytic Properties of Gold Nanoparticles}

The catalytic properties of AuNPs were already observed and reported in the 1970s [65] and 1980s [66, 67], when gold colloids were used as catalysts for the oxidation of carbon monoxide and proved that they are much more active and stable than conventional catalysts commercially available at that time. Parravano's group and Haruta et al. first reported these observations, leading the way in this field. Many applications have been explored ever since, as metallic nanoparticles in general and AuNPs in particular possess several catalytic activities [14] (i.e., oxidase [68], glucose oxidase [69, 70], peroxidase [71], catalase [72, 73], superoxide dismutase "SOD" [72] and reductase [74]) (Fig. 1). This has completely changed the perception which would coin bulk gold as "the noblest metal of all" and "the least reactive metal towards atoms or molecules at the interface with a gas or a liquid" [75]. These discoveries led to the term "nanozyme" being coined in the early 2000s by Paolo Scrimin's group [76], in analogy to the nomenclature of catalytic polymers ("synzymes") reported by Klotz et al. [77]. This term initially referred to a combination of enzymes and AuNPs, which would offer multiple possibilities for diagnostic assay development [78]. Despite this review focusing specifically in gold nanozymes, it is interesting to note that many of the properties described herein were previously observed in other types of nanomaterials. A clear example of this was set by Yan and co-workers, who first reported that magnetite nanoparticles possess intrinsic peroxidase-like activity comparable to that of an enzyme-catalysed reaction [79]. This pioneer study successfully applied the observed peroxidase-like activity in an immunoassay, paving the way for future gold nanozyme applications.

Since then, the nanozyme activity of different families of nanomaterials has been reviewed. Some of these studies are more generic [80-84], while some others are specific for gold nanomaterials [14], metal-organic frameworks (MOFs) [85, 86] or metal-oxide nanomaterials (MONMs) [87]. Although similar reviews have been published elsewhere, e.g., covering either the factors controlling the activity of 
gold nanozymes [88] or their potential biosensing and therapeutic applications [89], this review is presented as a comprehensive analysis intending to link both sections, from the fabrication of gold nanozymes, their catalytic mechanisms, potential applications and obstacles in the biomedical field.

Most gold nanozyme studies reported in the literature are based on AuNPs synthesized using bottom-up approaches due to their low-cost and facile syntheses. However, gold nanostructures exhibiting catalytic properties have also been fabricated through top-down approaches [90-92]. Cao et al. [90] found that these properties could be improved by fabrication of nanostructured arrays on Au thin film. Nanosphere lithography followed by oxygen plasma reactive ion etching (NSL-RIE) was the method used to fabricate ordered Au nanoring arrays, giving rise to Au nanopyramids due to the preferential etching of $\{111\}$ lattice planes of Au. It was observed that their sharp tips along with the Au atoms around the edges provided active sites with high surface energy that could help to overcome the activation energy required for the oxidation of ethanol on the nanoarray surface. Moreover, this study showed that the oxidation of ethanol could follow two pathways, one leading to $\mathrm{CO}_{2}$ as a final product and favoured in alkaline medium and the other leading to acetic acid or acetates as final products [90]. Electron beam lithography has also been used to fabricate a nanofluidic device consisting of 11 sets of 5 nanochannels, each decorated with a set of single-Au nanoparticles with identical size. These NPs were grown through $\mathrm{Au}$ evaporation and used for the reduction of fluorescein as a model reaction [91]. Also arrays of electrically driven plasmonic nanorods have been used for catalytic purposes, as the numerous resulting tunnel junctions favour the generation of hot electrons, facilitating strongly confined chemical reactions. Oxidation and reduction reactions (such as the oxidation of aromatic amines or the reduction of aromatic nitro compounds) have been studied following this approach, induced by the presence of $\mathrm{O}_{2}$ and $\mathrm{H}_{2}$, respectively [92]. Despite the diverse possibilities that these approaches offer, the aforementioned limitations for syntheses based on top-down methods have created the perfect environment for bottom-up-based nanomaterials to become predominant in the field of nanozymes.

Scientific efforts have been put together in an attempt to explain this phenomenon, on a proven basis that these chemical reactions take place at the interfacial perimeter around the AuNPs [93]. Thus, several NP parameters such as the size, morphology, surface chemistry or functional layers can strongly affect these catalytic effects, as well as some external parameters such as $\mathrm{pH}$ or temperature of the surrounding media. Therefore, understanding the reaction fundaments remains essential to comprehend how all these parameters might affect the efficiency of AuNPs as catalysts.

\subsection{Size and Shape Dependence}

It has been evident that smaller AuNPs usually possess better catalytic properties, which has been attributed to a higher population of low-coordinated gold atoms (corner sites) in the nanomaterial. Such gold atoms were suggested to play a major role in the catalytic activity [94-96]. According to these models, the electron-rich gold plane at the interface would lie behind the observed catalytic properties. As a result, a nanoparticle size of about $2 \mathrm{~nm}$ or a height of six atomic monolayers has been found to be optimum for CO oxidation [95]. Therefore, there is a threshold from which a further decrease in NP size will not result in better catalytic activities. This was observed by Lin et al. [97] using AuNPs with sizes ranging from 1.7 to $8.2 \mathrm{~nm}$ to reduce p-nitrophenol, resulting in the 3.4-nm-sized NPs in a better catalytic efficiency than the smaller size. Various studies have confirmed this model, using the reduction of resazurin to resorufin catalysed by AuNPs as a model reaction to follow at single-molecule level [98]. Zhou et al. demonstrated that not only the catalytic product formation reaction, but also the product dissociation reaction was affected by the NP size (Fig. 3a). These size-dependent activities are explained from a thermodynamic point of view by changes in the adsorption free energies of the substrate and product, which in turn would be explained by the nanosized effect of AuNPs. According to this explanation, both the unoccupied and the occupied electronic states of the AuNPs increase in energy with a decreasing NP size. Considering that the NP surface acts as electron acceptor as it interacts with the substrate and as electron donor with the product, the mentioned energy increase weakens the NP-resazurin substrate pair and strengthens the NP-resorufin product one. Similar observations were made by He et al., who compared different-sized AuNPs from $2 \mathrm{~nm}$ (all atoms are on surface) to $5 \mathrm{~nm}$ as catalysts for $\mathrm{CO}$ oxidation. The results evidenced the activation of 
(a)
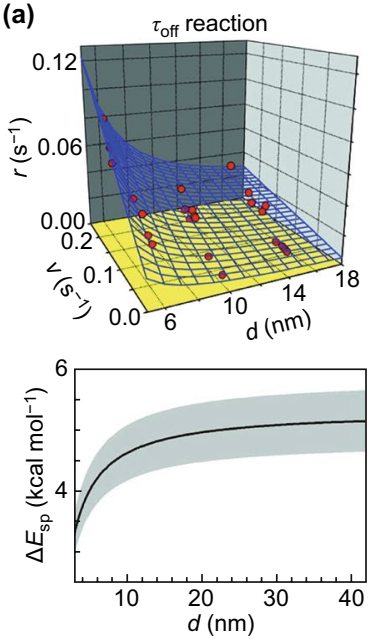
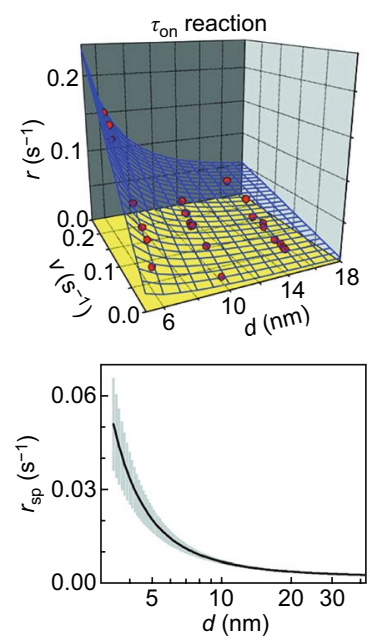

(b)

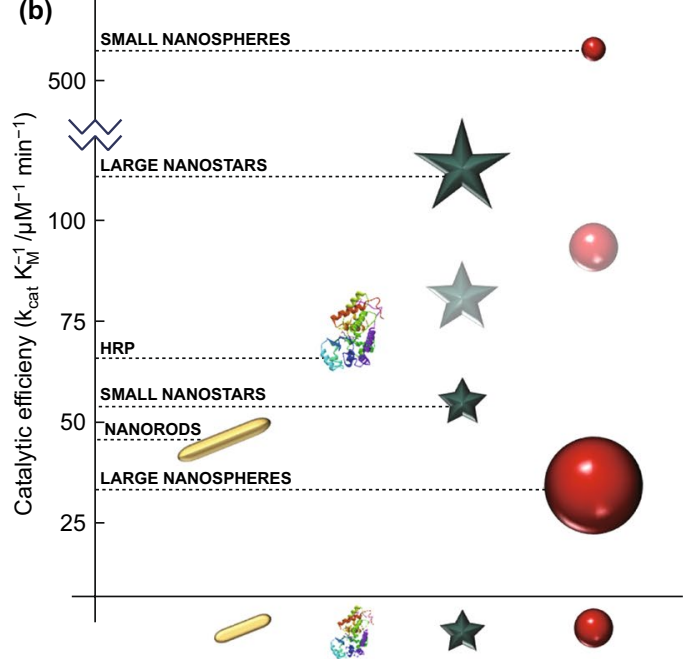

Fig. 3 Comparison of the catalytic efficiency of AuNPs with different sizes and shapes. a Dynamics of the reduction reaction of resazurin to resorufin catalysed by different-sized AuNPs. It shows how the NP size affects the surface restructuring rate dependence on the rate of turnovers for the catalytic product formation (top left) and for the product dissociation (top right), and the NP size dependence of the activation energy (bottom left) and of the rate of spontaneous dynamic surface restructuring (bottom right) [98]. Copyright American Chemical Society 2010. b Comparison of the catalytic efficiency for the peroxidase-like activity of different-shaped and different-sized AuNPs. HRP, their biological counterpart, is also included in the graph

more atoms and the generation of dynamic "single atoms" on surface in smaller Au clusters, which boosts the $\mathrm{CO}$ oxidation rate either by a facile transport of $\mathrm{CO}$ to the active sites or single-atom catalysis [99].

However, this general size dependence rule cannot be extrapolated to AuNPs with different shapes, despite being true for nanospheres. This is an important remark as very little information has been compiled so far for non-spherical AuNPs. Besides, there is some evidence that the shape of the catalyst affects its properties [100,101]. Biswas et al. found gold nanorods (AuNRs) of 2.8 aspect ratio to possess a catalytic efficiency for 3,3',5,5'-tetramethylbenzidine (TMB) oxidation slightly higher than cysteamine-capped gold nanospheres (AuNSs) of $34 \mathrm{~nm}$. However, McVey et al. [102] observed that smaller AuNSs (14 nm diameter) showed a much higher catalytic efficiency, in agreement with the catalytic model studies previously mentioned. Moreover, these smaller AuNSs have overcome the efficiency of biological enzymes (Fig. 3b). Despite lacking further research to explore different shapes and sizes to obtain empirical information, as a general rule, higher surface-to-volume ratios are expected to show enhanced catalytic properties, which would be in accordance with the above explanation related to a higher population of low-coordinated gold atoms in the nanomaterial.

\section{$2.2 \mathrm{pH}$ and Temperature Dependence}

Similar to what happens with biological enzymes, $\mathrm{pH}$ and temperature also need to be controlled in reactions catalysed by gold nanozymes. For example, TMB oxidation implemented by different AuNPs shows an optimum activity at $\mathrm{pH}$ values between 3.5 and 4 , whereas its optimum temperature is commonly set between 40 and $50^{\circ} \mathrm{C}$ (Fig. 4a) [103-107]. These observations, again, cannot be extrapolated to different peroxidase substrates, i.e., 2,2'-azino-bis(3-ethylbenzothiazoline-6-sulphonic acid) (ABTS) oxidation takes place optimally at lower $\mathrm{pH}$ values, while 4-aminoantipyrine (AAP) oxidation is improved at basic $\mathrm{pH}$ values [103]. More importantly, some studies have reported that differences in the $\mathrm{pH}$ of the media can cause AuNPs to switch their catalytic functionality, potentially leading to the opposite effect. Li et al. observed this by loading AuNPs inside a cell in the presence of $\mathrm{H}_{2} \mathrm{O}_{2}$. In acidic conditions, the peroxidaselike activity was boosted, leading to reactive oxygen species (ROS) generation. When the $\mathrm{pH}$ was increased to neutral $\mathrm{pH}$ values, the catalase-like activity became predominant and detoxification was the observed effect (Fig. 4b) [108]. The former relates to the base-like decomposition of $\mathrm{H}_{2} \mathrm{O}_{2}$ whereas the latter relates to the acid-like decomposition on the metal surfaces. This pH switchability is triggered by 

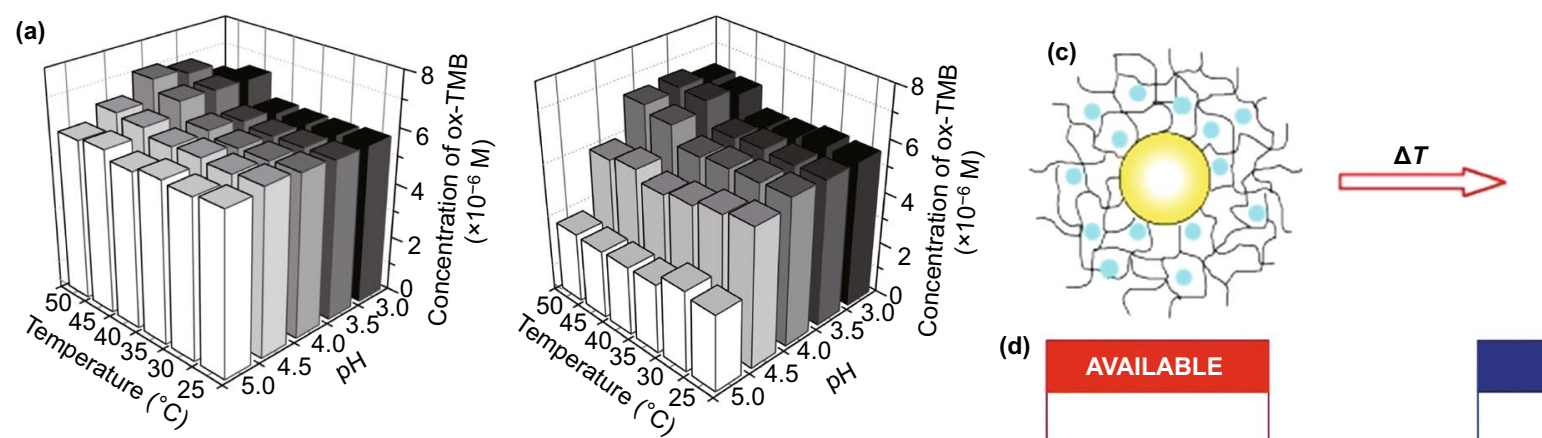

(d)

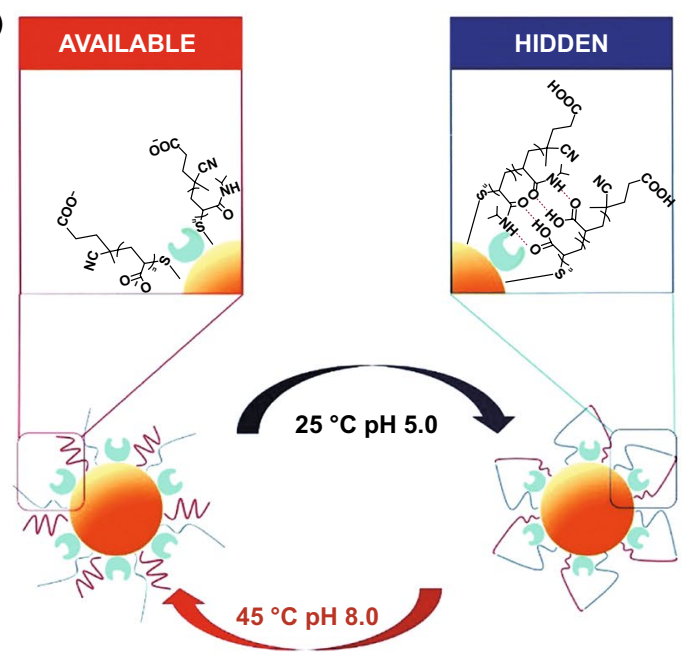

Fig. $4 \mathrm{pH}$ and temperature dependence of different catalytic activities of AuNPs. a AuNPs coated with different concentrations of the same peptide ( 3 times higher on the left) will respond differently to temperature and $\mathrm{pH}$ changes as for their peroxidase-like capability to oxidize TMB [107]. Copyright 2019 Lee et al. b pH switchability of AuNPs in terms of their catalytic activity, which shows different $\mathrm{H}_{2} \mathrm{O}_{2}$ decomposition routes caused by the adsorption of $\mathrm{OH}$ groups to the gold surface in basic conditions [108]. Copyright 2015 Elsevier Ltd. c Thermosensitive polymeric layers used to stabilize AuNPs might undergo structural changes that block the catalytic active state of the nanomaterials [111]. Copyright 2006 Wiley-VCH Verlag GmbH \& Co. KgaA. d "On/off" nanozyme controlled by means of a temperature and pH change that result in the formation of a cage-like structure by hydrogen bonding between polymer chains in the surface of the AuNP [112]. Copyright 2019 The Royal Society of Chemistry

pre-adsorbed $\mathrm{OH}$ groups on the gold surface, a feature that only happens at basic $\mathrm{pH}$ values as observed by $\mathrm{Li}$ et al. [108]. Cao and co-workers have tried to explain the mechanism underlying these observations [71]. They proposed that $\mathrm{H}_{2} \mathrm{O}_{2}$ can be adsorbed on the surface of the AuNPs, being the $\mathrm{O}-\mathrm{O}$ bond broken up to generate $\mathrm{OH}$ radicals. A partial electron exchange interaction between the generated radicals and the AuNPs not only would stabilize the radicals, but also may contribute to the peroxidase-like activity of AuNPs. In the case of the catalase-like activity reported at basic conditions, on the other hand, the $\mathrm{OH}$ groups are pre-adsorbed on the gold surface, which become the active sites for the reaction and trigger the acid-like decomposition of $\mathrm{H}_{2} \mathrm{O}_{2}$ into $\mathrm{H}_{2} \mathrm{O}$ and $\mathrm{O}_{2}$ [108].

Similar studies have been developed to elucidate the mechanisms of various enzyme-like activities described for AuNPs. Qu and co-workers investigated whether the presence of an active intermediate could explain the oxidaselike activity of AuNPs [68]. It was unambiguously observed that these nanomaterials had the capability to generate singlet oxygen $\left({ }^{1} \mathrm{O}_{2}\right)$, hydroxyl radicals ( $(\mathrm{OH})$ and superoxide $\left(\mathrm{O}_{2}{ }^{-}\right)$, which lies behind the oxidase-like properties that AuNPs possess. Likewise, Rossi and co-workers studied the mechanism why complex organic molecules like glucose could be oxidized by AuNPs [109], which is closely related to observations that had previously been done on AuNPs to catalyse the two-electron reduction of dioxygen to convert molecular hydrogen into hydrogen peroxide [110]. Thus, an electron-rich gold species is generated when hydrated glucose interacts with gold surface atoms, which activates molecular oxygen by nucleophilic attack. As a result, a dioxogold intermediate (either $\mathrm{Au}^{+}-\mathrm{O}_{2}{ }^{-}$or $\mathrm{Au}^{2+}-\mathrm{O}_{2}{ }^{2-}$ ) is formed, acting as a bridge for the two-electron transfer from glucose to dioxygen [109]. Regarding their reductase-like 
activity, it has mainly been described for aromatic nitro compounds being reduced to their corresponding amino derivatives using $\mathrm{NaBH}_{4}$. In this case, the substrates are adsorbed on the AuNP surface, while $\mathrm{NaBH}_{4}$, a strong nucleophile with high electron injection capability, transfers electrons to the substrate via metal particles [74]. Finally, further investigation is required to explain the catalytic mechanism by which AuNPs scavenge superoxide-mimicking SOD enzymes, which equally involves the adsorption of superoxide onto the AuNPs followed by an electron transfer [72].

The temperature, on the other hand, not only has direct effects on the reaction rate, but also can affect the surface layer that stabilizes the AuNPs. Many polymers used for stabilizing AuNPs might undergo thermodynamic transitions that alter their 3-dimensional structure on the nanoparticle surface (Fig. 4c), leading to a state where reagents cannot diffuse freely to the nanoparticle that acts as catalyst at certain temperatures [111]. This observation has been exploited to create "on/off nanozymes". Sun et al. immobilized pyrophosphatase on AuNPs, which were subsequently coated with a polymer dually responsive to temperature and $\mathrm{pH}$. The activity of the immobilized enzyme at $45^{\circ} \mathrm{C}$ and $\mathrm{pH} 8$ was similar to that of the free enzyme. However, the media conditions switch to $25^{\circ} \mathrm{C}$ and $\mathrm{pH} 5$ would favour the formation of interpolymer hydrogen bonding to create a cage-like structure that suppressed the enzymatic activity down to $2 \%$ of its initial activity (Fig. 4d) [112].

\subsection{Effect of Surface Coating Layers}

Not only the NP shape and size or external parameters such as $\mathrm{pH}$ and temperature, but also any surface coating layers affect the catalytic properties (i.e., surfactants, stabilizing and functional moieties). It has long been understood that thiolates interact with gold surfaces, resulting in the formation of a strong bond [113]. Therefore, most capping agents utilized to stabilize or to coat AuNPs contain a thiol group to bind the AuNPs. Ever since it was first reported, various reviews have collected and analysed the knowledge related to these bonds to understand the formation of self-assembled monolayers of thiolates on metal surfaces [114, 115], where the reason for these catalytic properties suppression may lie. Many studies have proved that the peroxidase-like activity of unmodified AuNPs is significantly reduced when the
AuNPs are amino-modified or citrate-capped [116]. These results support the theory of superficial gold atoms as the main contributors to the catalytic effects. Liu et al. have shed some light on the determination of surface accessibility for TMB using AuNPs stabilized with different capping agents (gum Arabic, polyvinylpyrrolidone, citrate, cysteamine and unmodified NPs). The Michaelis-Menten parameters of all these NPs were determined, showing that the catalytic efficiency of unmodified AuNPs outperformed that of horseradish peroxidase (HRP), although the AuNP surface modification could suppress their activity down to $11 \%$ of their original activity [117]. These results are illustrated in Fig. 5.

All this knowledge has resulted in numerous biomedical applications, which nowadays start to be exploited from different perspectives, either as diagnostic devices using biological samples or as ROS modifiers for in vivo applications (Fig. 6), which are reviewed in the following sections. Some other applications in the environmental and food sector are also discussed in this review. The methodology followed for the literature review consisted in extracting every research article included in scientific databases such as Scopus and Web of Science, under the search "gold nanozyme" up to January 2020. This resulted

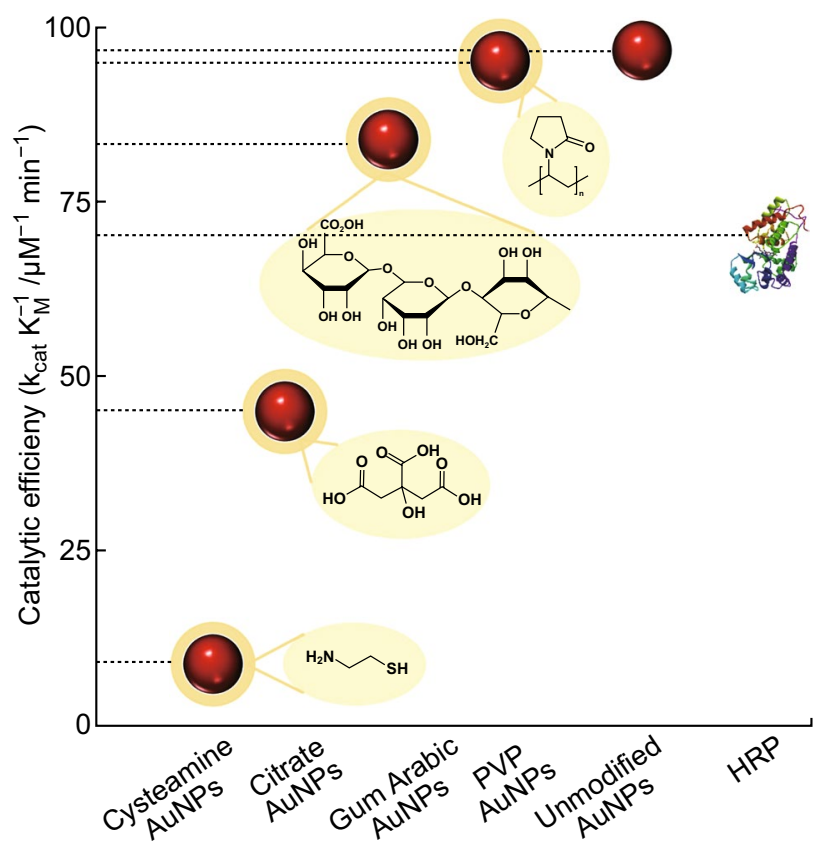

Fig. 5 Peroxidase-like activity of AuNP dependence on different surface modifications, measured as its catalytic efficiency [117] 


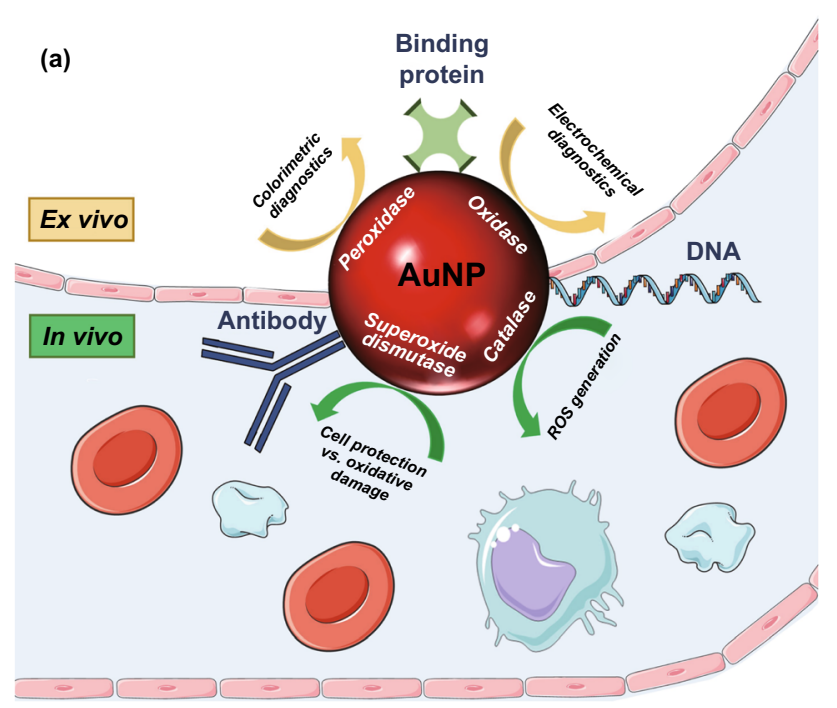

(b)

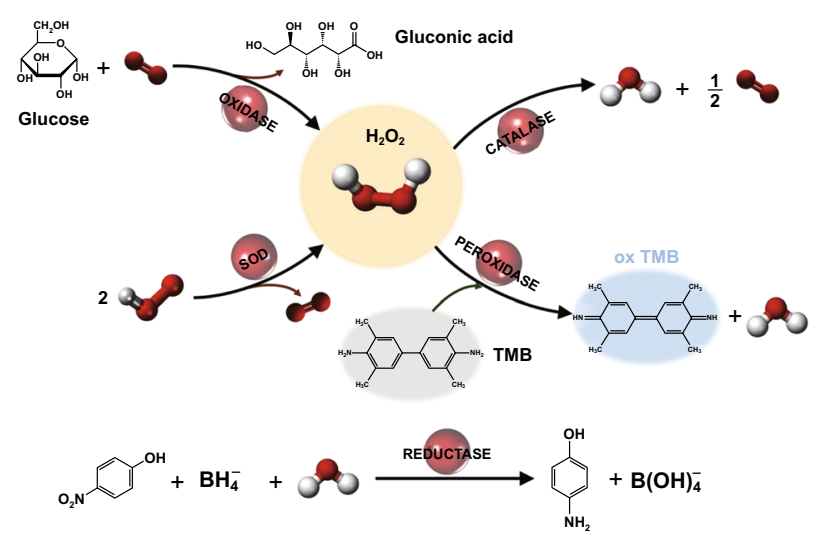

Fig. 6 a Summary of the different catalytic activities of AuNPs mainly used in biomedical applications. b A description of these activities with a representative example

in 142 documents that were analysed and classified in an Excel table according to the nature of the nanomaterial used, the catalytic activity exploited, the type of sensor or system developed, the target and the category in which the application could be included (either biomedical, chemical, environmental, veterinary, etc.). Many of these research documents report the fundaments of the nanozyme activity, but the main focus of this review will revolve around developed applications with some direct relevance in biomedicine or indirect implications for health. The potential and limitations of such systems will also be discussed along the text, highlighting the gaps in the field to give readers a complete picture of the state-of-the-art applications of gold nanozymes.

\section{Biomedical Applications of Gold Nanozymes}

Gold nanomaterials have been demonstrated for a wide range of applications in biomedicine, such as photothermal therapy [118], taking advantage of their ability to absorb light and convert it to heat. They have been used as drug delivery vehicles exploiting different loading approaches, such as partitioning [119], surface complexation [120], attachment to capping agents [121], layer-by-layer assembly [122] or even encapsulating drugs inside the AuNPs [123]. Cellular and in vivo imaging using scattering and fluorescence enhancement properties of AuNPs have also been documented [124]. However, the most successful applications in biomedicine relate to the use of AuNPs as visible optical indicators incorporated in lateral flow assays, i.e., the underlying technology used in pregnancy tests. With the discovery of the many nanozyme properties, a new path was unlocked, leading to a wide range of biomedical applications hitherto unexplored. Considering the little information reported so far in vivo for nanoparticles toxicity and distribution, it is not surprising that most applications are related to diagnostics ex vivo, which are reviewed herein.

\subsection{Biosensing and Biosensor Developments: Clinical Diagnostics}

For many diseases and physiological conditions such as cancer, diabetes or neurodegeneration, the best cure is an early detection that could be achieved by the implementation of biosensors. Many diagnostic tools have already become part of our lives: pregnancy or glucose tests can be bought in pharmacies, whereas antidoping, legal highs or explosive tests are commonly carried out in police controls or at immigration ports. Many other forms of biosensors are being developed and soon will be as common as the previous ones (e.g., detection of clinically important biomarkers such as creatinine and phenylalanine or monitoring of environmental pollutants) [125]. Ever since AuNPs were discovered to possess peroxidase-mimicking activity, they have been used as signal transducers capable to generate a colourimetric signal. Despite the fact that they can catalyse for various substrates such as TMB, ABTS or $o$-phenylenediamine (OPD) [104, 116], gold nanomaterials have mostly been applied for the oxidization of TMB, a substrate catalysed by HRP 
widely used in immunological assays (i.e., ELISA). Many examples can be found in the literature for sensors applied in biomedicine that use the peroxidase-like activity of gold nanomaterials to oxidize TMB and generate a colourimetric signal [126-132]. Due to the ease of surface modification with specific ligands, gold nanomaterials could allow the development of these diagnostic tools for diverse targets, such as viruses [129-131], exosomes [133], red blood cells [127], amino acids or even ions [126]. Apart from coloured products, gold nanozymes can catalyse for the conversion of different substrates into fluorescent, luminescent or Raman active products. Alternatively, some systems use the electrons produced in the reaction to develop electrochemical sensors. All these possibilities are discussed in this section.

Hybrid systems based on Au with other nanomaterials could lead to an enhanced catalysis. The applicability of this phenomenon in the biosensor field was first reported by Liu et al., who described the synergism between catalytic active graphene and AuNPs to detect specific DNA molecules (Fig. 7a) [134]. A similar strategy was followed by Ahmed and co-workers, who immobilized AuNPs on the surface of carbon nanotubes to enhance the peroxidase-like activity of the resulting nanohybrid, which developed a more intense colour in less time. This system (Fig. 7b) could effectively detect influenza virus A (H3N2) in human serum with a sensitivity of $3.4 \mathrm{PFU} \mathrm{mL} \mathrm{m}^{-1}$ (i.e., plaque-forming units per $\mathrm{mL}$ ) [131], 100 times higher than reported conventional ELISA assays and 500 times higher than commercial immunochromatography kits (ImunoAce Flu, TAUNS Laboratories, Inc., Numazu, Shizuoka, Japan). These synergistic effects for oxidizing TMB were also observed with $\mathrm{Au}-\mathrm{Pt}$ core/shell nanorods for detection of measles virus (Fig. 7c) [129]. Furthermore, Oh et al. [130] developed a different sensor including a capturing step with magnetic nanoparticles for the detection of influenza virus A (H1N1) in human serum (Fig. 7d). Following this approach, a similar limit of detection (LOD) was observed without making use of synergistic catalytic effects. Several studies have attempted to explain the mechanism by which the synergistic effect occurs. Liu et al. [134] proposed that the attractive interaction between carbon $2 p$ (from reduced graphene) and $\mathrm{Au} 5 \mathrm{~d}$ (from AuNP) orbitals around the carbon vacancy and defect would explain not only the strong covalent interfacing, but also the observed favourable $\mathrm{H}_{2} \mathrm{O}_{2}$ adsorption, thus enhancing its reduction. Similar charge transfer mechanisms have been proposed to explain this synergism in bimetallic nanoparticles [135].
Due to their simplicity and unnecessity of laboratorybased requirements, all these systems have a clear potential to become portable sensors and to be applied for point-ofcare (POC) diagnostics. A good example has been developed by $\mathrm{Wu}$ et al. (Fig. 7e) to detect occult blood in urine, commonly linked to a serious health condition such as chronic nephrotic syndrome or urinary system tumours. It consists of a flexible container with two tiny containers inside it, one with TMB and $\mathrm{H}_{2} \mathrm{O}_{2}$ reagents for the colourimetric reaction and the other with buffered AuNPs. After adding the urine sample to the flexible tube this is bended to break the tiny containers inside and develop the colourimetric reaction only in the presence of $\mathrm{Fe}^{2+}$ ions, which restore the peroxidase-like activity of AuNP capped with a purine derivative, otherwise remaining inactive. This system permits to detect either haemoglobin or red blood cells presence in urine due to their high content in $\mathrm{Fe}^{2+}$, by using a colour chart that enables a fast and visual detection [127]. This system, however, remains qualitative, providing a semi-quantitative estimation in the best-case scenario. This limitation could be circumvented using a smartphone camera, which would permit to quantify the colour intensity by means of a calibration curve previously built. It is curious to see that, to date, only one publication [136] is obtained when the terms "gold nanozyme" AND "smartphone" are searched in Scopus database. The proposed method to detect mercury ions in environmental water samples is further discussed in Sect. 3.1.

Gold nanozymes are used for the development of not only colourimetric sensors but also electrochemical detection platforms. The electrochemical approaches have been shown to have great repeatability, accuracy and robustness, while advancements in miniaturization have made the design of portable and quantitative sensors possible. Boriachek et al. [133] used gold-loaded ferric oxide nanocubes functionalized with an exosome-associated antibody to allow magnetic isolation of the captured target, whereas the peroxidase-like activity of the encapsulated AuNPs could generate a colourimetric signal. Abreast of the colourimetric output, the reaction happened on a screen-printed carbon electrode; therefore, the electroactive diimine generated during the TMB oxidation process [137] could also be quantified through chronoamperometry (Fig. 7f). In the same line, other research groups have used screen-printed gold electrodes modified with aptamers specific for cardiac troponin I, a well-known standard biomarker for the early detection of Acute Myocardial Infarction [138]. This system 


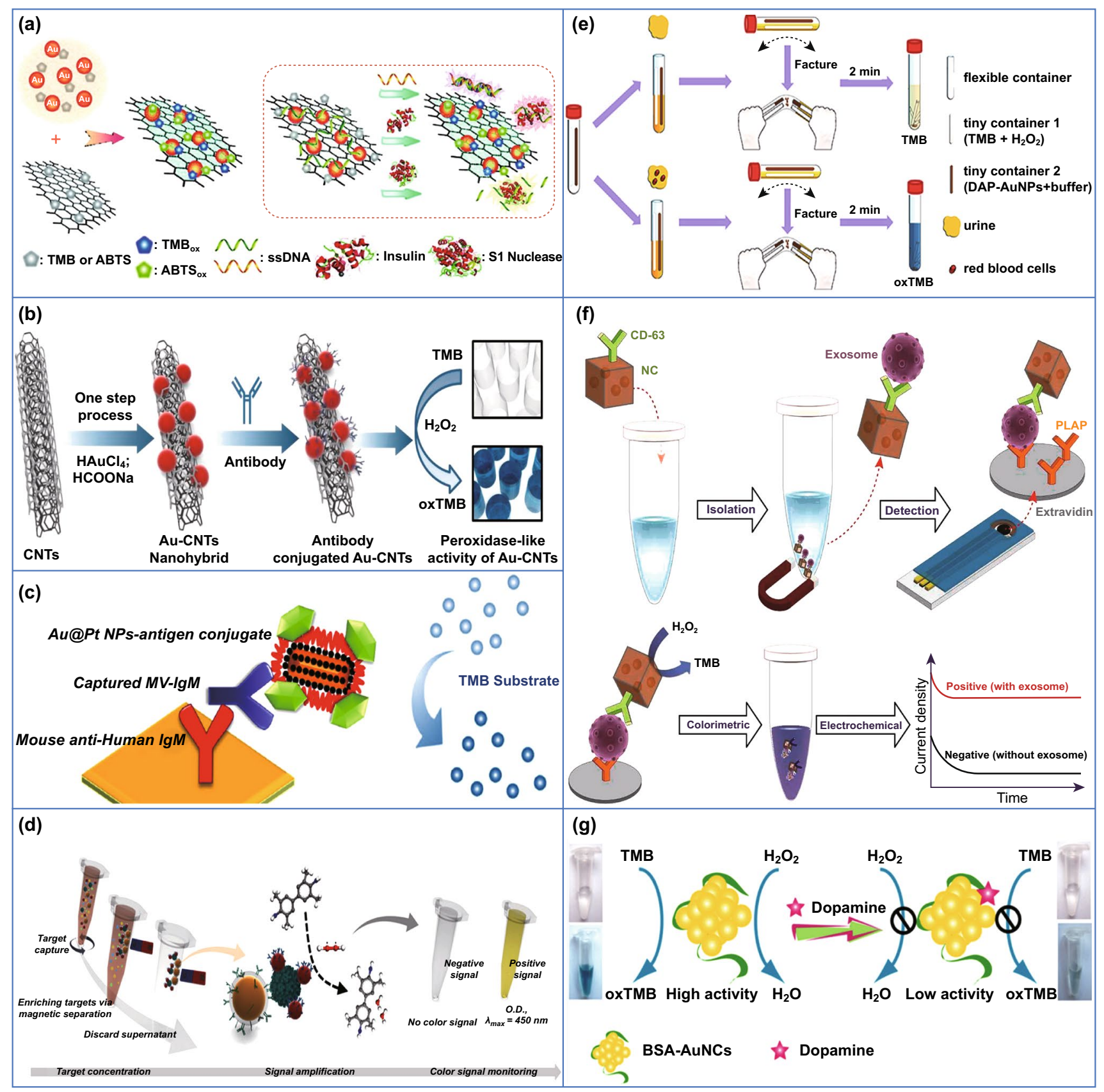

Fig. 7 Peroxidase-like activity of AuNPs used as clinical diagnostic tools. a AuNPs grown on graphene sheets used to develop a "off-on" colourimetric sensor [134]. Copyright 2012 American Chemical Society. b Nanohybrid composed of AuNPs and CNTs acting as colourimetric influenza virus detection [131]. Copyright 2016 Elsevier B.V. c Rod-shaped Au-Pt core/shell NPs used for measles virus detection [129]. Copyright 2018 Long et al. d Magnetic nanobeads combined with AuNPs for separation and detection of influenza virus [130]. Copyright 2018 American Chemical Society. e User-friendly device for haemoglobin and red blood cells detection in urine samples [127]. Copyright 2018 Elsevier B.V. f Gold-loaded nanoporous ferric oxide NPs used for direct exosome detection [133]. Copyright 2019 American Chemical Society. $\mathbf{g}$ Fluorometric and colourimetric detection of dopamine based on AuNCs [141]. Copyright 2012 Elsevier B.V.

uses bimetallic $\mathrm{Cu} @$ Au nanozymes (capable of oxidizing hydroquinone to benzoquinone) immobilized on magnetic metal organic framework nanocatalysts. Similar to other synergistic effects described above, the outstanding catalytic activity of the resulting nanohybrid allows highly sensitive detection through differential pulse voltammetry. 
Finally, gold nanozymes can also be harnessed in other sensing approaches based on fluorimetry and spectroscopy for the detection of urinary spermine [139], HIV and HCV [140] or dopamine [141] (Fig. 7g). Due to complicated optical components required, the spectroscopic methods often lack portability; thus, their development and practical implementations are more limited. In case of surface-enhanced Raman spectroscopy (SERS)-based systems, Hu et al. developed a system that uses the peroxidase activity of AuNPs to detect the lactate and glucose levels in living rats' brains, which are associated with ischaemic stroke. While there are some portable Raman spectrometers available on the market (such as QE Pro-Raman by Ocean Insight or TruScan ${ }^{\text {TM GP }}$ analyser by ThermoFisher), there is still a long way for engineering and optimizing the systems for POC diagnostics.

Together with a vast range of approaches for surface modifications and bioconjugations, it is evident that enzyme-mimicking activities of AuNPs and Au nanohybrid structures can allow versatile biosensor platforms generating either a colourimetric, electrochemical, fluorescent or spectroscopic measurable signal. As it is a new field, only a few examples have been described in the literature regarding gold nanozymes applied for clinical biosensors used in real samples. A summary is presented in Table 1.

\subsection{ROS Generation}

Gold nanozymes are not only applied for sensing devices, but can also be used as drug agents for therapeutics. This application has been mainly linked but not limited to small AuNPs (less than $2 \mathrm{~nm}$ in size), which are capable of penetrating the cells and cellular compartments and cause cytotoxicity (necrosis) by means of oxidative stress [142]. Thus, nanozymes with peroxidase-mimicking activity can catalyse the hydrogen peroxide decomposition and produce ROS [143-145]. The induced toxicity has been mainly used for tumour treatment, by first directing the nanoparticles to the targeted area and then enhancing their catalytic properties through photodynamic therapy (PDT). Despite not being a perfect photoregulation system, with clear on/off states, this approach can help reduce the secondary effects in nontargeted body tissues. Therefore, different nanocomplexes can be introduced in the body through the preferred administration via and after they are accumulated in the area of interest, the ROS generation process can be improved. This approach requires a smaller nanomaterial concentration to produce the same effect than the non-enhanced system, thus decreasing the drug concentration that needs to be administrated and the side effects caused by ROS generation elsewhere. However, very important external parameters govern nanozyme activities. Not only controllable parameters such as size, shape or nanoparticle surface modification, but also some others determined by the biological matrix, such as $\mathrm{pH}$, temperature or the presence of interfering molecules [146]. Therefore, it becomes very important to understand the tumour microenvironment if gold nanozyme properties are to be used for a clinical treatment. Well-known characteristics such as acidity [147], hypoxia [148] and abnormally high concentrations of $\mathrm{H}_{2} \mathrm{O}_{2}[149,150]$ in the affected area are a common denominator of the disease.

Conventional PDT involves light and a photosensitizing chemical substance, which combined with molecular oxygen, leads to phototoxicity. A recent approach used platinum nanoparticles (PtNPs) decorated on photosensitizer integrated metal-organic frameworks for enhanced PDT [151]. The nanoplatform successfully used the catalase-like activity of PtNPs to convert the abundant $\mathrm{H}_{2} \mathrm{O}_{2}$ in the tumour region into $\mathrm{O}_{2}$, thus modifying the hypoxic environment and facilitating the light-irradiated formation of cytotoxic ${ }^{1} \mathrm{O}_{2}$. This was the first study that exploited the nanozyme activity of metallic NPs to achieve an enhanced PDT. Different gold nanozymes have been combined with PDT ever since, paving the way for a new promising approach entirely to explore. Moreover, any laser wavelength within the therapeutic window (i.e., 650-1350 nm) can be used for this enhancement purpose, being one or another more convenient depending on the absorption profile of the nanocomplex being used. This way, 808-nm light irradiation has been used to improve the ROS generation of AuNPs embedded in porous hollow carbon shell nanospheres [143, 152], whereas other studies have used 660-nm irradiation to increase the method efficiency with AuNPs embedded in a zeolitic imidazolate framework [153] or $671 \mathrm{~nm}$ wavelength for hollow mesoporous organosilica nanoparticles containing AuNPs [154]. Interestingly, different nanomaterial combinations have been used, leading to different paths for generating ROS in which AuNPs can take diverse roles. Fan et al. pioneered the application of AuNPs for thermal cancer therapy combined with nanozyme activity. They encapsulated AuNPs in hollow carbon shell nanospheres and showed that, under an acidic environment, they retained 
Table 1 Clinical biosensors relate the use of the catalytic properties of gold nanomaterials

\begin{tabular}{|c|c|c|c|c|c|c|}
\hline Target & Nanomaterial & Activity & Outputs & Sample & LOD & References \\
\hline $\begin{array}{l}\text { Haemoglobin \& red } \\
\text { blood cells }\end{array}$ & AuNPs & Peroxidase & Colourimetric & Human urine & $\begin{array}{l}0.96 \mathrm{nM} \text { and } \\
1.6 \times 10^{6} \text { cells } \mathrm{L}^{-1}\end{array}$ & {$[127]$} \\
\hline $\begin{array}{l}\text { Heparine and hepa- } \\
\text { rinase }\end{array}$ & Gold nanoclusters & Peroxidase & Colourimetric & Diluted serum & $\begin{array}{l}0.3 \text { and } \\
0.06 \mu \mathrm{gL}^{-1}\end{array}$ & {$[106]$} \\
\hline $\mathrm{Cu}^{2+}$ and histidine & Gold nanoclusters & Peroxidase & Colourimetric & $\begin{array}{l}\text { Human serum, } \\
\text { blood }\end{array}$ & $0.1 \mathrm{nM}$ and $20 \mathrm{nM}$ & [126] \\
\hline $\begin{array}{l}\text { Pseudomonas aer- } \\
\quad \text { uginosa }\end{array}$ & AuNPs & Peroxidase & Electrochemical & Drinking water & $60 \mathrm{CFU} \mathrm{mL} \mathrm{m}^{-1}$ & [187] \\
\hline $\begin{array}{l}\text { Placental cell- } \\
\text { derived exosomes }\end{array}$ & $\begin{array}{c}\text { Au-loaded } \mathrm{Fe}_{2} \mathrm{O}_{3} \\
\text { nanocubes }\end{array}$ & Peroxidase & $\begin{array}{l}\text { Colourimetric, } \\
\text { electrochemical }\end{array}$ & Cell culture media & $\begin{array}{l}8 \times 10^{6} \text { vesicles } \\
\text { per million cells } \\
\text { per } 24 \mathrm{~h}\left(10^{3}\right. \\
\left.\text { exosomes } \mathrm{mL}^{-1}\right)\end{array}$ & [133] \\
\hline Spermine & $\begin{array}{l}\mathrm{Ag}-\mathrm{Au} \text { bimetallic } \\
\text { NPs }\end{array}$ & $\begin{array}{l}\text { Oxidase and Peroxi- } \\
\text { dase }\end{array}$ & Fluorescence & Urine & $0.87 \mathrm{nM}$ & [139] \\
\hline $\begin{array}{l}\text { Rubella virus (IgM } \\
\text { antibodies) }\end{array}$ & $\begin{array}{l}\mathrm{Au}-\mathrm{Pt} \text { core/shell } \\
\text { nanorods }\end{array}$ & Peroxidase & $\begin{array}{l}\text { Spectroscopic, } \\
\text { colourimetric }\end{array}$ & Human serum & $10 \mathrm{ng} \mathrm{mL}^{-1}$ & [225] \\
\hline $\begin{array}{l}\text { Cysteine and homo- } \\
\text { cysteine }\end{array}$ & $\mathrm{Au}-\mathrm{Pt}$ NPs & Peroxidase & $\begin{array}{l}\text { Spectroscopic, } \\
\text { colourimetric }\end{array}$ & Human serum & 3.5 and $1.6 \mathrm{nM}$ & {$[128]$} \\
\hline $\begin{array}{l}\text { Measles virus (IgM } \\
\text { antibodies) }\end{array}$ & $\begin{array}{l}\mathrm{Au}-\mathrm{Pt} \text { core/shell } \\
\text { nanorods }\end{array}$ & Peroxidase & Spectroscopic & Human serum & $10 \mathrm{ng} \mathrm{mL}^{-1}$ & [129] \\
\hline $\begin{array}{c}\text { Influenza virus A } \\
(\mathrm{H} 1 \mathrm{~N} 1, \mathrm{H} 3 \mathrm{~N} 2)\end{array}$ & $\begin{array}{l}\text { AuNPs and mag- } \\
\text { netic nanobeads }\end{array}$ & Peroxidase & $\begin{array}{l}\text { Spectroscopic, } \\
\text { colourimetric }\end{array}$ & $\begin{array}{l}\text { Spiked samples and } \\
\text { human serum }\end{array}$ & $\begin{array}{l}4.42 \times 10^{-14} \mathrm{~g} \mathrm{~mL}^{-1} \\
\text { and } 2.5 \mathrm{PFU} \mathrm{mL}\end{array}$ & [130] \\
\hline Cocaine & $\begin{array}{l}\text { Multi-shaped } \\
\text { AuNPs and ZnSeS } \\
\text { alloyed quantum } \\
\text { dots }\end{array}$ & Peroxidase & Spectroscopic & $\mathrm{KCl}-\mathrm{HCl}$ buffer & $112 \mathrm{nM}$ & [226] \\
\hline HIV and HCV DNA & $\begin{array}{l}\text { Pt-Au bimetallic } \\
\text { NPs }\end{array}$ & Oxidase & Fluorescence & Buffer & $5 \mathrm{pM}$ & {$[140]$} \\
\hline Glucose and lactate & AuNPs@MOF & $\begin{array}{l}\text { Peroxidase and } \\
\text { Oxidase }\end{array}$ & SERS & Living rats' brain & 4.2 and $5 \mu \mathrm{M}$ & {$[227]$} \\
\hline Murine norovirus & AuNPs & Peroxidase & Colourimetric & $\begin{array}{l}\text { Human serum, } \\
\text { shellfish homoge- } \\
\text { nate }\end{array}$ & $200 \mathrm{PFU} \mathrm{mL} \mathrm{m}^{-1}$ & [186] \\
\hline Dopamine & Au nanoclusters & Peroxidase & $\begin{array}{l}\text { Fluorescence, } \\
\text { colourimetric }\end{array}$ & PC12 cells & $10 \mathrm{nM}$ & [141] \\
\hline Xanthine & Au nanoclusters & Peroxidase & Spectroscopic & Urine and serum & $20 \mathrm{nM}$ & [228] \\
\hline $\begin{array}{l}\text { Influenza virus A } \\
\text { (H3N2) }\end{array}$ & AuNP-CNT hybrid & Peroxidase & $\begin{array}{l}\text { Spectroscopic, } \\
\text { colourimetric }\end{array}$ & Human serum & $\begin{array}{l}\text { 3.4 PFU mL } \\
\text { (10 PFU mL } \\
\text { real samples })\end{array}$ & [131] \\
\hline
\end{tabular}

the ability of ROS generation. More importantly, this process could be photoenhanced by the $808-n m$ laser irradiation, substantially inhibiting CT26 tumour growth in vivo [143]. This capability of ROS generation by AuNPs was confirmed by Zhang et al., who delved into the matter by using mesoporous carbon nanospheres doped with AuNPs as a drug delivery system. This nanocomplex was loaded with dye IR780 to enhance the photothermal therapy, so that when the tumour tissue was irradiated with the 808-nm laser it would also generate heat, thus further enhancing the photothermal therapy. Together with the nanozyme properties of AuNPs to decompose $\mathrm{H}_{2} \mathrm{O}_{2}$ located in the tumour cells to ${ }^{\circ} \mathrm{OH}$ and cause intracellular oxidative damage, this synergistic strategy has demonstrated favourable results as a therapy for folate-overexpressed gastric cancer tumours [152]. Many others $[155,156]$ came simultaneously to a conclusive consensus: the combination of photodynamic and photothermal therapies provides a novel approach with excellent synergistic therapeutic outcomes (Fig. 8a). However, some other tumour treatments take advantage of 
different gold nanozyme properties (Fig. 8b), either using their glucose oxidase activity [154, 157] or their catalase activity [153] to alleviate the pernicious effects. The former system used a nanocarrier loaded with collagenase to degrade the collagen I fibre in the extracellular matrix and enhance the penetration of the system and $\mathrm{O}_{2}$ infiltration, AuNPs capable of oxidizing glucose and generate $\mathrm{H}_{2} \mathrm{O}_{2}$ as a by-product and copper-based complexes to generate ROS. The latter addressed tumour hypoxia through the catalaselike activity observed in AuNPs, which takes advantage of the abundance of $\mathrm{H}_{2} \mathrm{O}_{2}$ in tumour areas to generate $\mathrm{O}_{2}$ that can be used by a photosensitizer to increase ROS levels. It is interesting to note that while different nanozyme activities derived from the same AuNPs can be boosted or inhibited, it is just likely that they coexist up to some points. Again, the microenvironment and the surface properties of the nanocomplex will play a crucial role in this sense. No studies have been found, however, clarifying whether these synergistic effects have any impact in the final outcomes for tumour treatment.

Likewise, ROS generation has also been used for bacterial inactivation and wound disinfection $[68,158]$. Qu and coworkers first reported that AuNPs embedded in mesoporous silica (MSN-AuNPs) could act as oxidase mimics [68] and were capable of generating ROS that led to antibacterial activity. This approach showed that MSN-AuNPs served as efficient and safe antibacterial agents even in the absence of $\mathrm{H}_{2} \mathrm{O}_{2}$, a powerful oxidizer which in high concentrations harms healthy tissues and delays wound healing. Microscopic analyses of Staphylococcus aureus and Escherichia coli showed that ROS generated by MSN-AuNPs could oxidize and destroy the bacterial lipid membranes, thus inhibiting the growth of both Gram-positive and Gram-negative bacteria. Further applications of MSN-AuNPs using Bacillus subtilis biofilms were investigated, whose antibacterial activity also resulted in an effective breakdown of existing biofilms and prevention of new biofilm formation. This was followed by a similar study, using AuNPs with ultrathin graphitic carbon nitride to take advantage of their synergistic effect and catalyse the decomposition of $\mathrm{H}_{2} \mathrm{O}_{2}$ to ${ }^{\circ} \mathrm{OH}$ radicals in an efficient manner [158]. Importantly, the mentioned synergism enables to use lower concentrations of $\mathrm{H}_{2} \mathrm{O}_{2}$ to reach the required antibacterial activity, thus avoiding the side effects mentioned above. This system has been applied for bacteria killing, biofilm degradation, wound disinfection and lung infection treatment. In vitro experiments showed the nanocomplex to have bactericidal activity against both Gram-negative and Gram-positive bacteria, as well as high efficiency in breaking down biofilms and preventing new ones to be formed. These approaches provide a novel alternative to tackle the growing healthy issue caused by persistent infections [159].

In addition to the applications described, AuNPs have also been used in conjunction with $\alpha-\mathrm{FeOOH} /$ porous carbon as biomimetic catalyst for Fenton reaction [160]. The proposed system used the glucose oxidase activity of AuNPs to generate gluconic acid, which helps to adjust the microenvironmental $\mathrm{pH}$ to promote the Fenton reaction and $\mathrm{H}_{2} \mathrm{O}_{2}$ to induce its reaction with $\mathrm{Fe}^{2+}$, thus generating ${ }^{\circ} \mathrm{OH}$ radicals. This reaction has many applications, especially for organic wastewater treatment [161], as the ROS formed can quickly and non-selectively degrade most organic pollutants to $\mathrm{CO}_{2}$ and $\mathrm{H}_{2} \mathrm{O}$. Correspondingly, any novelty that improves its yield could have a direct application in different sectors of the environmental field.

\subsection{Cell Protection}

Interestingly, AuNPs could also be used for ROS protective effects [162-165]. It might seem contradictory to what has just been explained, but as mentioned before, the nanozyme activity of AuNPs can be tuned or modulated depending on the surface chemistry of the nanoparticle or the microenvironment in which they are being used. This duality has been exploited to develop antioxidant nanocomplexes for protecting certain tissues from harmful effects caused by a high ROS presence. This is important since ROS, which are known to be involved in the regulation of gene expression and cell signalling cascades, can cause serious damage within biological systems of the human body if present at high concentrations [166]. For instance, a build-up of ROS within the body can induce an inflammatory-type response leading to diseases such as chronic obstructive pulmonary disease (COPD) [167]. Additionally, brain tissue damage and central nervous system-related disorders are associated with ROS, being the attenuation of oxidative stress a promising strategy to prevent conditions such as Parkinson, Alzheimer or amyotrophic lateral sclerosis [168, 169]. Most approaches propose to use antioxidant enzymes to revert this situation, but their delivery to the brain has shown major challenges, including proteolytic degradation, immunogenicity, short circulation 
(a)

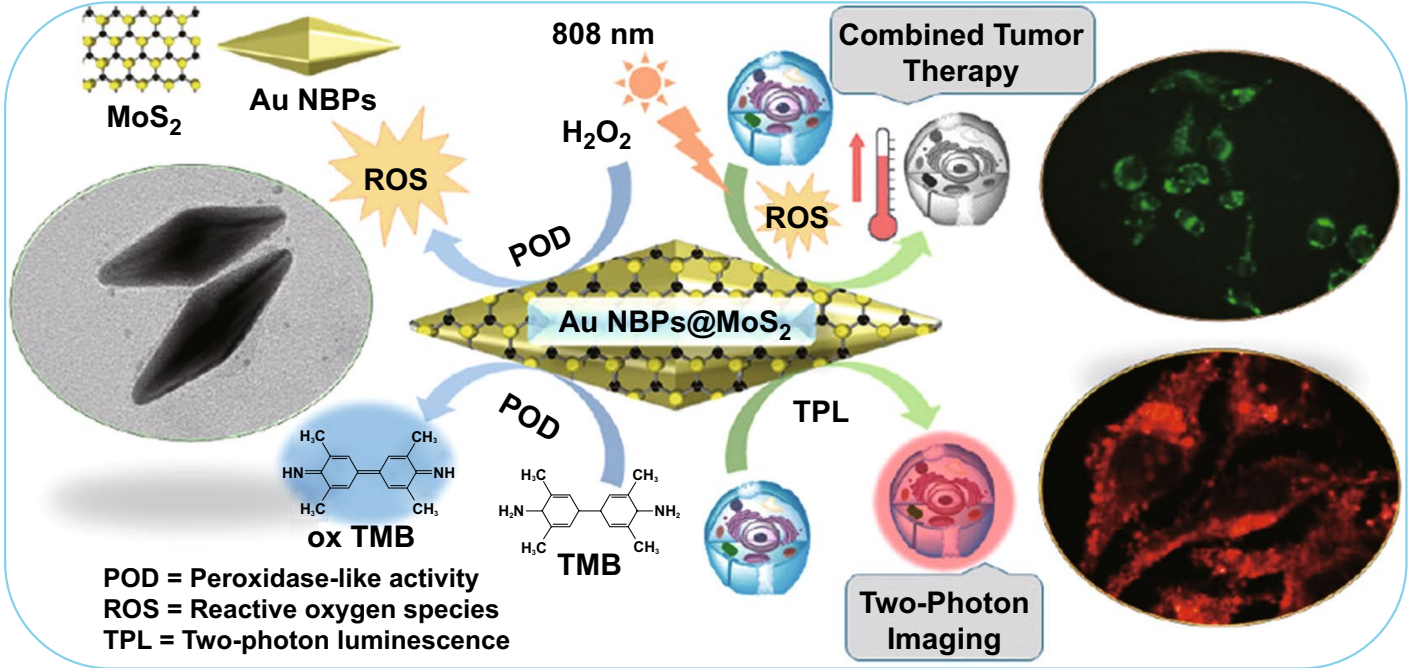

(b)
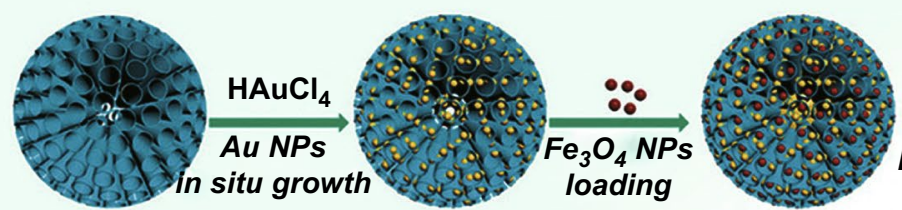

PEgylation

DMSN

DMSN-Au

DMSN-Au- $\mathrm{Fe}_{3} \mathrm{O}_{4}$

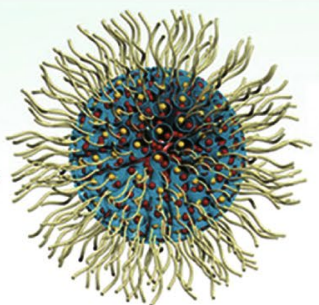

DMSN-Au-Fe ${ }_{3} \mathrm{O}_{4}-\mathrm{PEG}$

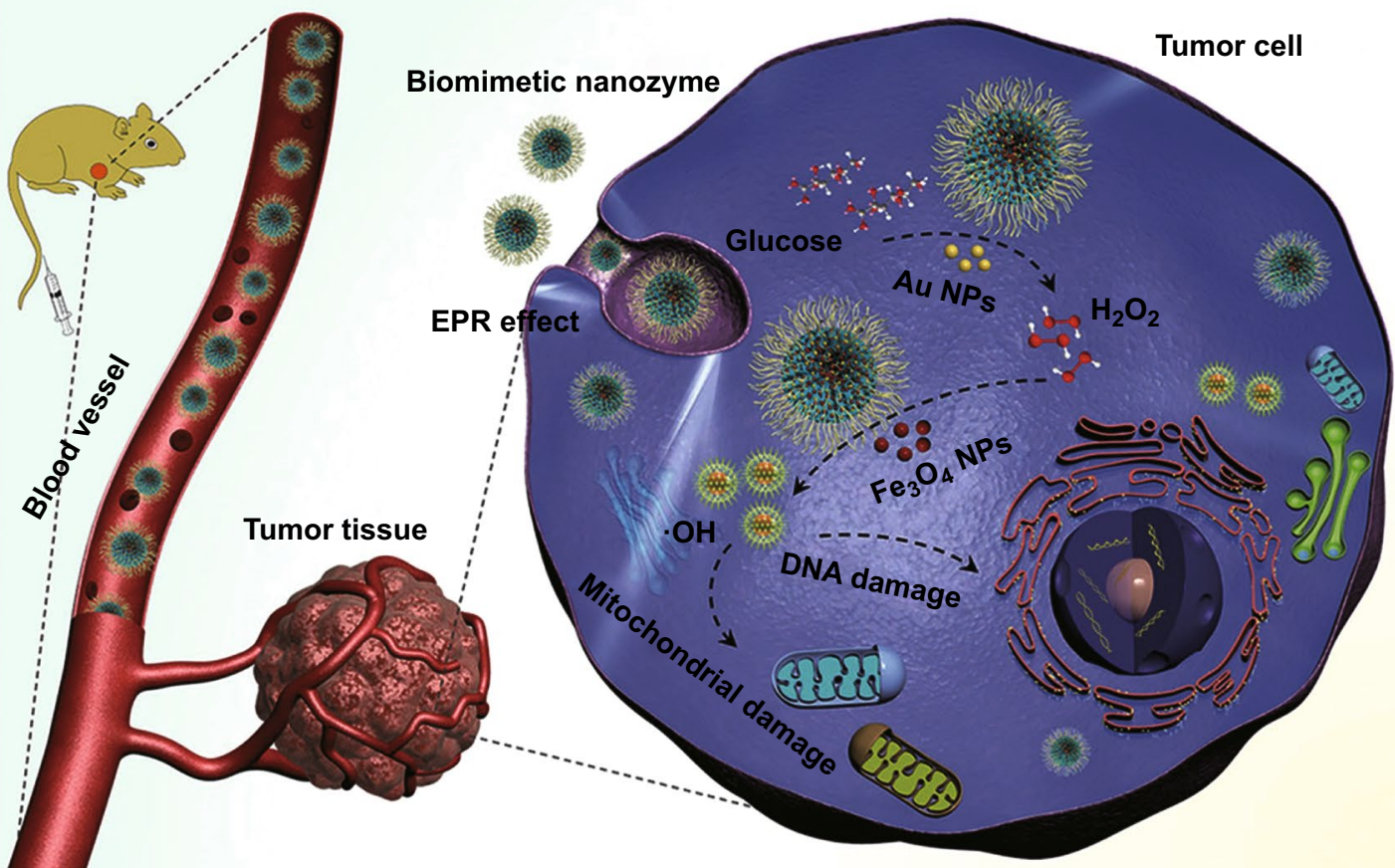

Fig. 8 Gold nanozymes applied for tumour therapy. a Peroxidase-like activity is combined with photodynamic and photothermal therapies for tumour imaging and localized treatment [155]. Copyright 2018 American Chemical Society. b Various enzymatic activities are combined to generate ROS inside the cell after directing the NPs to the affected tissue [157]. Copyright 2018 Wiley-VCH Verlag GmbH \& Co. KGaA 
half-time and poor permeability across the blood-brain barrier [168]. All these drawbacks open the way for alternative strategies using enzyme mimetic AuNPs as ROS scavengers.

Kunjiappan et al. [162] reported on these applications by using biologically synthesized AuNPs from Azolla microphylla extracts as antioxidant and hepatoprotective tools. This in vitro study compared the cell viability (among other parameters) of primary hepatocytes treated with acetaminophen (APAP) in the presence and absence of AuNPs. The study concluded that AuNPs presented antioxidant and hepatoprotective effects in APAP-treated hepatocytes by inhibiting ROS generation, scavenging free radicals and increasing the antioxidant defence enzymes. However, this empirical study did not prove the mechanisms underlying the effects observed and lacked some in vivo experiments to prove its applicability.

On the basis of previous works using iron oxide NPs [170] and platinum NPs [171], it had been observed that several nanozymes exhibited $\mathrm{pH}$-switchable catalase-like and peroxidase-like activities (Fig. 9). This effect was later demonstrated in other metallic NPs, such as gold and silver [108], being the adsorption energy between the metals and $\mathrm{H}_{2} \mathrm{O}_{2}$ the key aspect to favour one or the other reaction. Since the adsorption process is affected by the $\mathrm{pH}$ of the media, this explains the $\mathrm{pH}$-switchable activity empirically observed. It is based on this knowledge that Liu et al. published their work to shed some light on how to circumvent the $\mathrm{pH}$ dependence by simply modifying the NP surface. They discovered that gold nanoclusters (AuNCs) deprived

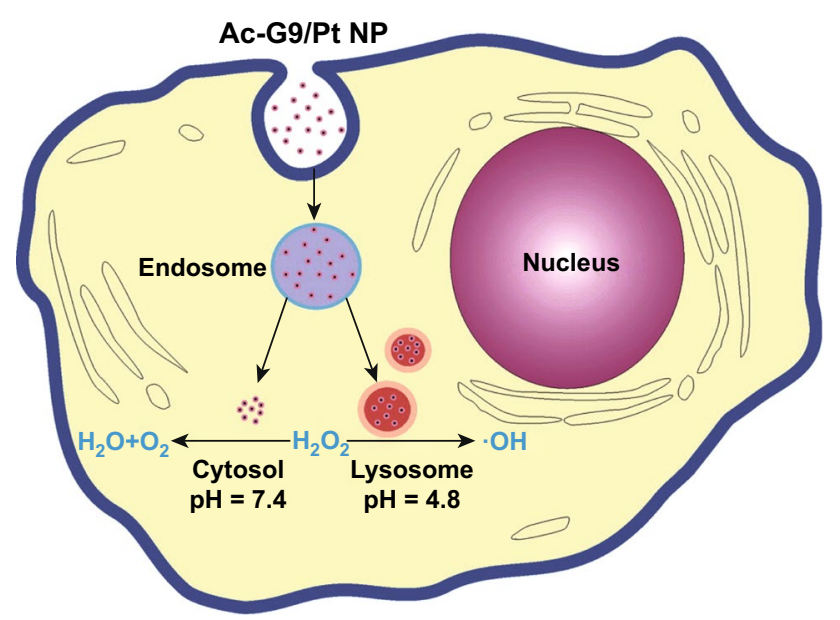

Fig. $9 \mathrm{pH}$ dependence of the catalytic properties of gold nanozymes shows two decomposition routes for $\mathrm{H}_{2} \mathrm{O}_{2}$. Acidic media promote the splitting of $\mathrm{H}_{2} \mathrm{O}_{2}$ into two hydroxyl radicals (peroxidase-like activity), whereas neutral $\mathrm{pH}$ media decompose it into $\mathrm{H}_{2} \mathrm{O}$ and $\mathrm{O}_{2}$ (catalaselike activity) [171]. Copyright 2013 American Chemical Society of their peroxidase-like activity while retaining their catalase-like activity under different $\mathrm{pH}$ values if modified with amine-terminated poly(amidoamine) (PAMAM). It was suggested that $3^{\circ}$-amines on the surface of the NP provided sufficient suppression of the critical mediator OH [164]. This system was used as a primary neuronal protection against oxidative damage (Fig. 10a), after demonstrating that mice neurons did internalize the AuNCs by endocytosis and that these neurons showed a significantly higher survival rate when treated with $\mathrm{H}_{2} \mathrm{O}_{2}$. Other approaches have used a light-mediated modulation system to control ROS levels in living cells, giving rise to smart nanozymes (Fig. 10b). This was achieved by encapsulating AuNPs in azobenzene (Azo) decorated mesoporous silica NP. Under visible light, cyclodextrin (CD) interacts with Azo through host-guest chemistry, blocking the catalytic sites of the nanocomplex and inhibiting its catalase-like activity at neutral $\mathrm{pH}$ conditions. However, UV illumination causes an isomerization of Azo to its cis conformation, resulting in $\mathrm{CD}$ being released from the system and recovering the catalase-like activity to become an effective ROS scavenger [163]. This turn on/off system was tested in MCF-7 cells, whose viability was modified at will depending on the light exposure. It is noteworthy that this system has some limitations, such as a relatively low nanozyme activity in the experimental conditions or low tissue penetration capacity of UV light. This approach resembles the PDT treatments before mentioned, arguably going a step further in terms of distinction between the two possible states. Be this as it may, there is no doubt that all these systems have paved the way for a whole new generation of smart nanozymes. Countless benefits may derive from these protective effects, not only for health purposes, but also for any process involving cell viability, such as in vitro fertilization (IVF). Dashtestani et al. [165] developed apoferritin-containing gold-silver NP to be used as ROS scavengers. The nanozyme showed both SOD- and catalase-like activity, thus decomposing superoxide ions to hydrogen peroxide, which subsequently is converted into water and molecular oxygen. This nanozyme was examined as a protective agent during the cryopreservation of human sperm, to control the freeze-thaw induced oxidative stress. The results showed a significant increase in the sperm motility and viability, being both parameters essential for sperm-egg fusion and fertilization. 
(a)

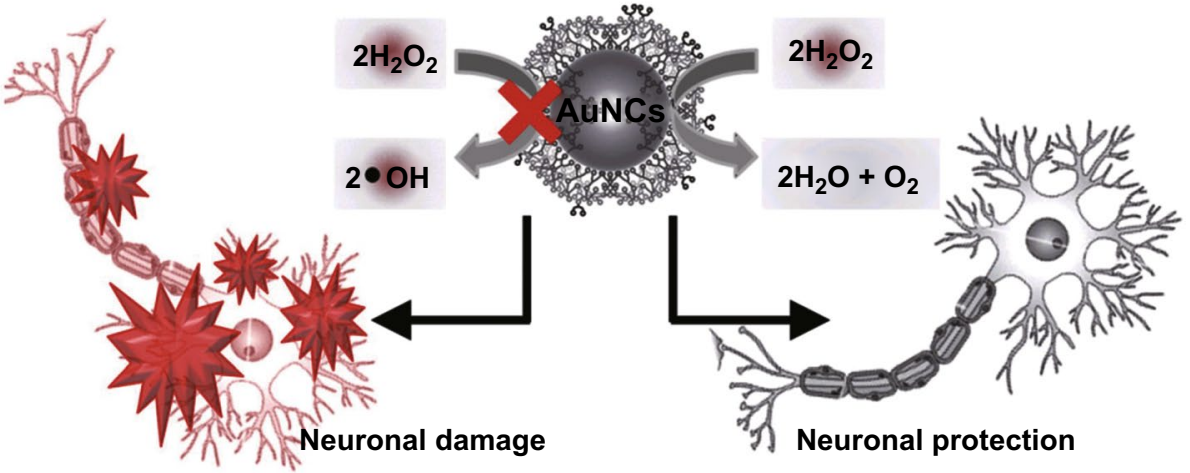

(b)

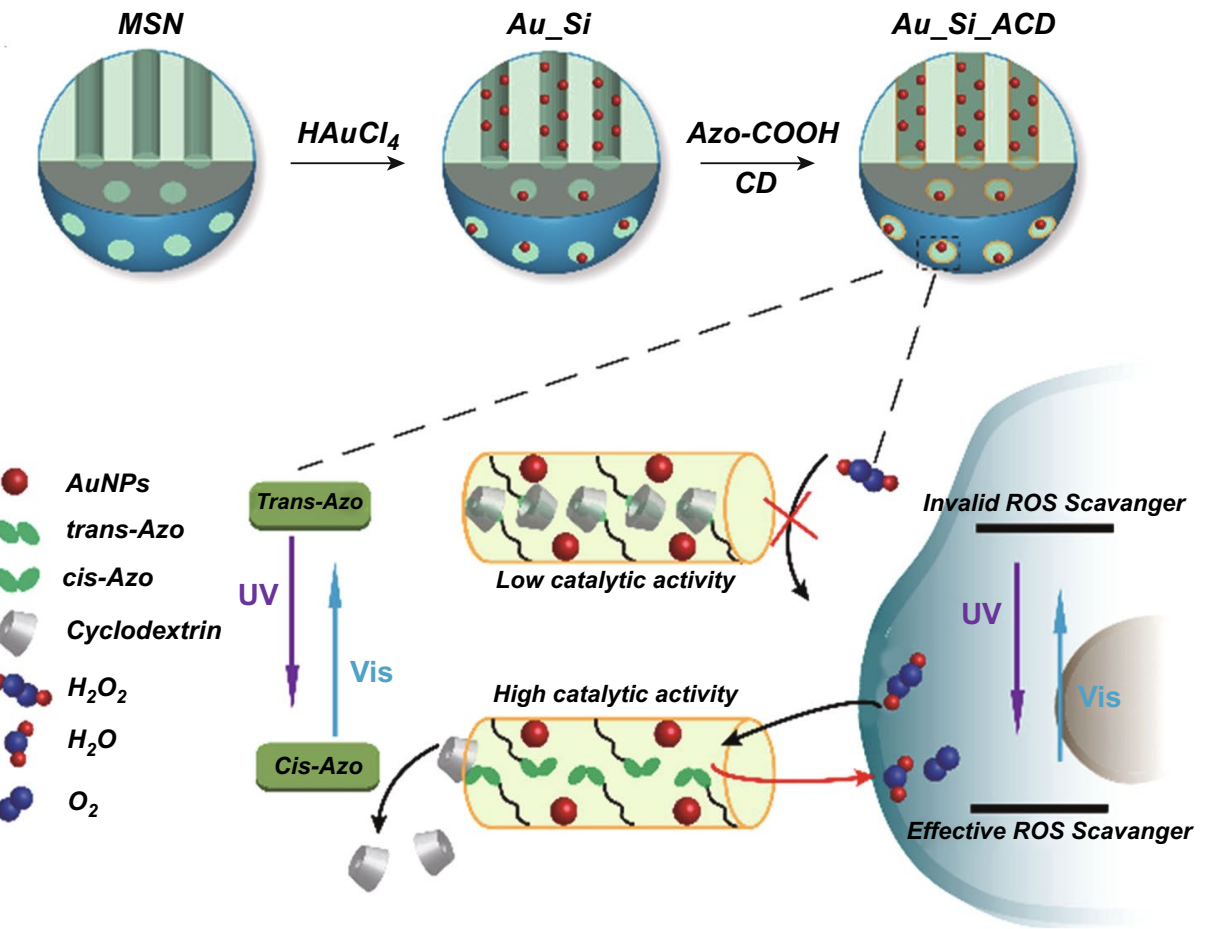

Fig. 10 Gold nanozymes used as ROS scavengers for cell protection. a Catalase-like activity of amine-terminated dendrimer-entrapped AuNCs used for neuronal protection against oxidative damage [164]. Copyright 2016 Wiley-VCH Verlag GmbH \& Co. KgaA. b Light-mediated reversible modulation of ROS levels using mesoporous NPs loaded with AuNPs [163]. Copyright 2017 Wiley-VCH Verlag GmbH \& Co. KGaA

\section{Other Applications of Gold Nanozymes}

Different options have been discussed throughout the review related to treating or diagnosing a certain biomedical condition. Conversely, little importance is often given to other matters that threaten our health in an indirect manner, such as environmental or food contamination. As a result, these conditions tend to fall by the wayside and only sporadic food- or water-related outbreaks remind us the potential risks of not diagnosing a disease in our environment. Fortunately, there is a high awareness of this within the scientific community, as our group previously reported in a comprehensive and interactive platform that reported over 900 sensors retrieved from the scientific literature and commercial market for aquatic toxins, mycotoxins, pesticides and micro-organism detection [172]. Furthermore, the catalytic properties of AuNPs can be applied to different bioprocesses with industrial or scientific interest, either for oxidizing amino acids [173], cleaving RNA [174], inducing the Fenton reaction [160] or even to catalyse enantioselective reactions [175]. Despite the fact that all these reactions can be carried out by biological 
counterparts, AuNPs may provide some key advantages during the process that sometimes can lead to lowering the production costs. These and other biological aspects of gold nanozymes, not strictly related to biomedicine, are discussed in this section.

\subsection{Environmental Applications}

Most applications encompassed in this category are related to diagnostic tools to detect toxic contaminants in environmental waters. This mainly includes heavy metals [136, 176-183], pesticides [100, 184, 185] or micro-organisms [102, 186-189], for being the most common contaminants, but it could potentially include any others. Nonetheless, these are not the only examples of gold nanozyme applications in the environmental sector, especially since their catalytic activities started to be exploited for wastewater treatment to degrade or convert toxic molecules into innocuous products $[190,191]$. It is important to note that many of these contaminants are anthropogenic. One obvious example is the E-waste, which comprises discarded electronic devices. It was estimated that 44.7 million tonnes of E-waste were generated globally in 2016, leading to lots of contaminants being released to the environment such as heavy metals ( $\mathrm{Pb}, \mathrm{Sb}, \mathrm{Hg}, \mathrm{Cd}, \mathrm{Ni}$ ), polybrominated diphenyl ethers (PBDEs) and polychlorinated biphenyls (PCBs) [192]. Moreover, the transfer of E-waste to ground and surface water, agricultural soils, rice, fish and humans has been proved [193]. A constant exposure to these contaminants brings harmful health effects with it. Far from being reduced, E-waste numbers are expected to keep growing, thus increasing the health threat.

Moving to the detection mechanisms themselves, the peroxidase-like activity of gold nanozymes is again the preferred approach for developing a sensor. Interestingly, many sensors for $\mathrm{Hg}$ detection have been reported in the literature using AuNP nanozyme activity [136, 176-178, 180]. The reason behind it is that mercury can form an $\mathrm{Au}-\mathrm{Hg}$ amalgam on the surface of the AuNP that enhances its peroxidase-like activity. This system has proved to be very sensitive and, more importantly, selective towards $\mathrm{Hg}$. Slight differences can be found between all these systems, whose sensitivity ranges between 0.15 and $6 \mathrm{nM}$. The best LOD was found using an $\mathrm{Au} / \mathrm{Fe}_{3} \mathrm{O}_{4} / \mathrm{GO}$ hybrid material that not only could detect $\mathrm{Hg}^{2+}$ in river and tap water samples, but would also allow for an efficient and quick $\mathrm{Hg}$ removal by deposition of $\mathrm{Hg}^{0}$ on the nanohybrid surface and its subsequent collection using an external magnetic field [177]. On the other hand, higher LOD (40 times less sensitive than the previous example) corresponds to a portable and paperbased approach that can be measured using a smartphone camera [136]. This approach has the particularity of being the only one that combines gold nanozymes with smartphones in any way. Recently, Logan and co-workers have lowered the LOD values reported for $\mathrm{Hg}$ detection using highly stable oligo ethylene glycol (OEG)-functionalized AuNPs [183], whose nanozyme activity was recovered in the presence of the metal (Fig. 11). A tenfold increased sensitivity was observed using this approach, which reached $10 \mathrm{pM}$ in tap and bottled water, while the sensitivity for saline solution was 65 pM. Despite most sensors described in this section target $\mathrm{Hg}$ ions, other systems have been developed to detect specifically $\mathrm{Ce}^{3+}$ [194] making use of its redox recycling ability to enhance TMB oxidation or $\mathrm{Ag}^{+}$[195] taking advantage of its ability to inhibit the nanozyme activity after being reduced onto AuNPs.

Other nanozyme sensors have been developed for malathion detection, a widely used pesticide in agriculture. These make use of the sulphanyl group from malathion molecules and its strong affinity for AuNP surfaces, thus quenching their peroxidase-like activity [185]. This inhibitory approach was first tested with AuNR [100], reaching a LOD of $1.78 \mu \mathrm{g} \mathrm{mL}^{-1}$ (though 10 times higher than the permissible levels of malathion in water). Then, a similar system using palladium-gold bimetallic nanorods [185] managed to lower the LOD down to $60 \mathrm{ng} \mathrm{mL}^{-1}$, well below the permissible levels, showing no cross-reactivity with analogous organophosphates or metal salts despite the lack of a biorecognition element in the system. Again, the synergistic effect of nanohybrids shows the great potential they have in this field.

Alternatively, gold nanozymes can be used for water treatment instead of diagnostics. This sometimes involves catalytic properties from AuNPs that have barely been mentioned herein: reductase properties. Such a system becomes a quite interesting approach for reducing the toxicity of water contaminants in industrial wastewaters before they are released to the environment. p-Nitrophenol (PNP) is a contaminant susceptible to this approach. It is widely used in petrochemical synthesis and its presence in industrial wastewaters might lead to liver and kidney 


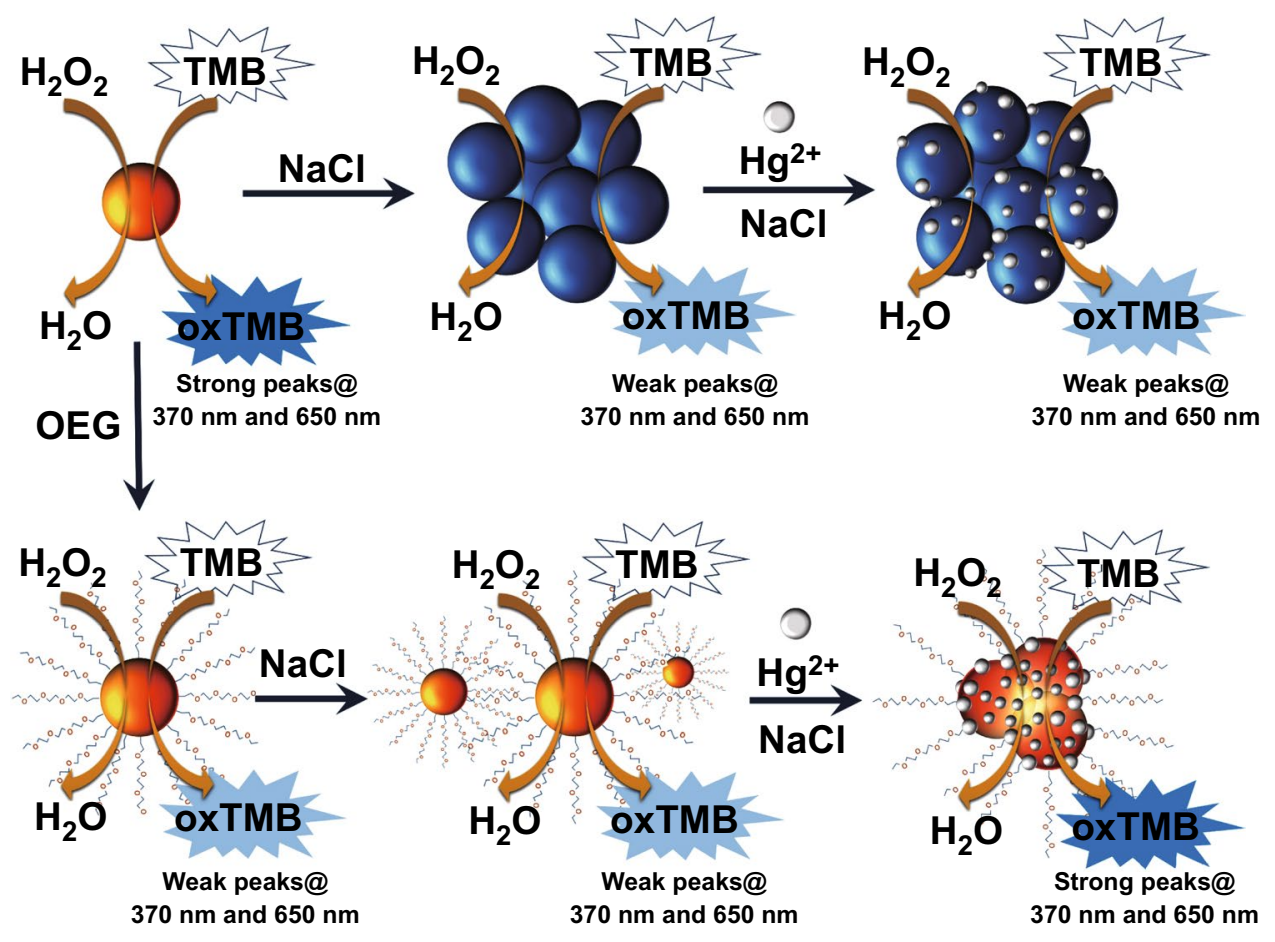

Fig. 11 Colourimetric sensor using gold nanozymes for the detection of $\mathrm{Hg}^{2+}$ ions in seawater samples [183]. Copyright 2020 Logan et al.

damage, anaemia or systemic poisoning in the receiving bodies [196]. $\mathrm{Fe}_{3} \mathrm{O}_{4} / \mathrm{Au}$ core-satellite nanocubes have been recently used to reduce PNP into para-aminophenol (PAP) [191], a product that has many useful applications such as analgesic drugs, photographic developer or even hair dyeing agents [197]. Other applications have made use of the AuNP dehydrogenase activity to degrade estradiol [190], which pollutes wastewaters and has been reported to feminize wild fish [198] and interfere with the human endocrine system [199].

\subsection{Food Safety Applications}

In a similar manner to environmental applications, food diagnostics remains of paramount importance due to the implications that a contamination in this matrix has for human health. The array of contaminants that can be found in food is diverse, as much as the variety in food products. This includes micro-organisms, pesticides, antibiotics or toxins among others. The biomedical consequences of consuming contaminated food go from diarrhoea to cancer, potentially causing more than 200 diseases. According to the WHO (2019) an estimated 600 million people fall ill after consuming contaminated food, while 420,000 die every year as a result of it, being children under 5 years of age who mostly suffer these consequences [200]. Moreover, since food supply chains cross-national borders, any contamination can reach far more people than ever. Taking all this into account, diagnosing food contamination on time remains an issue of high biomedical relevance. Some gold nanozyme-based sensors have been developed targeting microbiological contaminants: Escherichia coli $\mathrm{O} 157: \mathrm{H} 7$ [201], Pseudomonas aeruginosa [187] and murine norovirus [186]. The first system is based on a sandwich-type immunochromatographic assay that uses $\mathrm{Au}-\mathrm{Pt}$ bimetallic NPs to enhance the colour signal generated through their peroxidase-like activity. The second approach is based on the inhibition of the peroxidase-like activity of AuNPs: the NP are coated with a Pseudomonas-binding aptamer, which blocks the NP surface from developing the catalytic reaction, unless the target bacteria are present in the sample and sequester the aptamers, thus resuming the peroxidase activity. With the help of a disposable carbon screen-printed electrode, this simple system allows for the detection of $60 \mathrm{CFU} \mathrm{mL} \mathrm{m}^{-1}$ in $10 \mathrm{~min}$. The same approach has been used to detect murine norovirus in shellfish homogenates, reaching an LOD of $200 \mathrm{PFU} \mathrm{mL} \mathrm{mL}^{-1}$. However, the detection in 


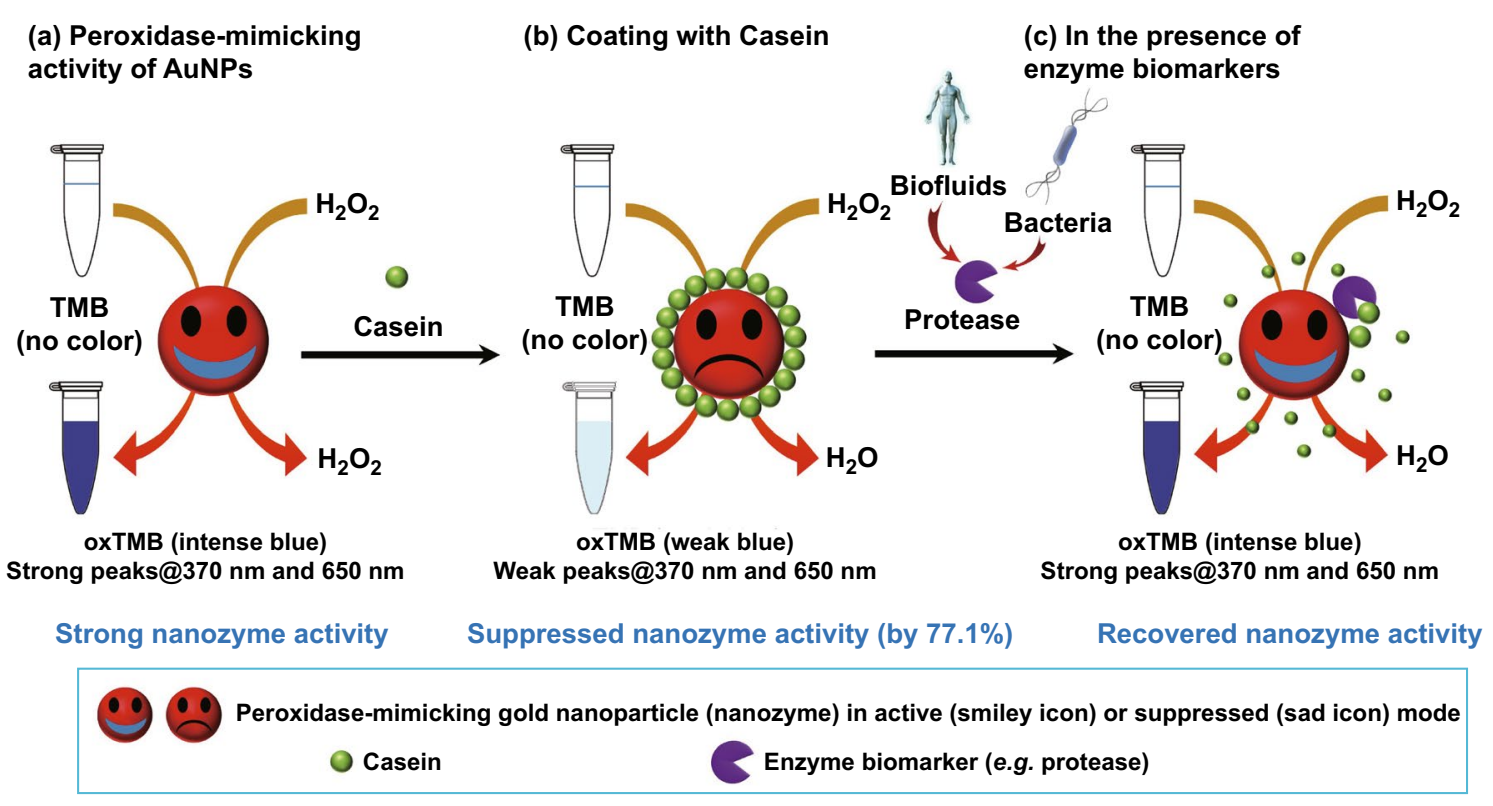

Fig. 12 Colourimetric sensor using gold nanozymes for the detection of proteolytic biomarkers indicative of food spoilage or human disease [102]. Copyright 2018 McVey et al.

this case is not electrochemical but colourimetric, showing the potential of this approach for point-of-care diagnostics, which remains an important goal considering that norovirus is the leading cause of viral foodborne outbreaks globally. In any case, this technology had been developed and applied for the detection of the pesticide acetamiprid [184] and the antibiotic kanamycin [202, 203] long before.

As mentioned in the previous section, children are especially sensitive to some of these contaminations. A clear example of this can be found in the melamine scandal happened in 2008 in China, when milk was illegally adulterated with this chemical. Melamine is a nitrogen-rich organic compound that has sometimes been illegally added to food products to increase the apparent protein content, thus masking a dilution in protein in the final product. This fraud should have been detected by routine tests implemented to ensure milk quality. However, these tests were either not carried out properly or ineffective [204, 205]. As a result, about 300,000 people were poisoned due to the high concentration of melamine, which caused many infants to develop kidney stones leading to renal failure and death of 6 babies [206]. Ever since, the number of publications related to melamine detection experienced a tenfold increase. Deng et al. [207] further demonstrated the versatility of gold nanozymes by developing a colourimetric sensor able to detect $0.02 \mathrm{mg} \mathrm{L}^{-1}$ of melamine in infant formula. This visual and straightforward system made use of the intrinsic binding of melamine to AuNPs to cause their aggregation and inhibit their peroxidase-like activity. This mechanism has the advantage of its simplicity, but as any sensor lacking a biorecognition element, the resulting specificity may be a matter of concern in complex matrixes. This LOD was reduced down to $8.51 \mathrm{nM}$ by Li et al. [208], who used SERS properties of popcorn-like $\mathrm{Au}-\mathrm{Ag}$ NPs to detect in a more sensitive manner the oxidized product generated by the bimetallic nanomaterial, oxTMB. They took advantage of the interaction between melamine and $\mathrm{H}_{2} \mathrm{O}_{2}$, which reduces the availability of the substrate for the peroxidase reaction of TMB, thus decreasing the colour generation in the presence of melamine. Interestingly, oxTMB is a Raman active compound, while anisotropic NPs are strong Raman enhancers [209, 210]. This can be exploited to detect the presence of melamine in milk powder with better sensitivity than the traditional colourimetric approach.

Similar frauds have occurred with different additives, not necessarily linked to fatal consequences. This is the case of unauthorized use of ascorbic acid (also known as vitamin $\mathrm{C}$ ). In meat products, the ascorbic acid prevents the formation of nitrosamines that lead to the 
Table 2 Other non-clinical biosensors relate the use of the catalytic properties of gold nanomaterials

\begin{tabular}{|c|c|c|c|c|c|c|}
\hline Target & Nanomaterial & Activity & Outputs & Sample & LOD & References \\
\hline $\mathrm{Hg}^{2+}$ & $\begin{array}{l}\text { g- } \mathrm{C}_{3} \mathrm{~N}_{4}-\mathrm{Au} \text { nano- } \\
\text { composites }\end{array}$ & Peroxidase & Colourimetric & Water & $3 \mathrm{nM}$ & [176] \\
\hline Glucose & AuNPs & Glucose oxidase & $\begin{array}{l}\text { Photoelectrochemi- } \\
\text { cal }\end{array}$ & - & $0.46 \mu \mathrm{M}$ & [229] \\
\hline $\mathrm{Hg}^{2+}$ & $\begin{array}{l}\mathrm{Au} / \mathrm{Fe}_{3} \mathrm{O}_{4} / \mathrm{GO} \text { hybrid } \\
\text { material }\end{array}$ & Peroxidase & Colourimetric & Water & $0.15 \mathrm{nM}$ & [177] \\
\hline Acetamiprid & AuNPs & Peroxidase & Colourimetric & - & $1.8 \mathrm{ppm}$ & [184] \\
\hline Kanamycin & AuNPs & Peroxidase & Colourimetric & - & $1.49 \mathrm{nM}$ & [202] \\
\hline Glucose & $\begin{array}{l}\mathrm{Au}-\mathrm{Ni} / \mathrm{g}-\mathrm{C}_{3} \mathrm{~N}_{4} \text { nano- } \\
\text { composites }\end{array}$ & Peroxidase & Colourimetric & - & $1.7 \mu \mathrm{M}$ & [230] \\
\hline $\mathrm{Hg}^{2+}$ and $\mathrm{Ag}^{+}$ & $\begin{array}{l}\text { Au-Pt core/shell } \\
\text { NPs }\end{array}$ & $\begin{array}{l}\text { Peroxidase (inhibi- } \\
\text { tion) }\end{array}$ & Colourimetric & Lake water & 3.5 and $2 \mathrm{nM}$ & {$[178]$} \\
\hline Malathion & $\mathrm{Pd}-\mathrm{Au}$ nanorods & $\begin{array}{l}\text { Peroxidase (inhibi- } \\
\text { tion) }\end{array}$ & Colourimetric & Tap water & $60 \mathrm{ng} \mathrm{mL}^{-1}$ & {$[185]$} \\
\hline Kanamycin & AuNPs & Peroxidase & Electrochemical & Standard and honey & 0.06 and $0.73 \mathrm{nM}$ & [203] \\
\hline Nitrite & $\begin{array}{l}\text { AuNCs/RGO nano- } \\
\text { composites }\end{array}$ & Peroxidase & $\begin{array}{l}\text { Colourimetric and } \\
\text { electrochemical }\end{array}$ & Sausages & 2 and $0.7 \mu \mathrm{M}$ & [231] \\
\hline $\mathrm{H}_{2} \mathrm{O}_{2}$ and Glucose & $\begin{array}{l}\text { AuNPs@DNA } \\
\text { hydrogel }\end{array}$ & $\begin{array}{l}\text { Peroxidase, glucose } \\
\text { oxidase }\end{array}$ & $\begin{array}{l}\text { Spectroscopic, } \\
\text { colourimetric }\end{array}$ & Serum & 1.7 and $38 \mu \mathrm{M}$ & [232] \\
\hline Malathion & Au nanorods & Peroxidase & $\begin{array}{l}\text { Spectroscopic, } \\
\text { colourimetric }\end{array}$ & Tap water & $1.78 \mu \mathrm{g} \mathrm{mL}^{-1}$ & {$[100]$} \\
\hline $\mathrm{Hg}^{2+}$ & AuNPs & Peroxidase & $\begin{array}{l}\text { Colourimetric } \\
\text { (smartphone) }\end{array}$ & Tap water & $\begin{array}{l}1.2 \mu \mathrm{g} \mathrm{L}^{-1} \\
(\approx 6 \mathrm{nM})\end{array}$ & [136] \\
\hline $\mathrm{H}_{2} \mathrm{O}_{2}$ & GO/AuNPs & Peroxidase & $\begin{array}{l}\text { Spectroscopic and } \\
\text { electrochemical }\end{array}$ & - & $2 \mu \mathrm{M}$ and $1.9 \mathrm{nM}$ & [233] \\
\hline $\mathrm{Hg}^{2+}$ and $\mathrm{Pb}^{2+}$ & $\begin{array}{l}\text { AuNPs/BiOI nano- } \\
\text { composites }\end{array}$ & Peroxidase & Fluorescence & $\begin{array}{l}\text { Water (tap, river, } \\
\text { lake, sea) }\end{array}$ & Nanomolar range & [179] \\
\hline $\mathrm{Ce}^{3+}$ & AuNPs & Peroxidase & Spectroscopic & Tap water & $2.2 \mathrm{nM}$ & [194] \\
\hline $\mathrm{Ag}^{+}$ & AuNPs & $\begin{array}{l}\text { Peroxidase (inhibi- } \\
\text { tion) }\end{array}$ & Spectroscopic & Lake water & $10 \mathrm{nM}$ & [195] \\
\hline Ascorbic acid & $\mathrm{Au} / \mathrm{Cu}$ nanorods & Peroxidase & Spectroscopic & Vitamin drink & $25 \mu \mathrm{M}$ & [212] \\
\hline Protease & AuNPs & Peroxidase & $\begin{array}{l}\text { Colourimetric, spec- } \\
\text { troscopic }\end{array}$ & Milk & $44 \mathrm{ng} \mathrm{mL}^{-1}$ & {$[102]$} \\
\hline $\mathrm{Hg}^{2+}$ & AuNPs & Peroxidase & $\begin{array}{l}\text { Colourimetric, spec- } \\
\text { troscopic }\end{array}$ & Water & $0.3 \mathrm{nM}$ & {$[180]$} \\
\hline Melamine & $\begin{array}{l}\text { Popcorn-like } \mathrm{Au}-\mathrm{Ag} \\
\text { NPs }\end{array}$ & Peroxidase & $\begin{array}{l}\text { Colourimetric, } \\
\text { SERS }\end{array}$ & Milk powder & $8.51 \mathrm{nM}$ & [208] \\
\hline Murine norovirus & AuNPs & Peroxidase & Colourimetric & $\begin{array}{l}\text { Human serum, shell- } \\
\text { fish homogenate }\end{array}$ & $200 \mathrm{PFU} \mathrm{mL}^{-1}$ & [186] \\
\hline $\begin{array}{l}\text { Pseudomonas aer- } \\
\quad \text { uginosa }\end{array}$ & AuNPs & Peroxidase & Electrochemical & Drinking water & $60 \mathrm{CFU} \mathrm{mL}^{-1}$ & [187] \\
\hline $\begin{array}{l}\text { Escherichia coli } \\
\text { O157:H7 }\end{array}$ & $\mathrm{Pt}-\mathrm{Au}$ porous NPs & Peroxidase & Colourimetric & - & $100 \mathrm{CFU} \mathrm{mL}^{-1}$ & [201] \\
\hline
\end{tabular}

discolouration of the meat during storage [211], a sign of spoilage. In agreement with the "no adulteration" policy in this matter, Xu et al. [212] developed a sensor based on $\mathrm{Au} / \mathrm{Cu}$ bimetallic NR for the determination of ascorbic acid in vitamin drink samples, reaching a LOD of $25 \mu \mathrm{M}$.
Again, the inhibition of the peroxidase-like activity of AuNPs is the approach used, combined with the synergistic effect observed between $\mathrm{Au}$ and $\mathrm{Cu}$, which results in a catalytic activity 4.5 times higher than Au NR. 


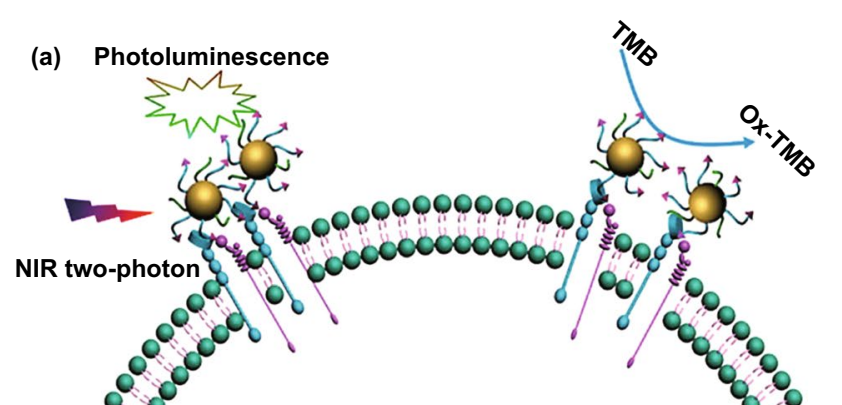

(i) Optical image

(b)

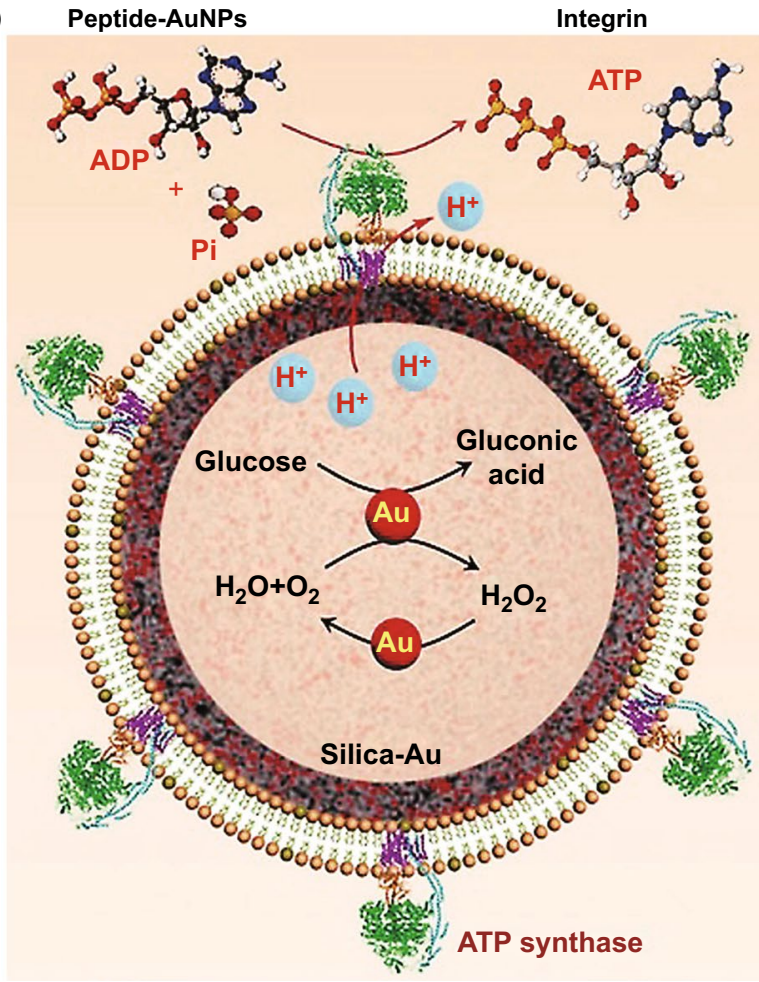

Fig. 13 Cell membrane engineering applications are used for a diagnostics of a health condition [214]. Copyright 2015 American Chemical Society or for $\mathbf{b}$ mimicking the biological machinery of ATP production in an artificial complex [213]. Copyright 2019 Wiley-VCH Verlag $\mathrm{GmbH} \& \mathrm{Co}$. KgaA, using in both cases the catalytic properties of AuNPs

More sophisticate systems have taken advantage of this peroxidase-like activity of gold nanozymes using an indirect approach to detect the presence of a significant biomarker of a certain condition. McVey et al. [102] developed a gold nanozyme sensor to determine the presence of proteolytic enzymes in human urine, where they may be related to diabetic kidney disease if elevated, and in cow milk, where their presence may be indicative of an infection by micro-organisms causing bovine mastitis. Protein coating of the AuNP surface blocks the TMB oxidation, while the presence of protease in the sample hydrolyses the protein and resumes the peroxidase-like activity of the AuNPs (Fig. 12). Some of these environment- and food-related examples are summarized in Table 2.

\subsection{Other Applications}

Lastly, gold nanozymes have proved useful beyond diagnosis and treatment possibilities. Many studies have already shown some potential bioapplications in diverse fields worth mentioning, either for building artificial biochemical models [213, 214] or for implementing chemical catalysis [215, 216]. Regarding biochemical models, two of them have been developed using gold nanozymes with different applicabilities. The first one uses a ligand exchange process to prepare peptide conjugated AuNPs that can recognize integrin GPIIb/IIIa in the membrane of human erythroleukaemia cells [214]. This ex vivo system enables the detection and quantification of membrane protein expression levels that constitute an early diagnosis approach for cancer. Specifically, the mentioned integrin expression level is closely related to platelet aggregation and cancer pathogenesis. As shown in Fig. 13a, AuNPs can be used for direct optical imaging through photoluminescence (thus locating the target protein in the membrane) or for quantification by making use of their peroxidase-like activity to calculate the precise expression level, that may be linked to a disease condition. The second example of biochemical models consists in an assembled natural-artificial hybrid architecture containing gold nanozymes to simulate the mitochondria oxidative phosphorylation process [213]. This system, illustrated in Fig. 13b, uses the glucose oxidase-like activity of AuNPs immobilized on hollow silica microspheres to generate gluconic acid, thus lowering the $\mathrm{pH}$ value within an artificial proteoliposome membrane containing ATP synthase. The proton gradient generated is then used to drive the rotary catalysis of ATP synthase, converting ADP and inorganic phosphate into ATP. However, there is a key drawback in this system, which is the generation of $\mathrm{H}_{2} \mathrm{O}_{2}$ as a secondary product. This could lead to the oxidation of the enzyme through ROS generation, whereas the potential effects of this $\mathrm{H}_{2} \mathrm{O}_{2}$ generation could have far more implications in vivo 
(a)
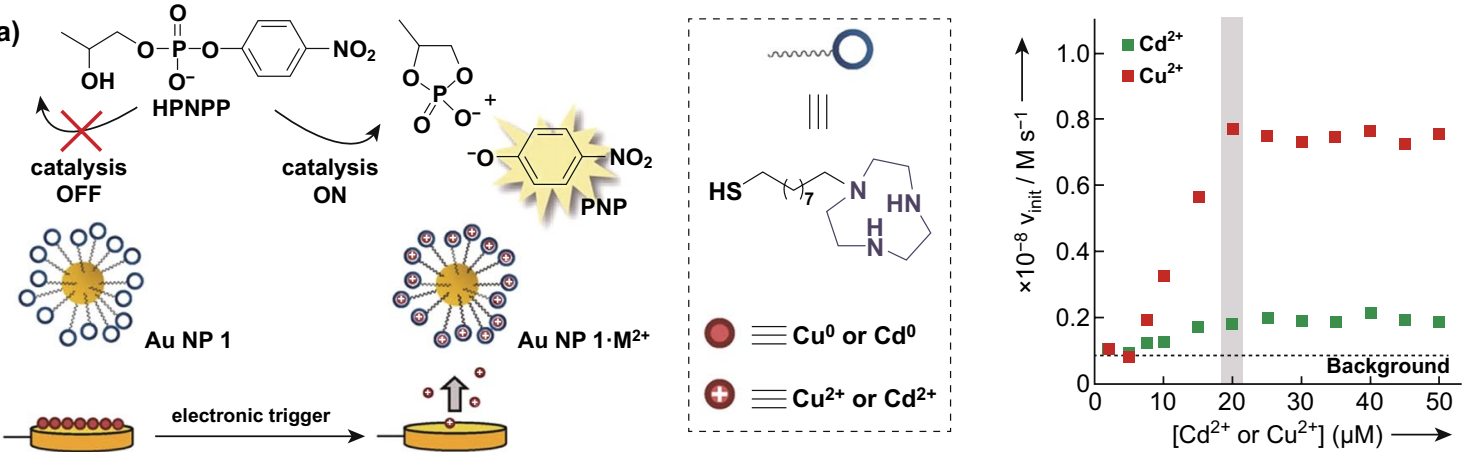

(b) Gold nanoparticle (NP)

Nanozyme (NZ)
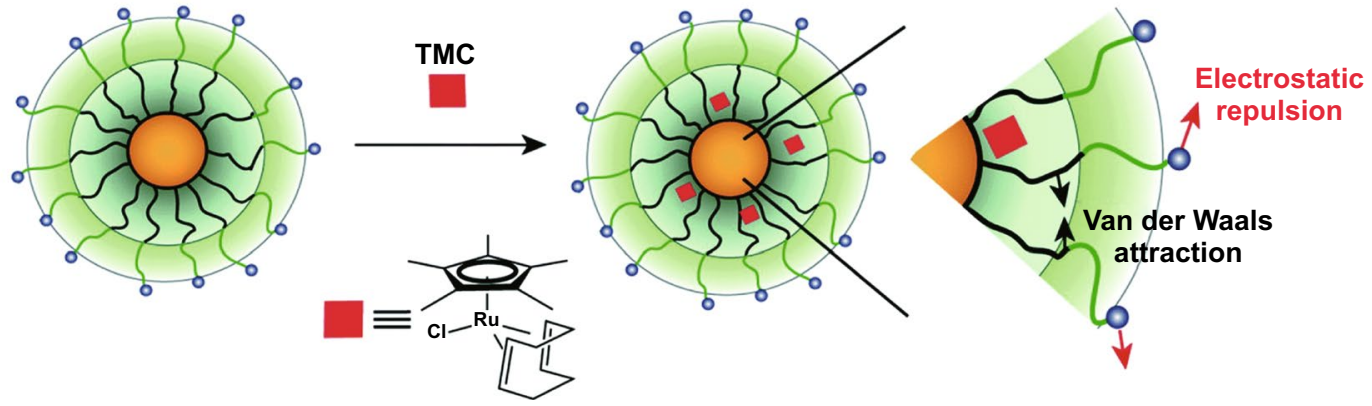

Fig. 14 Traditional nanozyme definition combining AuNPs with metallic ions used as catalysts. a Catalytic cleavage of HPNPP by Cd ${ }^{2+}$ and $\mathrm{Cu}^{2+}$ ions complexed by the AuNP-bound monolayer [216]. Copyright 2016 Wiley-VCH Verlag GmbH \& Co. KGaA. b Ru catalysts inserted in the protective layer of AuNPs [215]. Copyright 2017 The Royal Society of Chemistry

[217]. The duality of gold nanozymes helps to solve this problem through their peroxidase-mimicking activity, which in the presence of $\mathrm{H}_{2} \mathrm{O}_{2}$ and $\mathrm{HAuCl}_{4}$ results in the continuous enlargement of the AuNPs.

Finally, several supramolecular nanosystems that take part in more complex chemical reactions have also been reported. However, many of these examples use AuNPs as scaffolds in which the catalysts are immobilized. Metallic ions are commonly used for this purpose, such as $\mathrm{Cd}^{2+}$ and $\mathrm{Cu}^{2+}$ [216] or $\mathrm{Ru}$ [215]. These models follow the traditional nanozyme definition, coined by Scrimin's group [76], and referring to the combination of nanomaterials and catalysts, with no evaluation of the functionality of the nanomaterial itself as catalyst. The first nanosystem catalyses the cleavage of 2-hydroxypropyl-p-nitrophenyl phosphate (HPNPP) [216] and demonstrates that the activity of this supramolecular catalyst can be electrochemically regulated by releasing metallic cations from an electrode or by re-depositing these ions on the electrode (Fig. 14a). The second example uses biorthogonal ruthenium catalysts inserted in the protective monolayer of AuNPs [215] (Fig. 14b) to activate the lowfluorescent allyl carbamate-protected rhodamine into its fluorescent counterpart.

These are some examples showing important and useful applications of gold nanozymes. However, some other possibilities remain relatively undiscussed for being in a very primitive stage or lacking the desired portability, as many SERS studies on gold nanozymes show [218-221]. Thus, the applications in this field are expected to quickly grow in the near future, being the ones herein some exemplifications of the most pioneer approaches. 


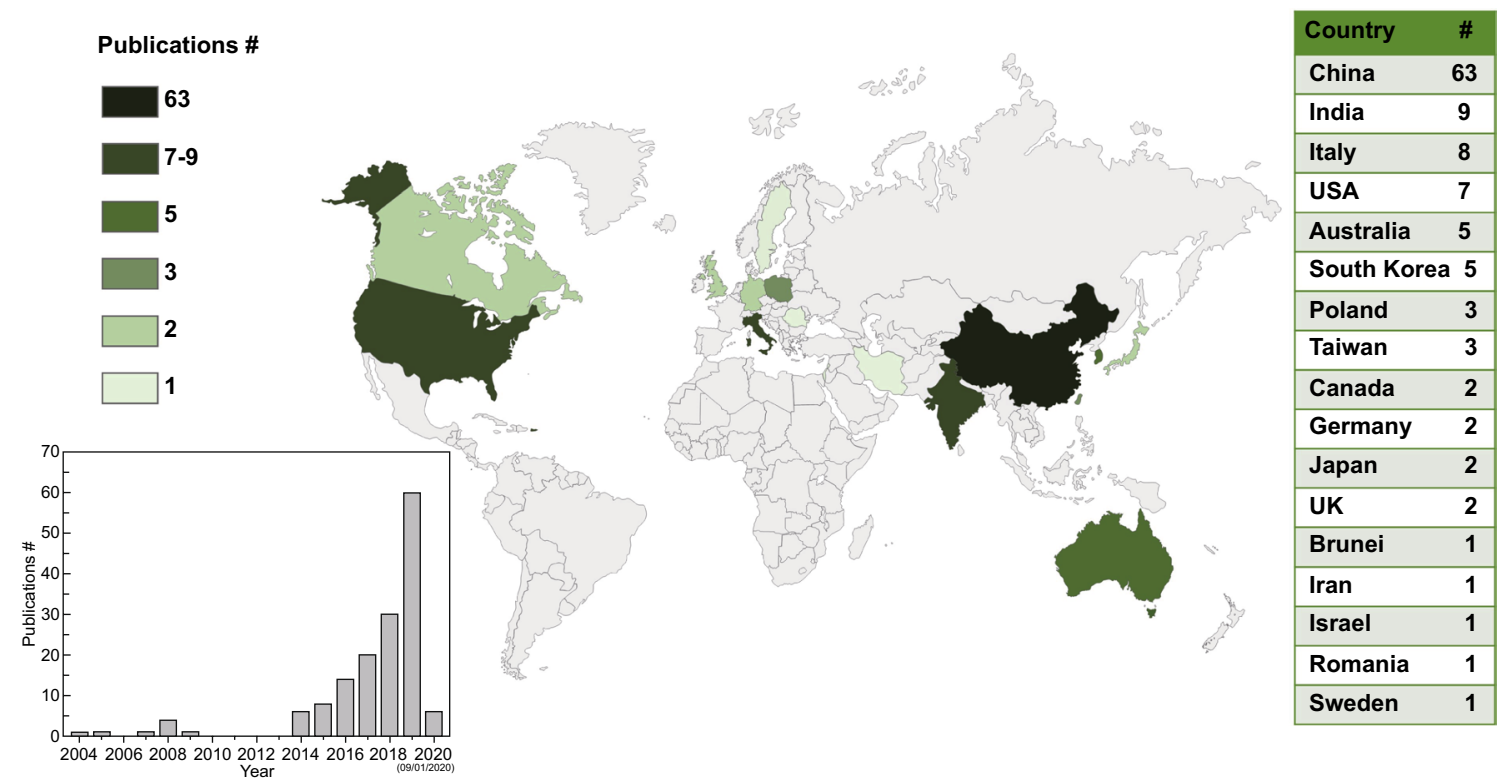

Fig. 15 Worldwide distribution of gold nanozyme publications, top-producing countries in the field and annual progression in the field by number of publications

\section{Conclusions and Future Perspectives}

The diversity of applications described so far (biosensors for biomedical, environmental or food applications, cancer treatment, cellular protection against conditions causing increased ROS levels, catalysis of many reactions used in the chemical industry, etc.) show the versatility and potential of gold nanozymes. Moreover, only the applications with some medical, biological and environmental relevant aspects have been discussed in this review. However, several gaps have been identified in the area of gold nanozymes that need to be solved before a further development of the area can be achieved.

The first observation that could diminish the potential of gold nanozymes if not considered would be the lack of robustness of these systems when their surface is chemically modified in any way. There is clear evidence that the immobilization of stabilizing agents on the surface of the AuNPs entails a modification of the catalytic properties of the nanosystem in question, most of the times resulting in the inhibition of the process due to the blockage of the gold surface where the reaction happens. This problem aggravates when the coating requires macromolecules (such as antibodies or other biological binders), leading to a complete inhibition of the catalytic process. Because of this, less than one quarter of the studies found in the searching databases using the term "gold nanozyme" make use of any sort of biorecognition macromolecule attached to the AuNPs, whereas all the others prefer to follow an approach that does not require much of a modification in the NP surface. The latter scenario, where no biorecognition elements are used, follows alternative approaches where the stabilizing agent of the nanomaterials (often polymers, detergents or other low molecular weight agents) shows some specificity towards a certain target analyte. Despite this approach being effective in a number of cases reported throughout the review, there are valid concerns about their specificity in real complex matrixes. Among the approaches that use immobilized biorecognition elements, most studies chose either aptamers or antibodies. In the first case, an approach that has gained popularity and that has been adapted in many systems consists in coating the AuNPs with an aptamer to inhibit the peroxidase-like activity of AuNPs and then restore it if the aptamer is released and captured by the presence of its target analyte. In the case of antibodies, an interesting approach to solve the inhibition consists in implementing a metallic deposition on the nanoconjugate (i.e., gold or silver deposition) to restore the catalytic properties lost during the surface modification [222]. Nevertheless, there are still many 
studies that have proved the potential of certain applications using bare AuNPs and never tested their applicability in real conditions where the surface modification is mandatory. This shows the first obstacle that must be overcome by gold nanozymes. Logically, the above explanation leads to another question: can the gold nanozyme-based systems be affected by the diversity of molecules present in the real matrixes? This is an interesting and valid question whose answer is difficult to predict and will depend on case to case. This might limit the potential of these systems for in vivo applications, where the nanosystems have to be administrated into the body while retaining their catalytic properties. Ex vivo applications, on the other hand, might not experience this problematic as the possibility of sample pre-treatment could avoid it.

Considering in vivo applications, which shape a big block within biomedical applications of gold nanozymes, the second obstacle that arises is the lack of information about toxicity and biodistribution of AuNPs. Nanomaterials used as pharmaceutical drugs must also be eliminated via metabolism or excretion processes after they enter the body, to reduce toxicity and prevent drug accumulation. Even if AuNPs are not inherently toxic to human cells, it has been evident that some precursors and capping molecules might cause toxicity. Previous studies using quantum dots in mice showed that these nanomaterials remained intact for more than 2 years in mouse tissues [223], which is a health and safety concern. Together with the lack of information about long-term effects of the presence of NP in human tissues, their applicability for health issues is stagnant. Nanomaterials whose hydrodynamic diameter is smaller than $5 \mathrm{~nm}$ will be excreted by the renal route, whereas bigger nanomaterials will not traverse the glomerular filter and thus will accumulate in spleen and liver $[118,200,224]$. The complexity of these studies leads to some biomedical applications of gold nanozymes being studied in vitro, such as the neuronal protection against oxidative stress illustrated in Fig. 10a, whose applicability in vivo still seems distant.

Furthermore, as it has been previously mentioned, AuNPs are extraordinarily versatile enzyme mimics, showing peroxidase activity, glucose oxidase, catalase, SOD or even reductase. More importantly, these activities coexist in some cases. However, there is a lack of information on what conditions favour or inhibit each of them, existing only very basic information related to the $\mathrm{pH}$ of the media to help explain this phenomenon. Finally, there is only one publication reporting to have combined gold nanozymes and smartphones in any way. Both gold nanozymes as transduction approach and smartphones as quantification devices are novel tools, which highlights the novelty of this area and the potential that it could have for portable diagnostics once it starts to develop.

All the points described in this section, in which the obstacles that one may encounter when developing a nanozymebased device are summarized, intend to convey useful and critical information extracted from the current state of the research rather than to discourage future works. As it is illustrated in the map (Fig. 15), only 17 countries have published research articles on gold nanozymes, which means the area is yet entirely to explore. More than half of these research activities were conducted in China, and only 8 articles containing the term "gold nanozyme" were published before 2014. All this is indicative of the novelty of the area, which according to Fig. 15 seems to be in an exponential growth phase. Therefore, the potential commercialization of the assays and therapies discussed herein would need more time to be realized and to be evaluated in order to bring the cutting-edge technologies to commercial market.

In summary, over 200 recently published research papers were systematically reviewed to present the current progress on the fundamentals of gold nanozymes and their potential applications. The review reveals that the morphology and surface chemistry of the nanoparticles play an important role in their catalytic properties, as well as external parameters such as $\mathrm{pH}$ or temperature. Yet, real applications often require specific biorecognition elements to be immobilized onto the nanozymes, leading to unexpected positive or negative effects on their activity. Thus, rational design of efficient nanozymes remains a challenge of paramount importance. Different implementation paths have already been explored, including the application of peroxidase-like nanozymes for the development of clinical diagnostics or the regulation of oxidative stress within cells via their catalase and SOD activities. The review also indicates that it is essential to understand how external parameters may boost or inhibit each of these activities, as more than one of them could coexist. Likewise, further toxicity studies are required to ensure the applicability of gold nanozymes in vivo. By providing insights into the fundamental aspects, applicability and difficulties of the gold nanozyme-based systems, this review is to provide 
an in-depth yet informative investigation. Although several concepts have been widely exploited, more studies are required to validate whether the approaches observed can be applied in real situations.

Acknowledgements The authors J.L., C.E. and C.C. acknowledge funding from the European Union's Horizon 2020 research and innovation programme under the Marie Sklodowska-Curie Grant Agreement No. 720325. B.D. and C.C. thank the support from the Commonwealth Split-site Scholarship.

Open Access This article is licensed under a Creative Commons Attribution 4.0 International License, which permits use, sharing, adaptation, distribution and reproduction in any medium or format, as long as you give appropriate credit to the original author(s) and the source, provide a link to the Creative Commons licence, and indicate if changes were made. The images or other third party material in this article are included in the article's Creative Commons licence, unless indicated otherwise in a credit line to the material. If material is not included in the article's Creative Commons licence and your intended use is not permitted by statutory regulation or exceeds the permitted use, you will need to obtain permission directly from the copyright holder. To view a copy of this licence, visit http://creativecommons.org/licenses/by/4.0/.

\section{References}

1. P. Fermo, G. Padeletti, The use of nano-particles to produce iridescent metallic effects on ancient ceramic objects. J. Nanosci. Nanotechnol. 12(11), 8764-8769 (2012). https:// doi.org/10.1166/jnn.2012.6464

2. I. Freestone, N. Meeks, M. Sax, C. Higgit, The lycurgus cup_a roman nanotechnology. Gold Bull. 40(4), 270-277 (2007). https://doi.org/10.1007/BF03215599

3. L. Dykman, N. Khlebtsov, Gold nanoparticles in biomedical applications: recent advances and perspectives. Chem. Soc. Rev. 41(6), 2256-2282 (2012). https://doi.org/10.1039/c1cs15166e

4. G.J. Higby, Gold in medicine - a review of its use in the west before 1900. Gold Bull. 15(4), 130-140 (1982). https://doi. org/10.1007/BF03214618

5. N. Culpeper, Pharmacopoeia Londinensis: Or the London Dispensatory (Royal College of Physicians, England, 1672)

6. R. James, A Medicinal Dictionary, Vol.1 (London, 1743)

7. J.A. Chrestien, De la méthode ïatraleptique, ou observations pratiques sur l'efficacité des remèdes administrés par la voie, de l'absorption cutanée dans le traitement de plusieurs maladies internes et externes; et sur un nouveau remède [pour les] maladies vénériennes et lymphatiques (Chez Croullebois: Chez Crochard, Paris, 1811)

8. R. Koch, Dtsch. Medizinische Wochenschrift. 16, 756-757 (1890)

9. J. Turkevich, P.C. Stevenson, J. Hillier, A study of the nucleation and growth processes in the synthesis of colloidal gold. Discuss. Faraday Soc. 11, 55-75 (1951)
10. R.P. Feynman, There's Plenty of Room at the Bottom (Perseus Books Publishing, New York, 1999)

11. M.C.M. Daniel, D. Astruc, Gold nanoparticles: assembly, supramolecular chemistry, quantum-size related properties and applications toward biology, catalysis and nanotechnology. Chem. Rev. 104(1), 293-346 (2004). https://doi. org/10.1021/cr030698+

12. M.A. Garcia, Surface plasmons in metallic nanoparticles: fundamentals and applications. J. Phys. D Appl. Phys. 45(38), 1-20 (2012). https://doi.org/10.1088/0022$3727 / 45 / 38 / 389501$

13. S. Trudel, Unexpected magnetism in gold nanostructures: making gold even more attractive. Gold Bull. 44(1), 3-13 (2011). https://doi.org/10.1007/s13404-010-0002-5

14. Y. Lin, J. Ren, X. Qu, Nano-gold as artificial enzymes: hidden talents. Adv. Mater. 26(25), 4200-4217 (2014). https:// doi.org/10.1002/adma.201400238

15. X. Huang, P.K. Jain, I.H. El-Sayed, M.A. El-Sayed, Gold nanoparticles: interesting optical properties and recent applications in cancer diagnostics and therapy. Nanomedicine 2(5), 681-693 (2007). https://doi.org/10.2217/17435 889.2.5.681

16. P.K. Jain, X. Huang, I.H. El-Sayed, M.A. El-Sayed, Noble metals on the nanoscale: optical and photothermal properties and some applications in imaging, sensing, biology, and medicine. Acc. Chem. Res. 41(12), 1578-1586 (2008). https://doi.org/10.1021/ar7002804

17. Y. Wang, Y. Xia, Bottom-up and top-down approaches to the synthesis of monodispersed spherical colloids of low melting-point metals. Nano Lett. 4(10), 2047-2050 (2004). https://doi.org/10.1021/n1048689j

18. J.F. Liu, L.G. Zhang, N. Gu, J.Y. Ren, Y.P. Wu et al., Fabrication of colloidal gold micro-patterns using photolithographed self-assembled monolayers as templates. Thin Solid Films 327-329(1-2), 176-179 (1998). https://doi. org/10.1016/S0040-6090(98)00623-3

19. M.K. Corbierre, J. Beerens, R.B. Lennox, Gold nanoparticles generated by electron beam lithography of gold(I)-thiolate thin films. Chem. Mater. 17(23), 5774-5779 (2005). https://doi.org/10.1021/cm051085b

20. D. Qin, Y. Xia, G.M. Whitesides, Soft lithography for micro- and nanoscale patterning. Nat. Protoc. 5(3), 491502 (2010). https://doi.org/10.1038/nprot.2009.234

21. H.W. Li, B.V.O. Muir, G. Fichet, W.T.S. Huck, Nanocontact printing: a route to sub-50-nm-scale chemical and biological patterning. Langmuir 19(6), 1963-1965 (2003). https ://doi.org/10.1021/la0269098

22. G. Barbillon, F. Hamouda, S. Held, P. Gogol, B. Bartenlian, Gold nanoparticles by soft UV nanoimprint lithography coupled to a lift-off process for plasmonic sensing of antibodies. Microelectron. Eng. 87(5-8), 1001-1004 (2010). https://doi.org/10.1016/j.mee.2009.11.114

23. B.J.Y. Tan, C.H. Sow, T.S. Koh, K.C. Chin, A.T.S. Wee, C.K. Ong, Fabrication of size-tunable gold nanoparticles array with nanosphere lithography, reactive ion etching, and 
thermal annealing. J. Phys. Chem. B 109(22), 11100-11109 (2005). https://doi.org/10.1021/jp045172n

24. S.M. Yang, S.G. Jang, D.G. Choi, S. Kim, H.K. Yu, Nanomachining by colloidal lithography. Small 2(4), 458475 (2006). https://doi.org/10.1002/smll.200500390

25. J.C. Garno, Y. Yang, N.A. Amro, S. Cruchon-Dupeyrat, S. Chen, G.Y. Liu, Precise positioning of nanoparticles on surfaces using scanning probe lithography. Nano Lett. 3(3), 389-395 (2003). https://doi.org/10.1021/n1025934v

26. S.H. Kim, B.Y.H. Liu, M.R. Zachariah, Synthesis of nanoporous metal oxide particles by a new inorganic matrix spray pyrolysis method. Chem. Mater. 14(7), 2889-2899 (2002). https://doi.org/10.1021/cm010957g

27. S. Stopić, B. Friedrich, K. Raić, T. Volkov-Husović, M. Dimitrijević, Characterization of nano-powder morphology obtained by ultrasonic spray pyrolysis. Metalurgija 14(1), 41-54 (2008)

28. J. Dokić, R. Rudolf, S. Tomíc, S. Stopić, B. Friedrich, B. Budič, I. Anžel, M. Čolić, Immunomodulatory properties of nanoparticles obtained by ultrasonic spray pirolysis from gold scrap. J. Biomed. Nanotechnol. 8(3), 528-538 (2012). https ://doi.org/10.1166/jbn.2012.1405

29. V. Pareek, A. Bhargava, R. Gupta, N. Jain, J. Panwar, Synthesis and applications of noble metal nanoparticles: a review. Adv. Sci. Eng. Med. 9(7), 527-544 (2017). https://doi. org/10.1166/asem.2017.2027

30. L. Wang, Y. Sun, Z. Li, A. Wu, G. Wei, Bottom-up synthesis and sensor applications of biomimetic nanostructures. Materials 9(53), 1-28 (2016). https://doi.org/10.3390/ma9010053

31. S. Zankovych, T. Hoffmann, J. Seekamp, J.U. Bruch, C.M. Sotomayor Torres, Nanoimprint lithography: challenges and prospects. Nanotechnology 12(2), 91-95 (2001). https://doi. org/10.1088/0957-4484/12/2/303

32. Q. Ruan, L. Shao, Y. Shu, J. Wang, H. Wu, Growth of monodisperse gold nanospheres with diameters from $20 \mathrm{~nm}$ to $220 \mathrm{~nm}$ and their core/satellite nanostructures. Adv. Opt. Mater. 2(1), 65-73 (2014). https://doi.org/10.1002/adom.201300359

33. B. Nikoobakht, M.A. El-Sayed, Preparation and growth mechanism of gold nanorods (NRs) using seed-mediated growth method. Chem. Mater. 15(10), 1957-1962 (2003). https://doi.org/10.1021/cm0207321

34. P.L. Truong, C. Cao, S. Park, M. Kim, S.J. Sim, A new method for non-labeling attomolar detection of diseases based on an individual gold nanorod immunosensor. Lab Chip 11(15), 2591-2597 (2011). https://doi.org/10.1039/ c1lc20085b

35. Y. Sun, Y. Xia, Shape-controlled synthesis of gold and silver nanoparticles. Science 298(5601), 2176-2179 (2002). https ://doi.org/10.1126/science.1077229

36. T.H. Ha, H.J. Koo, B.H. Chung, Shape-controlled syntheses of gold nanoprisms and nanorods influenced by specific adsorption of halide ions. J. Phys. Chem. C 111(3), 11231130 (2007). https://doi.org/10.1021/jp0664541

37. X. Ma, Y. Cheng, Y. Huang, Y. Tian, S. Wang, Y. Chen, PEGylated gold nanoprisms for photothermal therapy at low laser power density. RSC Adv. 5(99), 81682-81688 (2015). https://doi.org/10.1039/c5ra17385j

38. P. Senthil Kumar, I. Pastoriza-Santos, B. RodríguezGonzález, F. Javier García De Abajo, L.M. Liz-Marzán, High-yield synthesis and optical response of gold nanostars. Nanotechnology 19(1), 1-6 (2008). https://doi. org/10.1088/0957-4484/19/01/015606

39. E.C. Cho, L. Au, Q. Zhang, Y. Xia, The effects of size, shape, and surface functional group of gold nanostructures on their adsorption and internalization by cells. Small 6(4), 517-522 (2010). https://doi.org/10.1002/smll.200901622

40. F. Kim, S. Connor, H. Song, T. Kuykendall, P. Yang, Platonic gold nanocrystals. Angew. Chem. Int. Ed. 116(28), 37593763 (2004). https://doi.org/10.1002/ange.200454216

41. J. Shen, J. Su, J. Yan, B. Zhao, D. Wang et al., Bimetallic nano-mushrooms with DNA-mediated interior nanogaps for high-efficiency SERS signal amplification. Nano Res. 8(3), 731-742 (2015). https://doi.org/10.1007/s12274-014-0556-2

42. C. Fang, G. Zhao, Y. Xiao, J. Zhao, Z. Zhang, B. Geng, Facile growth of high-yield gold nanobipyramids induced by chloroplatinic acid for high refractive index sensing properties. Sci. Rep. 6, 1-8 (2016). https://doi.org/10.1038/srep36706

43. M.S. Vega, A.G. Martínez, F. Cucinotta, Facile strategy for the synthesis of Gold@Silica hybrid nanoparticles with controlled porosity and janus morphology. Nanomaterials 9(3), 348 (2019). https://doi.org/10.3390/nano9030348

44. N. Ji, Y. Chen, P. Gong, K. Cao, D.L. Peng, Investigation on the self-assembly of gold nanoparticles into bidisperse nanoparticle superlattices. Colloids Surf. A Physicochem. Eng. Asp. 480, 11-18 (2015). https://doi.org/10.1016/j.colsu rfa.2015.03.058

45. M. Grzelczak, J. Pérez-Juste, P. Mulvaney, L.M. Liz-Marzán, Shape control in gold nanoparticle synthesis. Chem. Soc. Rev. 37(9), 1783-1791 (2008). https://doi.org/10.1039/b711490g

46. K.D. Gilroy, A. Ruditskiy, H.C. Peng, D. Qin, Y. Xia, Bimetallic nanocrystals: syntheses, properties, and applications. Chem. Rev. 116(18), 10414-10472 (2016). https://doi. org/10.1021/acs.chemrev.6b00211

47. N. Patel, M.C. Davies, M. Hartshorne, R.J. Heaton, C.J. Roberts, S.J.B. Tendler, P.M. Williams, Immobilization of protein molecules onto homogeneous and mixed carboxylateterminated self-assembled monolayers. Langmuir 13(24), 6485-6490 (1997). https://doi.org/10.1021/la970933h

48. D. Bartczak, A.G. Kanaras, Preparation of peptide-functionalized gold nanoparticles using one pot EDC/Sulfo-NHS coupling. Langmuir 27(16), 10119-10123 (2011). https:// doi.org/10.1021/la2022177

49. J.Y. Chang, H. Wu, H. Chen, Y.C. Ling, W. Tan, Oriented assembly of Au nanorods using biorecognition system. Chem. Commun. 8, 1092-1094 (2005). https://doi.org/10.1039/ b414059a

50. S. Pathak, M.C. Davidson, G.A. Silva, Characterization of the functional binding properties of antibody conjugated quantum dots. Nano Lett. 7(7), 1839-1845 (2007). https:// doi.org/10.1021/n1062706i 
51. X. Wang, Z. Mei, Y. Wang, L. Tang, Comparison of four methods for the biofunctionalization of gold nanorods by the introduction of sulfhydryl groups to antibodies. Beilstein J. Nanotechnol. 8(1), 372-380 (2017). https://doi.org/10.3762/bjnano.8.39

52. E.C. Dreaden, A.M. Alkilany, X. Huang, C.J. Murphy, M.A. El-Sayed, The golden age: gold nanoparticles for biomedicine. Chem. Soc. Rev. 41(7), 2740-2779 (2012). https://doi. org/10.1039/c1cs $15237 \mathrm{~h}$

53. Y. Pan, A. Leifert, D. Ruau, S. Neuss, J. Bornemann et al., Gold nanoparticles of diameter $1.4 \mathrm{~nm}$ trigger necrosis by oxidative stress and mitochondrial damage. Small 5(18), 2067-2076 (2009). https://doi.org/10.1002/smll.200900466

54. A.M. Alkilany, P.K. Nagaria, C.R. Hexel, T.J. Shaw, C.J. Murphy, M.D. Wyatt, Cellular uptake and cytotoxicity of gold nanorods: molecular origin of cytotoxicity and surface effects. Small 5(6), 701-708 (2009). https://doi.org/10.1002/ smll.200801546

55. A.M. Alkilany, P.K. Nagaria, M.D. Wyatt, C.J. Murphy, Cation exchange on the surface of gold nanorods with a polymerizable surfactant: polymerization, stability, and toxicity evaluation. Langmuir 26(12), 9328-9333 (2010). https ://doi.org/10.1021/la100253k

56. T. Niidome, M. Yamagata, Y. Okamoto, Y. Akiyama, H. Takahashi et al., PEG-modified gold nanorods with a stealth character for in vivo applications. J. Control. Release 114(3), 343-347 (2006). https://doi.org/10.1016/j.jconr el.2006.06.017

57. M.K. Lai, C.Y. Chang, Y.W. Lien, R.C.C. Tsiang, Application of gold nanoparticles to microencapsulation of thioridazine. J. Control. Release 111(3), 352-361 (2006). https:// doi.org/10.1016/j.jconrel.2005.12.017

58. E.E. Connor, J. Mwamuka, A. Gole, C.J. Murphy, M.D. Wyatt, Gold nanoparticles are taken up by human cells but do not cause acute cytotoxicity. Small 1(3), 325-327 (2005). https://doi.org/10.1002/smll.200400093

59. G. Sonavane, K. Tomoda, K. Makino, Biodistribution of colloidal gold nanoparticles after intravenous administration: effect of particle size. Colloids Surfaces B Biointerfaces 66(2), 274-280 (2008). https://doi.org/10.1016/j.colsu rfb.2008.07.004

60. W.H. De Jong, P.J.A. Borm, Drug delivery and nanoparticles: applications and hazards. Int. J. Nanomed. 3(2), 133-149 (2008). https://doi.org/10.2147/ijn.s596

61. E. Boisselier, D. Astruc, Gold nanoparticles in nanomedicine: preparations, imaging, diagnostics, therapies and toxicity. Chem. Soc. Rev. 38(6), 1759-1782 (2009). https://doi. org/10.1039/b806051g

62. Scientific Committee on Emerging and Newly Identified Health Risks, Modified opinion (after public consultation) on the appropriateness of existing methodologies to assess the potential risks associated with engineered and adventitious products of nanotechnologies. (Health \& Consumer Protection Directorate-General, European Commission, 2006). https ://ec.europa.eu/health/ph_risk/committees/04_scenihr/docs/ scenihr_o_003b.pdf. Accessed 19 August 2020
63. C.M. Goodman, C.D. McCusker, T. Yilmaz, V.M. Rotello, Toxicity of gold nanoparticles functionalized with cationic and anionic side chains. Bioconjug. Chem. 15(4), 897-900 (2004). https://doi.org/10.1021/bc049951i

64. S.J. Soenen, W.J. Parak, J. Rejman, B. Manshian, (Intra)cellular stability of inorganic nanoparticles: effects on cytotoxicity, particle functionality, and biomedical applications. Chem. Rev. 115(5), 2109-2135 (2015). https://doi.org/10.1021/cr400714j

65. D.Y. Cha, G. Parravano, Surface reactivity of supported gold. I. Oxygen transfer between carbon monoxide and carbon dioxide. J. Catal. 18, 200-211 (1970)

66. M. Haruta, T. Kobayashi, H. Sano, N. Yamada, Novel gold catalysts for the oxidation of carbon monoxide at a temperature far below $0^{\circ} \mathrm{C}$. Chem. Lett. 16(2), 405-408 (1987). https://doi.org/10.1246/c1.1987.405

67. D.G. Duff, A. Baiker, Preparation and structural properties of ultrafine gold colloids for oxidation catalysis. Stud. Surf. Sci. Catal. 91, 505-512 (1995). https://doi.org/10.1016/ S0167-2991(06)81788-X

68. Y. Tao, E. Ju, J. Ren, X. Qu, Bifunctionalized mesoporous silica-supported gold nanoparticles: intrinsic oxidase and peroxidase catalytic activities for antibacterial applications. Adv. Mater. 27(6), 1097-1104 (2015). https://doi. org/10.1002/adma.201405105

69. M. Comotti, C. DellaPina, R. Matarrese, M. Rossi, The catalytic activity of "naked" gold particles. Angew. Chem. Int. Ed. 43(43), 5812-5815 (2004). https://doi.org/10.1002/ anie. 200460446

70. W. Luo, C. Zhu, S. Su, D. Li, Y. He, Q. Huang, C. Fan, Self-catalyzed, self-limiting growth of glucose oxidasemimicking gold nanoparticles. ACS Nano 4(12), 74517458 (2010). https://doi.org/10.1021/nn102592h

71. Y. Jv, B. Li, R. Cao, Positively-charged gold nanoparticles as peroxidiase mimic and their application in hydrogen peroxide and glucose detection. Chem. Commun. 46(42), 8017-8019 (2010). https://doi.org/10.1039/c0cc02698k

72. W. He, Y.T. Zhou, W.G. Wamer, X. Hu, X. Wu et al., Intrinsic catalytic activity of Au nanoparticles with respect to hydrogen peroxide decomposition and superoxide scavenging. Biomaterials 34(3), 765-773 (2013). https://doi. org/10.1016/j.biomaterials.2012.10.010

73. C.W. Tseng, H.Y. Chang, J.Y. Chang, C.C. Huang, Detection of mercury ions based on mercury-induced switching of enzyme-like activity of platinum/gold nanoparticles. Nanoscale 4(21), 6823-6830 (2012). https://doi. org/10.1039/c2nr31716h

74. N. Pradhan, A. Pal, T. Pal, Catalytic reduction of aromatic nitro compounds by coinage metal nanoparticles. Langmuir 17(5), 1800-1802 (2001). https://doi.org/10.1021/la000862d

75. B. Hammer, J.K. Norskov, Why gold is the noblest of all the metals. Nature 376, 238-240 (1995)

76. F. Manea, F.B. Houillon, L. Pasquato, P. Scrimin, Nanozymes: gold-nanoparticle-based transphosphorylation catalysts. Angew. Chem. Int. Ed. 43(45), 6165-6169 (2004). https://doi.org/10.1002/anie.200460649 
77. I.M. Klotz, G.P. Royer, I.S. Scarpa, Synthetic derivatives of polyethyleneimine with enzyme-like catalytic activity (synzymes). Proc. Natl. Acad. Sci. U.S.A. 68(2), 263-264 (1971). https://doi.org/10.1073/pnas.68.2.263

78. X. Xie, W. Xu, X. Liu, Improving colorimetric assays through protein enzyme-assisted gold nanoparticle amplification. Acc. Chem. Res. 45(9), 1511-1520 (2012). https://doi. org/10.1021/ar300044j

79. L. Gao, J. Zhuang, L. Nie, J. Zhang, Y. Zhang et al., Intrinsic peroxidase-like activity of ferromagnetic nanoparticles. Nat. Nanotechnol. 2(9), 577-583 (2007). https://doi.org/10.1038/ nnano. 2007.260

80. H. Wei, E. Wang, Nanomaterials with enzyme-like characteristics (nanozymes): next-generation artificial enzymes. Chem. Soc. Rev. 42(14), 6060-6093 (2013). https://doi.org/10.1039/ c3cs35486e

81. X. Li, L. Wang, D. Du, L. Ni, J. Pan, X. Niu, Emerging applications of nanozymes in environmental analysis: opportunities and trends. Trends Anal. Chem. 120, 115653 (2019). https://doi.org/10.1016/j.trac.2019.115653

82. A. Mohamad, H. Teo, N.A. Keasberry, M.U. Ahmed, Recent developments in colorimetric immunoassays using nanozymes and plasmonic nanoparticles. Crit. Rev. Biotechnol. 39(1), 50-66 (2019). https://doi.org/10.1080/07388 551.2018 .1496063

83. D.P. Cormode, L. Gao, H. Koo, Emerging biomedical applications of enzyme-like catalytic nanomaterials. Trends Biotechnol. 36(1), 15-29 (2018). https://doi.org/10.1016/j.tibte ch.2017.09.006

84. M. Liang, X. Yan, Nanozymes: from new concepts, mechanisms, and standards to applications. Acc. Chem. Res. 52(8), 2190-2200 (2019). https://doi.org/10.1021/acs.accou nts. 9 b00140

85. S. Li, X. Liu, H. Chai, Y. Huang, Recent advances in the construction and analytical applications of metal-organic frameworks-based nanozymes. Trends Anal. Chem. 105, 391-403 (2018). https://doi.org/10.1016/j.trac.2018.06.001

86. X. Zhang, G. Li, D. Wu, X. Li, N. Hu et al., Recent progress in the design fabrication of metal-organic frameworks-based nanozymes and their applications to sensing and cancer therapy. Biosens. Bioelectron. 137, 178-198 (2019). https://doi. org/10.1016/j.bios.2019.04.061

87. B. Liu, J. Liu, Sensors and biosensors based on metal oxide nanomaterials. Trends Anal. Chem. 121, 115690 (2019). https://doi.org/10.1016/j.trac.2019.115690

88. M. Sharifi, K. Faryabi, A.J. Talaei, M.S. Shekha, M. AleEbrahim et al., Antioxidant properties of gold nanozyme: a review. J. Mol. Liq. 297, 112004 (2020). https://doi. org/10.1016/j.molliq.2019.112004

89. M. Sharifi, S.H. Hosseinali, P. Yousefvand, A. Salihi, M.S. Shekha et al., Gold nanozyme: biosensing and therapeutic activities. Mater. Sci. Eng., C 108, 110422 (2020). https:// doi.org/10.1016/j.msec.2019.110422

90. X. Cao, C. Li, Y. Lu, B. Zhang, Y. Wu et al., Catalysis of $\mathrm{Au}$ nano-pyramids formed across the surfaces of ordered $\mathrm{Au}$ nano-ring arrays. J. Catal. 377, 389-399 (2019). https://doi. org/10.1016/j.jcat.2019.07.038

91. S. Levin, J. Fritzsche, S. Nilsson, A. Runemark, B. Dhokale et al., A nanofluidic device for parallel single nanoparticle catalysis in solution. Nat. Commun. 10(1), 1-8 (2019). https ://doi.org/10.1038/s41467-019-12458-1

92. P. Wang, A.V. Krasavin, M.E. Nasir, W. Dickson, A.V. Zayats, Reactive tunnel junctions in electrically driven plasmonic nanorod metamaterials. Nat. Nanotechnol. 13(2), 159-164 (2018). https://doi.org/10.1038/s41565-017-0017-7

93. G.C. Bond, D.T. Thompson, Gold-catalysed oxidation of carbon monoxide. Gold Bull. 33(2), 41-50 (2000). https://doi. org/10.1007/BF03216579

94. N. Lopez, T.V.W. Janssens, B.S. Clausen, Y. Xu, M. Mavrikakis, T. Bligaard, J.K. Nørskov, On the origin of the catalytic activity of gold nanoparticles for low-temperature $\mathrm{CO}$ oxidation. J. Catal. 223(1), 232-235 (2004). https://doi. org/10.1016/j.jcat.2004.01.001

95. M.C. Saint-Lager, I. Laoufi, A. Bailly, O. Robach, S. Garaudée, P. Dolle, Catalytic properties of supported gold nanoparticles: new insights into the size-activity relationship gained from in operando measurements. Faraday Discuss. 152, 253-265 (2011). https://doi.org/10.1039/c1fd00028d

96. F. Vigneron, V. Caps, Evolution in the chemical making of gold oxidation catalysts. Comptes Rendus Chim. 19(1-2), 192-198 (2016). https://doi.org/10.1016/j.crci.2015.11.015

97. C. Lin, K. Tao, D. Hua, Z. Ma, S. Zhou, Size effect of gold nanoparticles in catalytic reduction of p-nitrophenol with $\mathrm{NaBH}_{4}$. Molecules 18(10), 12609-12620 (2013). https://doi. org/10.3390/molecules181012609

98. X. Zhou, W. Xu, G. Liu, D. Panda, P. Chen, Size-dependent catalytic activity and dynamics of gold nanoparticles at the single-molecule level. J. Am. Chem. Soc. 132(1), 138-146 (2010). https://doi.org/10.1021/ja904307n

99. Y. He, J.C. Liu, L. Luo, Y.G. Wang, J. Zhu et al., Sizedependent dynamic structures of supported gold nanoparticles in CO oxidation reaction condition. Proc. Natl. Acad. Sci. U.S.A. 115(30), 7700-7705 (2018). https://doi. org/10.1073/pnas.1800262115

100. S. Biswas, P. Tripathi, N. Kumar, S. Nara, Gold nanorods as peroxidase mimetics and its application for colorimetric biosensing of malathion. Sensors Actuat. B Chem. 231, 584-592 (2016). https://doi.org/10.1016/j.snb.2016.03.066

101. T. Ma, W. Yang, S. Liu, H. Zhang, F. Liang, A comparison reduction of 4-nitrophenol by gold nanospheres and gold nanostars. Catalysts 7(38), 1-10 (2017). https://doi. org/10.3390/catal7020038

102. C. McVey, N. Logan, N.T.K. Thanh, C. Elliott, C. Cao, Unusual switchable peroxidase-mimicking nanozyme for the determination of proteolytic biomarker. Nano Res. 12(3), 509-516 (2019). https://doi.org/10.1007/s12274-018-2241-3

103. M. Drozd, M. Pietrzak, P. Parzuchowski, M. MazurkiewiczPawlicka, E. Malinowska, Peroxidase-like activity of gold nanoparticles stabilized by hyperbranched polyglycidol derivatives over a wide $\mathrm{pH}$ range. Nanotechnology 26(49), (2015). https://doi.org/10.1088/0957-4484/26/49/495101 
104. M. Drozd, M. Pietrzak, P.G. Parzuchowski, E. Malinowska, Pitfalls and capabilities of various hydrogen donors in evaluation of peroxidase-like activity of gold nanoparticles. Anal. Bioanal. Chem. 408(29), 8505-8513 (2016). https://doi. org/10.1007/s00216-016-9976-Z

105. C. Zheng, W. Ke, T. Yin, X. An, Intrinsic peroxidase-like activity and the catalytic mechanism of gold @ carbon dots nanocomposites. RSC Adv. 6, 35280-35286 (2016). https:// doi.org/10.1039/C6RA01917J

106. L. Hu, H. Liao, L. Feng, M. Wang, W. Fu, Accelerating the peroxidase-like activity of gold nanoclusters at neutral $\mathrm{pH}$ for colorimetric detection of heparin and heparinase activity. Anal. Chem. 90(10), 6247-6252 (2018). https://doi. org/10.1021/acs.analchem.8b00885

107. N. Lee, S.M. Lee, D.W. Lee, High catalytic activity of gold nanoparticle-templated, tyrosine-rich peptide self-assemblies for 3,3',5,5'-tetramethylbenzidine oxidation in the absence of hydrogen peroxide. React. Kinet. Mech. Catal. 128(1), 349-359 (2019). https://doi.org/10.1007/s11144-019-01619 $-4$

108. J. Li, W. Liu, X. Wu, X. Gao, Mechanism of pH-switchable peroxidase and catalase-like activities of gold, silver, platinum and palladium. Biomaterials 48, 37-44 (2015). https:// doi.org/10.1016/j.biomaterials.2015.01.012

109. M. Comotti, C. Della Pina, E. Falletta, M. Rossi, Aerobic oxidation of glucose with gold catalyst: hydrogen peroxide as intermediate and reagent. Adv. Synth. Catal. 348(3), 313-316 (2006). https://doi.org/10.1002/adsc.200505389

110. P. Landon, P.J. Collier, A.J. Papworth, C.J. Kiely, G.J. Hutchings, Direct formation of hydrogen peroxide from $\mathrm{H}_{2} /$ $\mathrm{O}_{2}$ using a gold catalyst. Chem. Commun. 18, 2058-2059 (2002). https://doi.org/10.1039/b205248m

111. Y. Lu, Y. Mei, M. Drechsler, M. Ballauff, Thermosensitive core-shell particles as carriers for Ag nanoparticles: modulating the catalytic activity by a phase transition in networks. Angew. Chem. Int. Ed. 45(5), 813-816 (2006). https://doi. org/10.1002/anie.200502731

112. Y. Sun, Z. Li, J. Wu, Z. Wang, Y. Dong et al., Gold nanoparticle-protein conjugate dually-responsive to $\mathrm{pH}$ and temperature for modulation of enzyme activity. J. Mater. Chem. B 7(20), 3260-3267 (2019). https://doi.org/10.1039/c9tb0 $0325 \mathrm{~h}$

113. R.G. Nuzzo, B.R. Zegarski, L.H. DuBois, Fundamental studies of the chemisorption of organosulfur compounds on $\mathrm{Au}(111)$. Implications for molecular self-assembly on gold surfaces. J. Am. Chem. Soc. 109(3), 733-740 (1987). https ://doi.org/10.1021/ja00237a017

114. J.C. Love, L.A. Estroff, J.K. Kriebel, R.G. Nuzzo, G.M. Whitesides, Self-assembled monolayers of thiolates on metals as a form of nanotechnology. Chem. Rev. 105(4), 1103-1169 (2005). https://doi.org/10.1021/cr0300789

115. H. Häkkinen, The gold-sulfur interface at the nanoscale. Nat. Chem. 4(6), 443-455 (2012). https://doi.org/10.1038/nchem .1352

116. S. Wang, W. Chen, A. Liu, L. Hong, H. Deng, X. Lin, Comparison of the peroxidase-like activity of unmodified, amino-modified and citrate-capped gold nnaoparticles. ChemPhysChem 13, 1199-1204 (2012). https://doi. org/10.1002/cphc.201100906

117. C.P. Liu, K.C. Chen, C.F. Su, P.Y. Yu, P.W. Lee, Revealing the active site of gold nanoparticles for the peroxidase-like activity: the determination of surface accessibility. Catalysts 9(6), 517 (2019). https://doi.org/10.3390/catal9060517

118. X. Huang, I.H. El-Sayed, W. Qian, M.A. El-Sayed, Cancer cell imaging and photothermal therapy in the near-infrared region by using gold nanorods. J. Am. Chem. Soc. 128(6), 2115-2120 (2006). https://doi.org/10.1021/ja057254a

119. A.M. Alkilany, R.L. Frey, J.L. Ferry, C.J. Murphy, Gold nanorods as nanoadmicelles: 1-naphthol partitioning into a nanorod-bound surfactant bilayer. Langmuir 24(18), 1023510239 (2008). https://doi.org/10.1021/la8018343

120. Y. Cheng, A.C. Samia, J. Li, M.E. Kenney, A. Resnick, C. Burda, Delivery and efficacy of a cancer drug as a function of the bond to the gold nanoparticle surface. Langmuir 26(4), 2248-2255 (2010). https://doi.org/10.1021/la902390d

121. S.D. Brown, P. Nativo, J.A. Smith, D. Stirling, P.R. Edwards et al., Gold nanoparticles for the improved anticancer drug delivery of the active component of oxaliplatin. J. Am. Chem. Soc. 132(13), 4678-4684 (2010). https://doi.org/10.1021/ja908117a

122. S. Guo, Ḱ.Y. Huang, Ḱ.Q. Jiang, Y. Sun, L. Deng et al., Enhanced gene delivery and sirna silencing by gold nanoparticles coated with charge-reversal polyelectrolyte. ACS Nano 4(9), 5505-5511 (2010). https://doi.org/10.1021/nn101 $638 \mathrm{u}$

123. J. You, G. Zhang, C. Li, Exceptionally high payload of doxorubicin in hollow gold nanospheres for near-infrared lighttriggered drug release. ACS Nano 4(2), 1033-1041 (2010). https://doi.org/10.1021/nn901181c

124. E.C. Dreaden, A.M. Alkilany, X. Huang, C.J. Murphy, M.A. El-Sayed, The golden age: gold nanoparticles for biomedicine. Chem. Soc. Rev. 176(10), 139-148 (2017). https://doi. org/10.1016/j.physbeh.2017.03.040

125. Y. Yang, E. Noviana, M.P. Nguyen, B.J. Geiss, D.S. Dandy, C.S. Henry, Paper-based microfluidic devices: emerging themes and applications. Anal. Chem. 89(1), 71-91 (2017). https://doi.org/10.1021/acs.analchem.6b04581

126. Y. Liu, D. Ding, Y. Zhen, R. Guo, Amino acid-mediated 'turn-off/turn-on' nanozyme activity of gold nanoclusters for sensitive and selective detection of copper ions and histidine. Biosens. Bioelectron. 92, 140-146 (2017). https://doi. org/10.1016/j.bios.2017.01.036

127. Y. Wu, Y. Chen, Y. Li, J. Huang, H. Yu, Z. Wang, Accelerating peroxidase-like activity of gold nanozymes using purine derivatives and its application for monitoring of occult blood in urine. Sensors Actuat. B Chem. 270, 443-451 (2018). https ://doi.org/10.1016/j.snb.2018.05.057

128. Y. Sun, J. Wang, W. Li, J. Zhang, Y. Zhang, Y. Fu, DNA-stabilized bimetallic nanozyme and its application on colorimetric assay of biothiols. Biosens. Bioelectron. 74, 1038-1046 (2015). https://doi.org/10.1016/j.bios.2015.08.001

129. L. Long, J. Liu, K. Lu, T. Zhang, Y. Xie, Y. Ji, X. Wu, Highly sensitive and robust peroxidase-like activity of Au-Pt core/ 
shell nanorod-antigen conjugates for measles virus diagnosis. J. Nanobiotechn. 16(1), 1-10 (2018). https://doi.org/10.1186/ s12951-018-0371-0

130. S. Oh, J. Kim, V.T. Tran, D.K. Lee, S.R. Ahmed et al., Magnetic nanozyme-linked immunosorbent assay for ultrasensitive influenza a virus detection. ACS Appl. Mater. Interfaces. 10(15), 12534-12543 (2018). https://doi.org/10.1021/acsam i. $8 \mathrm{~b} 02735$

131. S.R. Ahmed, J. Kim, T. Suzuki, J. Lee, E.Y. Park, Enhanced catalytic activity of gold nanoparticle-carbon nanotube hybrids for influenza virus detection. Biosens. Bioelectron. 85, 503-508 (2016). https://doi.org/10.1016/j. bios.2016.05.050

132. S. Cho, H.Y. Shin, M. Il Kim, Nanohybrids consisting of magnetic nanoparticles and gold nanoclusters as effective peroxidase mimics and their application for colorimetric detection of glucose. Biointerphases 12(1), 01A401 (2017). https://doi.org/10.1116/1.4974198

133. K. Boriachek, M.K. Masud, C. Palma, H.-P. Phan, Y. Yamauchi et al., Avoiding pre-isolation step in exosome analysis: direct isolation and sensitive detection of exosomes using gold-loaded nanoporous ferric oxide nanozymes. Anal. Chem. 91(6), 3827-3834 (2019). https://doi.org/10.1021/acs. analchem.8b03619

134. M. Liu, H. Zhao, S. Chen, H. Yu, X. Quan, Interface engineering catalytic graphene for smart colorimetric biosensing. ACS Nano 6(4), 3142-3151 (2012). https://doi.org/10.1021/ nn3010922

135. Z. Sun, Q. Zhao, G. Zhang, Y. Li, G. Zhang, F. Zhang, X. Fan, Exfoliated $\mathrm{MoS}_{2}$ supported $\mathrm{Au}-\mathrm{Pd}$ bimetallic nanoparticles with core-shell structures and superior peroxidase-like activities. RSC Adv. 5(14), 10352-10357 (2015). https://doi. org/10.1039/c4ra13575j

136. K.N. Han, J.S. Choi, J. Kwon, Gold nanozyme-based paper chip for colorimetric detection of mercury ions. Sci. Rep. 7(1), 1-7 (2017). https://doi.org/10.1038/s41598-017-02948-x

137. S. Laing, A. Hernandez-Santana, J. Sassmannshausen, D.L. Asquith, I.B. McInnes, K. Faulds, D. Graham, Quantitative detection of human tumor necrosis factor $\alpha$ by a resonance raman enzyme-linked immunosorbent assay. Anal. Chem. 83(1), 297-302 (2011). https://doi. org/10.1021/ac1024039

138. D. Sun, Z. Luo, J. Lu, S. Zhang, T. Che, Z. Chen, L. Zhang, Electrochemical dual-aptamer-based biosensor for nonenzymatic detection of cardiac troponin I by nanohybrid electrocatalysts labeling combined with DNA nanotetrahedron structure. Biosens. Bioelectron. 134, 49-56 (2019). https:// doi.org/10.1016/j.bios.2019.03.049

139. P.-C. Kuo, C.-W. Lien, J.-Y. Mao, B. Unnikrishnan, H.-T. Chang, H.-J. Lin, C.-C. Huang, Detection of urinary spermine by using silver-gold/silver chloride nanozymes. Anal. Chim. Acta 1009, 89-97 (2018). https://doi.org/10.1016/j. aca.2018.01.018

140. X. Lin, Y. Liu, Z. Tao, J. Gao, J. Deng, J. Yin, S. Wang, Nanozyme-based bio-barcode assay for high sensitive and logic-controlled specific detection of multiple DNAs.
Biosens. Bioelectron. 94, 471-477 (2017). https://doi. org/10.1016/j.bios.2017.01.008

141. Y. Tao, Y. Lin, J. Ren, X. Qu, A dual fluorometric and colorimetric sensor for dopamine based on BSA-stabilized Au nanoclusters. Biosens. Bioelectron. 42(1), 41-46 (2013). https://doi.org/10.1016/j.bios.2012.10.014

142. A.M. Alkilany, C.J. Murphy, Toxicity and cellular uptake of gold nanoparticles: what we have learned so far? J. Nanoparticle Res. 12(7), 2313-2333 (2010). https://doi.org/10.1007/ s11051-010-9911-8

143. L. Fan, X. Xu, C. Zhu, J. Han, L. Gao, J. Xi, R. Guo, Tumor catalytic-photothermal therapy with yolk-shell gold@ carbon nanozymes. ACS Appl. Mater. Interfaces. 10(5), 4502-4511 (2018). https://doi.org/10.1021/acsami.7b17916

144. D. Zhang, Y.X. Zhao, Y.J. Gao, F.P. Gao, Y.S. Fan et al., Antibacterial and in vivo tumor treatment by reactive oxygen species generated by magnetic nanoparticles. J. Mater. Chem. B 1(38), 5100-5107 (2013). https://doi.org/10.1039/c3tb20907e

145. L. Gao, K.M. Giglio, J.L. Nelson, H. Sondermann, A.J. Travis, Ferromagnetic nanoparticles with peroxidase-like activity enhance the cleavage of biological macromolecules for biofilm elimination. Nanoscale 6(5), 2588-2593 (2014). https://doi.org/10.1039/c3nr05422e

146. Y. Liu, M. Yuan, L. Qiao, R. Guo, An efficient colorimetric biosensor for glucose based on peroxidase-like protein$\mathrm{Fe}_{3} \mathrm{O}_{4}$ and glucose oxidase nanocomposites. Biosens. Bioelectron. 52, 391-396 (2014). https://doi.org/10.1016/j. bios.2013.09.020

147. S. Maman, I.P. Witz, A history of exploring cancer in context. Nat. Rev. Cancer 18(6), 359-376 (2018). https://doi. org/10.1038/s41568-018-0006-7

148. J.M. Brown, W.R. Wilson, Exploiting tumour hypoxia in cancer treatment. Nat. Rev. Cancer 4(6), 437-447 (2004). https ://doi.org/10.1038/nrc1367

149. Q. Chen, C. Liang, X. Sun, J. Chen, Z. Yang et al., $\mathrm{H}_{2} \mathrm{O}_{2}$-responsive liposomal nanoprobe for photoacoustic inflammation imaging and tumor theranostics via in vivo chromogenic assay. Proc. Natl. Acad. Sci. U.S.A. 114(21), 5343-5348 (2017). https://doi.org/10.1073/pnas.1701976114

150. M. López-Lázaro, Dual role of hydrogen peroxide in cancer: possible relevance to cancer chemoprevention and therapy. Cancer Lett. 252(1), 1-8 (2007). https://doi.org/10.1016/j. canlet.2006.10.029

151. Y. Zhang, F. Wang, C. Liu, Z. Wang, L. Kang et al., Nanozyme decorated metal-organic frameworks for enhanced photodynamic therapy. ACS Nano 12(1), 651-661 (2018). https://doi.org/10.1021/acsnano.7b07746

152. A. Zhang, S. Pan, Y. Zhang, J. Chang, J. Cheng et al., Carbongold hybrid nanoprobes for real-time imaging, photothermal/ photodynamic and nanozyme oxidative therapy. Theranostics 9(12), 3443-3458 (2019). https://doi.org/10.7150/thno.33266

153. Y.-C. Ma, Y.-H. Zhu, X.-F. Tang, L.-F. Hang, W. Jiang et al., $\mathrm{Au}$ nanoparticles with enzyme-mimicking activity-ornamented ZIF-8 for highly efficient photodynamic therapy. Biomater. Sci. 7(7), 2740-2748 (2019). https://doi.org/10.1039/ c9bm00333a 
154. L. Li, Z. Yang, W. Fan, L. He, C. Cui et al., In situ polymerized hollow mesoporous organosilica biocatalysis nanoreactor for enhancing ROS-mediated anticancer therapy. Adv. Funct. Mater. 1907716, 1-11 (2019). https://doi.org/10.1002/ adfm.201907716

155. S.K. Maji, S. Yu, K. Chung, M. Sekkarapatti Ramasamy, J.W. Lim et al., Synergistic nanozymetic activity of hybrid gold bipyramid-molybdenum disulfide core@shell nanostructures for two-photon imaging and anticancer therapy. ACS Appl. Mater. Interfaces. 10(49), 42068-42076 (2018). https://doi.org/10.1021/acsami.8b15443

156. C. Liu, L. Luo, L. Zeng, J. Xing, Y. Xia et al., Porous gold nanoshells on functional $\mathrm{NH}_{2}$-MOFs: facile synthesis and designable platforms for cancer multiple therapy. Small 14(35), 1801851 (2018). https://doi.org/10.1002/ smll.201801851

157. S. Gao, H. Lin, H. Zhang, H. Yao, Y. Chen, J. Shi, Nanocatalytic tumor therapy by biomimetic dual inorganic nanozymecatalyzed cascade reaction. Adv. Sci. 6(3), 1801733 (2019). https://doi.org/10.1002/advs.201801733

158. Z. Wang, K. Dong, Z. Liu, Y. Zhang, Z. Chen, 1801733 Activation of biologically relevant levels of reactive oxygen species by $\mathrm{Au} / \mathrm{g}-\mathrm{C}_{3} \mathrm{~N}_{4}$ hybrid nanozyme for bacteria killing and wound disinfection. Biomaterials 113, 145-157 (2017). https://doi.org/10.1016/j.biomaterials.2016.10.041

159. H. Koo, R.N. Allan, R.P. Howlin, P. Stoodley, L. HallStoodley, Targeting microbial biofilms: current and prospective therapeutic strategies. Nat. Rev. Microbiol. 15(12), 740-755 (2017). https://doi.org/10.1038/nrmicro.2017.99

160. Q. Zhang, S. Chen, H. Wang, H. Yu, Exquisite enzymefenton biomimetic catalysts for hydroxyl radical production by mimicking an enzyme cascade. ACS Appl. Mater. Interfaces. 10(10), 8666-8675 (2018). https://doi.org/10.1021/ acsami.7b18690

161. M. Hui Zhang, H. Dong, L. Zhao, D. Xi Wang, D. Meng, A review on Fenton process for organic wastewater treatment based on optimization perspective. Sci. Total Environ. 670, 110-121 (2019). https://doi.org/10.1016/j.scitotenv.2019.03.180

162. S. Kunjiappan, C. Bhattacharjee, R. Chowdhury, In vitro antioxidant and hepatoprotective potential of Azolla microphylla phytochemically synthesized gold nanoparticles on acetaminophen-induced hepatocyte damage in Cyprinus carpio L. Vitr. Cell. Dev. Biol. Anim. 51(6), 630-643 (2015). https://doi.org/10.1007/s11626-014-9841-3

163. F. Wang, E. Ju, Y. Guan, J. Ren, X. Qu, Light-mediated reversible modulation of ROS level in living cells by using an activity-controllable nanozyme. Small 13(25), 1603051 (2017). https://doi.org/10.1002/smll.201603051

164. C.-P. Liu, T.-H. Wu, Y.-L. Lin, C.-Y. Liu, S. Wang, S.-Y. Lin, Tailoring enzyme-like activities of gold nanoclusters by polymeric tertiary amines for protecting neurons against oxidative stress. Small 12(30), 4127-4135 (2016). https:// doi.org/10.1002/smll.201503919

165. F. Dashtestani, H. Ghourchian, A. Najafi, Silver-gold-apoferritin nanozyme for suppressing oxidative stress during cryopreservation. Mater. Sci. Eng., C 94, 831-840 (2019). https://doi.org/10.1016/j.msec.2018.10.008

166. J.T. Hancock, R. Desikan, S.J. Neill, Role of reactive oxygen species in cell signalling pathways. Biochem. Soc. Trans. 29(2), 345-350 (2001). https://doi. org/10.1042/0300-5127:0290345

167. S. Boukhenouna, M.A. Wilson, K. Bahmed, B. Kosmider, Reactive oxygen species in chronic obstructive pulmonary disease. Oxid. Med. Cell. Longev. (2018). https://doi. org/10.1155/2018/5730395

168. D.S. Manickam, A.M. Brynskikh, J.L. Kopanic, P.L. Sorgen, N.L. Klyachko et al., Well-defined cross-linked antioxidant nanozymes for treatment of ischemic brain injury. J. Control. Release 162(3), 636-645 (2012). https://doi.org/10.1016/j. jconrel.2012.07.044

169. M. Valko, D. Leibfritz, J. Moncol, M.T.D. Cronin, M. Mazur, J. Telser, Free radicals and antioxidants in normal physiological functions and human disease. Int. J. Biochem. Cell Biol. 39(1), 44-84 (2007). https://doi.org/10.1016/j.bioce 1.2006.07.001

170. Z. Chen, J.J. Yin, Y.T. Zhou, Y. Zhang, L. Song et al., Dual enzyme-like activities of iron oxide nanoparticles and their implication for diminishing cytotoxicity. ACS Nano 6(5), 4001-4012 (2012). https://doi.org/10.1021/nn300291r

171. X. Wang, Y. Zhang, T. Li, W. Tian, Q. Zhang, Y. Cheng, Generation 9 polyamidoamine dendrimer encapsulated platinum nanoparticle mimics catalase size, shape, and catalytic activity. Langmuir 29(17), 5262-5270 (2013). https://doi. org/10.1021/la3046077

172. J.L.D. Nelis, A.S. Tsagkaris, Y. Zhao, J. Lou-Franco, P. Nolan et al., The end user sensor tree: an end-user friendly sensor database. Biosens. Bioelectron. 130, 245-253 (2019). https ://doi.org/10.1016/j.bios.2019.01.055

173. J. Hou, M. Vázquez-González, M. Fadeev, X. Liu, R. Lavi, I. Willner, Catalyzed and electrocatalyzed oxidation of L-tyrosine and L-phenylalanine to dopachrome by nanozymes. Nano Lett. 18(6), 4015-4022 (2018). https://doi.org/10.1021/acs. nanolett.8b01522

174. M. Diez-Castellnou, F. Mancin, P. Scrimin, Efficient phosphodiester cleaving nanozymes resulting from multivalency and local medium polarity control. J. Am. Chem. Soc. 136(4), 1158-1161 (2014). https://doi.org/10.1021/ja411969e

175. Y. Zhou, H. Sun, H. Xu, S. Matysiak, J. Ren, X. Qu, Mesoporous encapsulated chiral nanogold for use in enantioselective reactions. Angew. Chem. Int. Ed. 57(51), 1679116795 (2018). https://doi.org/10.1002/anie.201811118

176. Y.-W. Wang, Q. Liu, L. Wang, S. Tang, H.-H. Yang, H. Song, A colorimetric mercury(II) assay based on the $\mathrm{Hg}$ (II)-stimulated peroxidase mimicking activity of a nanocomposite prepared from graphitic carbon nitride and gold nanoparticles. Microchim. Acta 186(1), 7 (2019). https://doi.org/10.1007/s0060 4-018-3137-3

177. S. Zhang, H. Li, Z. Wang, J. Liu, H. Zhang, B. Wang, Z. Yang, A strongly coupled $\mathrm{Au} / \mathrm{Fe}_{3} \mathrm{O}_{4} / \mathrm{GO}$ hybrid material with 
enhanced nanozyme activity for highly sensitive colorimetric detection, and rapid and efficient removal of $\mathrm{Hg}^{2+}$ in aqueous solutions. Nanoscale 7(18), 8495-8502 (2015). https://doi. org/10.1039/c5nr00527b

178. C.-F. Peng, Y.-Y. Zhang, L.-Y. Wang, Z.-Y. Jin, G. Shao, Colorimetric assay for the simultaneous detection of $\mathrm{Hg}^{2+}$ and $\mathrm{Ag}^{+}$based on inhibiting the peroxidase-like activity of coreshell Au@ Pt nanoparticles. Anal. Methods 9(30), 4363-4370 (2017). https://doi.org/10.1039/c7ay01317e

179. C.-L. Hsu, C.-W. Lien, S.G. Harroun, R. Ravindranath, H.-T. Chang, J.-Y. Mao, C.-C. Huang, Metal-deposited bismuth oxyiodide nanonetworks with tunable enzyme-like activity: sensing of mercury and lead ions. Mater. Chem. Front. 1(5), 893-899 (2017). https://doi.org/10.1039/c6qm00149a

180. Y.J. Long, Y.F. Li, Y. Liu, J.J. Zheng, J. Tang, C.Z. Huang, Visual observation of the mercury-stimulated peroxidase mimetic activity of gold nanoparticles. Chem. Commun. 47(43), 11939-11941 (2011). https://doi.org/10.1039/c1cc1 $4294 \mathrm{a}$

181. C. Cao, J. Zhang, S. Li, Q. Xiong, Intelligent and ultrasensitive analysis of mercury trace contaminants via plasmonic metamaterial-based surface-enhanced raman spectroscopy. Small 10(16), 3252-3256 (2014). https://doi.org/10.1002/ smll.201400165

182. L. Zhang, Y. Yuan, X. Wen, Y. Li, C. Cao, Q. Xiong, A coordination and ligand replacement based three-input colorimetric logic gate sensing platform for melamine, mercury ions, and cysteine. RSC Adv. 5(73), 59106-59113 (2015). https:// doi.org/10.1039/c5ra09570k

183. N. Logan, C. McVey, C. Elliott, C. Cao, Amalgamated goldnanoalloys with enhanced catalytic activity for the detection of mercury ions $\left(\mathrm{Hg}^{2+}\right)$ in seawater samples. Nano Res. 13(4), 989-998 (2020). https://doi.org/10.1007/s12274-020-2731-y

184. P. Weerathunge, R. Ramanathan, R. Shukla, T.K. Sharma, V. Bansal, Aptamer-controlled reversible inhibition of gold nanozyme activity for pesticide sensing. Anal. Chem. 86(24), 11937-11941 (2014). https://doi.org/10.1021/ac5028726

185. S. Singh, P. Tripathi, N. Kumar, S. Nara, Colorimetric sensing of malathion using palladium-gold bimetallic nanozyme. Biosens. Bioelectron. 92, 280-286 (2017). https://doi. org/10.1016/j.bios.2016.11.011

186. P. Weerathunge, R. Ramanathan, V.A. Torok, K. Hodgson, Y. $\mathrm{Xu}$ et al., Ultrasensitive colorimetric detection of murine norovirus using nanozyme aptasensor. Anal. Chem. 91(5), 32703276 (2019). https://doi.org/10.1021/acs.analchem.8b03300

187. R. Das, A. Dhiman, A. Kapil, V. Bansal, T.K. Sharma, Aptamer-mediated colorimetric and electrochemical detection of Pseudomonas aeruginosa utilizing peroxidase-mimic activity of gold NanoZyme. Anal. Bioanal. Chem. 411(6), 1229-1238 (2019). https://doi.org/10.1007/s00216-018-1555-Z

188. C. McVey, F. Huang, C. Elliott, C. Cao, Endonuclease controlled aggregation of gold nanoparticles for the ultrasensitive detection of pathogenic bacterial DNA. Biosens. Bioelectron. 92, 502-508 (2017). https://doi.org/10.1016/j. bios.2016.10.072
189. C. Cao, L.C. Gontard, L.L. ThuyTram, A. Wolff, D.D. Bang, Dual enlargement of gold nanoparticles: from mechanism to scanometric detection of pathogenic bacteria. Small 7(12), 1701-1708 (2011). https://doi.org/10.1002/smll.201100294

190. Z. Zhang, L.M. Bragg, M.R. Servos, J. Liu, Gold nanoparticles as dehydrogenase mimicking nanozymes for estradiol degradation. Chinese Chem. Lett. 30(9), 1655-1658 (2019). https://doi.org/10.1016/j.cclet.2019.05.062

191. Y. Liu, Y.Y. Zhang, Q.W. Kou, D.D. Wang, D.L. Han et al., $\mathrm{Fe}_{3} \mathrm{O}_{4} / \mathrm{Au}$ binary nanocrystals: facile synthesis with diverse structure evolution and highly efficient catalytic reduction with cyclability characteristics in 4-nitrophenol. Powder Technol. 338, 26-35 (2018). https://doi.org/10.1016/j.powte c.2018.06.037

192. B.H. Robinson, E-waste: an assessment of global production and environmental impacts. Sci. Total Environ. 408(2), 183 191 (2009). https://doi.org/10.1016/j.scitotenv.2009.09.044

193. G. Zhao, Y. Xu, G. Han, B. Ling, Biotransfer of persistent organic pollutants from a large site in China used for the disassembly of electronic and electrical waste. Environ. Geochem. Health 28(4), 341-351 (2006). https://doi.org/10.1007/ s10653-005-9003-3

194. H.-H. Deng, B.-Y. Luo, S.-B. He, R.-T. Chen, Z. Lin et al., Redox recycling-triggered peroxidase-like activity enhancement of bare gold nanoparticles for ultrasensitive colorimetric detection of rare-earth $\mathrm{Ce}^{3+}$ Ion. Anal. Chem. 91(6), 40394046 (2019). https://doi.org/10.1021/acs.analchem.8b05552

195. Y. Liu, Y. Xiang, D. Ding, R. Guo, Structural effects of amphiphilic protein/gold nanoparticle hybrid based nanozyme on peroxidase-like activity and silver-mediated inhibition. RSC Adv. 6(113), 112435-112444 (2016). https ://doi.org/10.1039/C6RA23773H

196. Z. Wu, X. Yuan, H. Zhong, H. Wang, G. Zeng et al., Enhanced adsorptive removal of p-nitrophenol from water by aluminum metal-organic framework/reduced graphene oxide composite. Sci. Rep. 6, 1-13 (2016). https://doi.org/10.1038/ srep 25638

197. X. Kong, H. Zhu, C. Le Chen, G. Huang, Q. Chen, Insights into the reduction of 4-nitrophenol to 4-aminophenol on catalysts. Chem. Phys. Lett. 684, 148-152 (2017). https://doi. org/10.1016/j.cplett.2017.06.049

198. R.N. Tanna, G.R. Tetreault, C.J. Bennett, B.M. Smith, L.M. Bragg et al., Occurrence and degree of intersex (testis-ova) in darters (Etheostoma SPP.) across an urban gradient in the Grand River, Ontario, Canada. Environ. Toxicol. Chem. 32(9), 1981-1991 (2013). https://doi.org/10.1002/etc.2262

199. M. Giulivo, M. Lopez de Alda, E. Capri, D. Barceló, Human exposure to endocrine disrupting compounds: their role in reproductive systems, metabolic syndrome and breast cancer. A review. Environ. Res. 151, 251-264 (2016). https://doi. org/10.1016/j.envres.2016.07.011

200. Anonymous, Food safety. (World Health Organization, 2020). https://www.who.int/news-room/fact-sheets/detail/food-safet y. Accessed 19 August 2020 
201. T. Jiang, Y. Song, T. Wei, H. Li, D. Du, M.-J. Zhu, Y. Lin, Sensitive detection of Escherichia coli O157:H7 using PtAu bimetal nanoparticles with peroxidase-like amplification. Biosens. Bioelectron. 77, 687-694 (2016). https://doi. org/10.1016/j.bios.2015.10.017

202. T. Kumar Sharma, R. Ramanathan, P. Weerathunge, M. Mohammadtaheri, H. KumarDaima, R. Shukla, V. Bansal, Aptamer-mediated "turn-off/turn-on" nanozyme activity of gold nanoparticles for kanamycin detection. Chem. Commun. 50(100), 15856-15859 (2014). https://doi.org/10.1039/c4cc0 $7275 \mathrm{~h}$

203. C. Wang, C. Liu, J. Luo, Y. Tian, N. Zhou, Direct electrochemical detection of kanamycin based on peroxidase-like activity of gold nanoparticles. Anal. Chim. Acta 936, 75-82 (2016). https://doi.org/10.1016/j.aca.2016.07.013

204. X. Pei, A. Tandon, A. Alldrick, L. Giorgi, W. Huang, R. Yang, The China melamine milk scandal and its implications for food safety regulation. Food Policy 36(3), 412-420 (2011). https://doi.org/10.1016/j.foodpol.2011.03.008

205. H. Xin, R. Stone, Tainted milk scandal: Chinese probe unmasks high-tech adulteration with melamine. Science 322(5906), 1310-1311 (2008). https://doi.org/10.1126/scien ce.322.5906.1310

206. C. Xiu, K.K. Klein, Melamine in milk products in China: examining the factors that led to deliberate use of the contaminant. Food Policy 35(5), 463-470 (2010). https://doi. org/10.1016/j.foodpol.2010.05.001

207. H.H. Deng, G.W. Li, L. Hong, A.L. Liu, W. Chen, X.H. Lin, X.H. Xia, Colorimetric sensor based on dual-functional gold nanoparticles: analyte-recognition and peroxidaselike activity. Food Chem. 147, 257-261 (2014). https://doi. org/10.1016/j.foodchem.2013.09.151

208. J. Li, G. Zhang, L. Wang, A. Shen, J. Hu, Simultaneous enzymatic and SERS properties of bifunctional chitosan-modified popcorn-like $\mathrm{Au}-\mathrm{Ag}$ nanoparticles for high sensitive detection of melamine in milk powder. Talanta 140, 204-211 (2015). https://doi.org/10.1016/j.talanta.2015.03.050

209. N.R. Jana, T. Pal, Anisotropic metal nanoparticles for use as surface-enhanced Raman substrates. Adv. Mater. 19(13), 1761-1765 (2007). https://doi.org/10.1002/adma.200601749

210. E. Nalbant Esenturk, A.R. Hight Walker, Surface-enhanced Raman scattering spectroscopy via gold nanostars. J. Raman Spectrosc. 40(1), 86-91 (2009). https://doi.org/10.1002/jrs.2084

211. M. Varvara, G. Bozzo, G. Celano, C. Disanto, C.N. Pagliarone, G.V. Celano, The use of ascorbic acid as a food additive: technical-legal issues. Ital. J. Food Saf. 5(1), 7-10 (2016). https://doi.org/10.4081/ijfs.2016.4313

212. S. Xu, X. Dong, S. Chen, Y. Zhao, G. Shan et al., The preparation of high-index facet $\mathrm{Au} / \mathrm{Cu}$ NRs and their application for colorimetric determination ascorbic acid. Sensors Actuat. B Chem. 281, 375-382 (2019). https://doi.org/10.1016/j. snb.2018.10.114

213. Y. Xu, J. Fei, G. Li, T. Yuan, X. Xu, J. Li, Nanozyme-catalyzed cascade reactions for mitochondria-mimicking oxidative phosphorylation. Angew. Chem. Int. Ed. 58(17), 55725576 (2019). https://doi.org/10.1002/anie.201813771
214. L. Gao, M. Liu, G. Ma, Y. Wang, L. Zhao et al., Peptideconjugated gold nanoprobe: intrinsic nanozyme-linked immunsorbant assay of integrin expression level on cell membrane. ACS Nano 9(11), 10979-10990 (2015). https:// doi.org/10.1021/acsnano.5b04261

215. R. Cao-Milán, L.D. He, S. Shorkey, G.Y. Tonga, L.-S. Wang et al., Modulating the catalytic activity of enzyme-like nanoparticles through their surface functionalization. Mol. Syst. Des. Eng. 2(5), 624-628 (2017). https://doi.org/10.1039/ c7me00055c

216. F. della Sala, J.L.-Y. Chen, S. Ranallo, D. Badocco, P. Pastore, F. Ricci, L.J. Prins, Reversible electrochemical modulation of a catalytic nanosystem. Angew. Chem. Int. Ed. 55(36), 10737-10740 (2016). https://doi.org/10.1002/anie.20160 5309

217. S. Lee, E. Tak, J. Lee, M. Rashid, M.P. Murphy, J. Ha, S.S. Kim, Mitochondrial $\mathrm{H}_{2} \mathrm{O}_{2}$ generated from electron transport chain complex I stimulates muscle differentiation. Cell Res. 21(5), 817-834 (2011). https://doi.org/10.1038/cr.2011.55

218. Y. Sun, R. Wang, X. Liu, G. Shan, Y. Chen, T. Tong, Y. Liu, Laser-induced formation of $\mathrm{Au} / \mathrm{Pt}$ nanorods with peroxidase mimicking and SERS enhancement properties for application to the colorimetric determination of $\mathrm{H}_{2} \mathrm{O}_{2}$. Microchim. Acta 185(9), 445 (2018). https://doi.org/10.1007/s00604-018-2981-5

219. J. Wu, K. Qin, D. Yuan, J. Tan, L. Qin, X. Zhang, H. Wei, Rational design of Au@Pt multibranched nanostructures as bifunctional nanozymes. ACS Appl. Mater. Interfaces. 10(15), 12954-12959 (2018). https://doi.org/10.1021/acsam i. 7 b17945

220. K. Zhang, Y. Liu, Y. Wang, J. Zhao, B. Liu, Direct SERS tracking of a chemical reaction at a single $13 \mathrm{~nm}$ gold nanoparticle. Chem. Sci. 10(6), 1741-1745 (2019). https://doi. org/10.1039/c8sc04496a

221. Q. Cui, B. Xia, S. Mitzscherling, A. Masic, L. Li, M. Bargheer, H. Möhwald, Preparation of gold nanostars and their study in selective catalytic reactions. Colloids Surfaces A Physicochem. Eng. Asp. 465, 20-25 (2015). https://doi. org/10.1016/j.colsurfa.2014.10.028

222. D. Lou, Y. Tian, Y. Zhang, J. Yin, T. Yang et al., Peroxidaselike activity of gold nanoparticles and their gold staining enhanced ELISA application. J. Nanosci. Nanotechnol. 18(2), 951-958 (2018). https://doi.org/10.1166/jnn.2018.13977

223. J.A.J. Fitzpatrick, S.K. Andreko, L.A. Ernst, A.S. Waggoner, B. Ballou, M.P. Bruchez, Long-term persistence and spectral blue shifting of quantum dots in vivo. Nano Lett. 9(7), 2736-2741 (2009). https://doi.org/10.1021/n1901534q

224. M. Longmire, P.L. Choyke, H. Kobayashi, Clearance properties of nano-sized particles and molecules as imaging agents: consideration and caveats. Nanomedicine 3(5), 703-717 (2012). https://doi.org/10.2217/17435889.3.5.703.Clearance

225. T. Zhang, F. Tian, L. Long, J. Liu, X. Wu, Diagnosis of rubella virus using antigen-conjugated Au@Pt nanorods as nanozyme probe. Int. J. Nanomedicine 13, 4795-4805 (2018). https://doi.org/10.2147/IJN.S171429

226. O. Adegoke, C. McKenzie, N.N. Daeid, Multi-shaped cationic gold nanoparticle-L-cysteine-ZnSeS quantum dots 
hybrid nanozyme as an intrinsic peroxidase mimic for the rapid colorimetric detection of cocaine. Sensors Actuat. B Chem. 287, 416-427 (2019). https://doi.org/10.1016/j. snb.2019.02.074

227. Y. Hu, H. Cheng, X. Zhao, J. Wu, F. Muhammad et al., Surface-enhanced raman scattering active gold nanoparticles with enzyme-mimicking activities for measuring glucose and lactate in living tissues. ACS Nano 11(6), 5558-5566 (2017). https://doi.org/10.1021/acsnano.7b00905

228. X.X. Wang, Q. Wu, Z. Shan, Q.M. Huang, BSA-stabilized Au clusters as peroxidase mimetics for use in xanthine detection. Biosens. Bioelectron. 26(8), 3614-3619 (2011). https://doi. org/10.1016/j.bios.2011.02.014

229. L. Cao, P. Wang, L. Chen, Y. Wu, J. Di, A photoelectrochemical glucose sensor based on gold nanoparticles as a mimic enzyme of glucose oxidase. RSC Adv. 9(27), 15307-15313 (2019). https://doi.org/10.1039/c9ra02088h

230. G. Darabdhara, J. Bordoloi, P. Manna, M.R. Das, Biocompatible bimetallic Au-Ni doped graphitic carbon nitride sheets: a novel peroxidase-mimicking artificial enzyme for rapid and highly sensitive colorimetric detection of glucose. Sensors Actuat. B Chem. 285, 277-290 (2019). https://doi. org/10.1016/j.snb.2019.01.048

231. L. Liu, J. Du, W.-E. Liu, Y. Guo, G. Wu, W. Qi, X. Lu, Enhanced His@AuNCs oxidase-like activity by reduced graphene oxide and its application for colorimetric and electrochemical detection of nitrite. Anal. Bioanal. Chem. 411(10), 2189-2200 (2019). https://doi.org/10.1007/s0021 6-019-01655-y

232. X. Zhu, X. Mao, Z. Wang, C. Feng, G. Chen, G. Li, Fabrication of nanozyme@DNA hydrogel and its application in biomedical analysis. Nano Res. 10(3), 959-970 (2017). https ://doi.org/10.1007/s12274-016-1354-9

233. G.H. Jin, E. Ko, M.K. Kim, V.-K. Tran, S.E. Son et al., Graphene oxide-gold nanozyme for highly sensitive electrochemical detection of hydrogen peroxide. Sensors Actuat. B Chem. 274, 201-209 (2018). https://doi.org/10.1016/j. snb.2018.07.160 